Prepared in cooperation with the Bureau of Reclamation

\title{
Aquatic Trophic Productivity Model: A Decision Support Model for River Restoration Planning in the Methow River, Washington
}

Open-File Report 2016-1075 



\section{Aquatic Trophic Productivity Model: A Decision Support Model for River Restoration Planning in the Methow River, Washington}

By Joseph R. Benjamin and J. Ryan Bellmore

Prepared in cooperation with the Bureau of Reclamation

Open-File Report 2016-1075

U.S. Department of the Interior

U.S. Geological Survey 


\section{U.S. Department of the Interior \\ SALLY JEWELL, Secretary}

\section{U.S. Geological Survey \\ Suzette M. Kimball, Director}

U.S. Geological Survey, Reston, Virginia: 2016

For more information on the USGS—-the Federal source for science about the Earth,

its natural and living resources, natural hazards, and the environment-visit

http://www.usgs.gov/ or call 1-888-ASK-USGS (1-888-275-8747).

For an overview of USGS information products, including maps, imagery, and publications, visit http://store.usgs.gov.

Any use of trade, firm, or product names is for descriptive purposes only and does not imply endorsement by the U.S. Government.

Although this information product, for the most part, is in the public domain, it also may contain copyrighted materials as noted in the text. Permission to reproduce copyrighted items must be secured from the copyright owner.

Suggested citation:

Benjamin, J.R., and Bellmore, J.R., 2016, Aquatic trophic productivity model: A decision support model for river restoration planning in the Methow River, Washington: U.S. Geological Survey Open-File Report 2016-1075, 85 p., http://dx.doi.org/10.3133/ofr20161075.

ISSN 2331-1258 (online) 


\section{Contents}

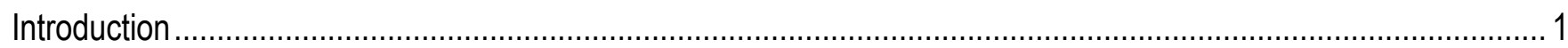

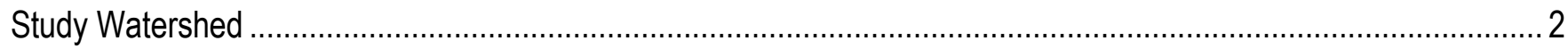

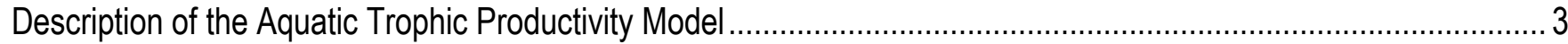

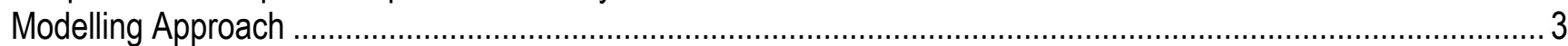

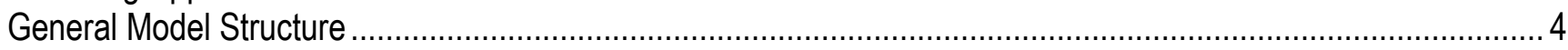

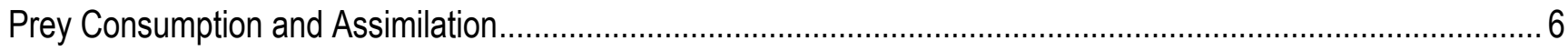

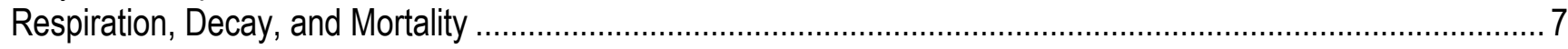

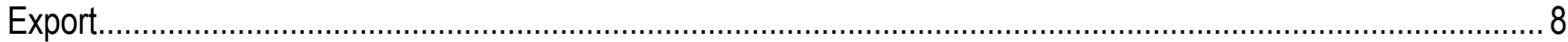

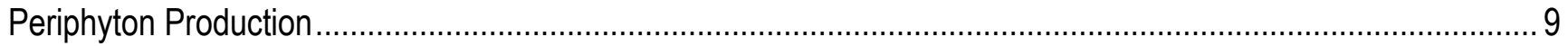

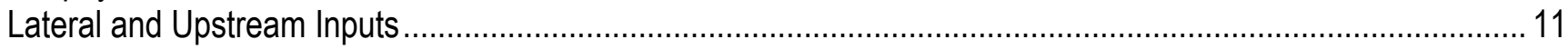

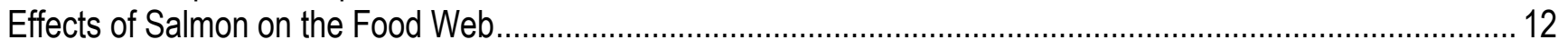

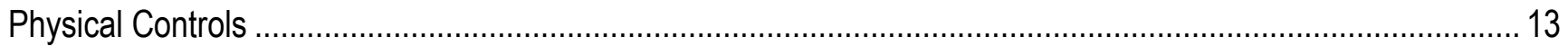

Parameterizing and Corroborating the Model.................................................................................... 15

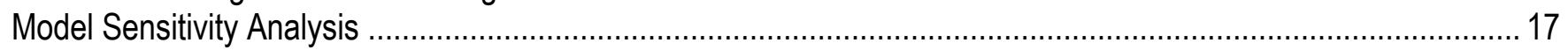

Case Study 1: The Middle Part of the Methow River (M2 Segment)............................................................... 20

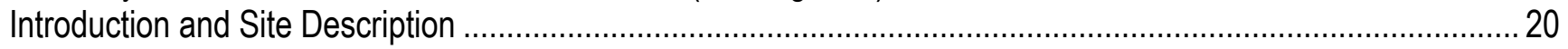

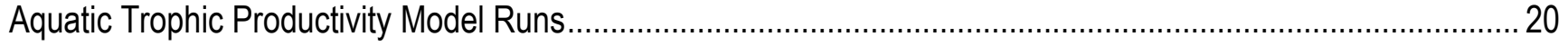

Environmental Inputs and Model Parameterization .................................................................................. 21

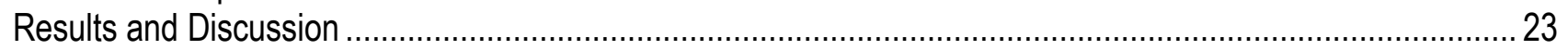

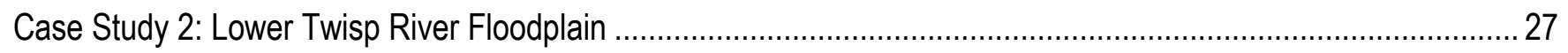

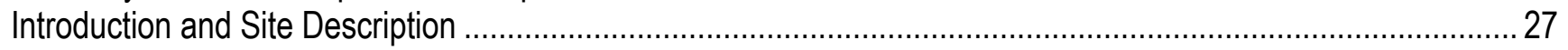

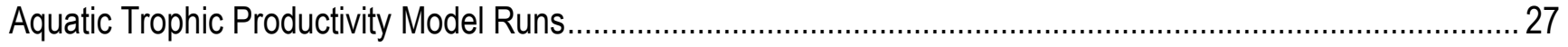

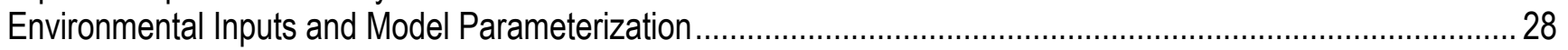

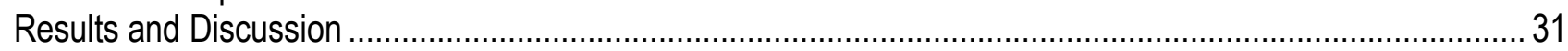

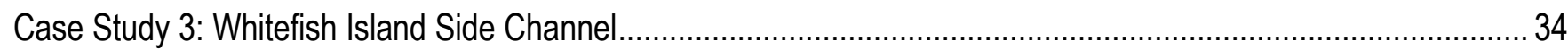

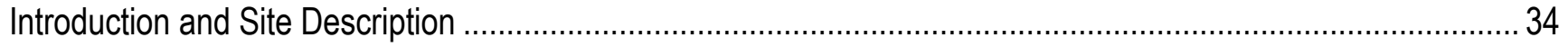

Aquatic Trophic Productivity Model Runs ……………………

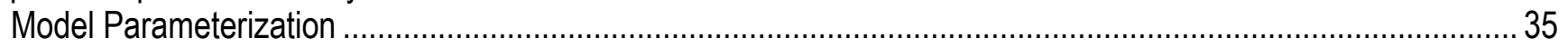

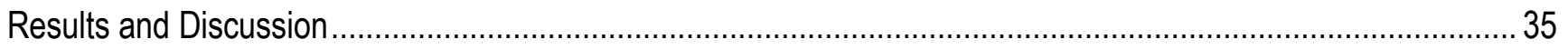

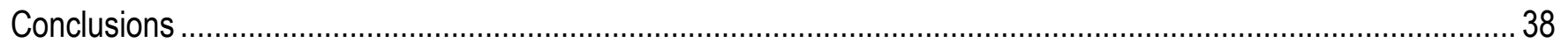

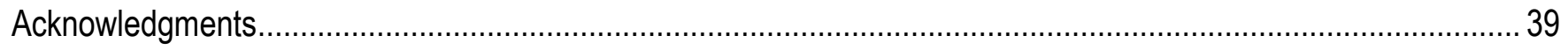

References Cited ................................................................................................................ 39

Appendix A. Parameters Used in the Aquatic Trophic Productivity Model, Including a Description of Each Parameter, the Value Used in Model Runs, the Range of Values Applied to Sensitivity Analyses, and Literature

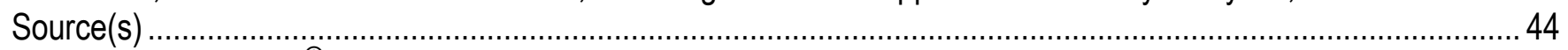

Appendix B. STELLA ${ }^{\odot}$ diagrams and code for the Aquatic Trophic Productivity (ATP) model.............................. 48 


\section{Figures}

Figure 1. Map showing locations of restoration sites for the Methow River watershed, Washington ......

Figure 2. Conceptual diagram showing Aquatic Trophic Productivity model, illustrating biomass stocks of organisms and organic matter, consumer-resource interactions, inputs of energy, nutrients and organic matter from outside the system, and explicit linkages to in-stream physical habitat and adjacent riparian vegetation. 3

Figure 3. Diagram showing hydraulic inputs to the Aquatic Trophic Productivity model. 14

Figure 4. Diagram showing trophic stacks comparing simulated average annual biomasses (grams of ash-free dry mass per square meter) to empirical biomass data for the middle portion (river kilometer 66-80) of the Methow River (M2)

Figure 5. Graph showing simulated biomass dynamics for periphyton, terrestrial detritus, aquatic invertebrates, and fish for the middle portion (river kilometer 66-80) of the Methow River 16

Figure 6. Graphs showing relative importance parameters from global sensitivity analysis for biomass of $(A)$ fish, $(B)$ aquatic invertebrates, $(C)$ periphyton, and $(D)$ terrestrial detritus . 18

Figure 7. Graph showing temporally dynamic environmental inputs used to parameterize the Aquatic Trophic Productivity model to the middle portion (river kilometer 66-80) of the Methow River, Washington 23

Figure 8. Graphs showing effects of alternative restoration strategies on the biomass dynamics of terrestrial detritus, periphyton, aquatic invertebrates, and fish relative to background conditions (left), and the percent change in average annual biomass from background associated with each treatment (right) in the middle portion (river kilometer 66-80) of the Methow River

Figure 9. Box-and-whisker plot showing the range of restoration responses for middle Methow River (M2) section in terms of change in fish numbers observed across a 500 run model sensitivity analysis 26

Figure 10. Graphs showing temporally dynamic environmental inputs used to parameterize the Aquatic Trophic Productivity model to a floodplain segment of the Twisp River floodplain, Washington

Figure 11. Graphs showing effects of alternative restoration strategies on the biomass dynamics of terrestrial detritus, periphyton, aquatic invertebrates and fish relative to background conditions, and the percent change in average annual biomass from background associated with each treatment in the Twisp River floodplain

Figure 12. Box-and-whisker plot showing the range of restoration responses for Twisp River floodplain in terms of change in fish numbers observed across a 500-run model sensitivity analysis .

Figure 13. Photographs showing Whitefish Island side channel prior to restoration and after restoration 34

Figure 14. Graphs showing effects of restoration on the biomass dynamics of terrestrial detritus, periphyton, aquatic invertebrates, and fish relative to background conditions, and the percent change in average annual biomass from background associated with each treatment. 36

Figure 15. Box-and-whisker plots showing the range of restoration responses for Whitefish Island side channel in terms of change in total fish biomass and change in fish numbers observed across a 500-run model sensitivity analysis 


\section{Tables}

Table 1. Biomass mass-balance equations for the state variables in the Aquatic Trophic Productivity model ......... 5

Table 2. Values and sources of environmental input data used to parameterize the Aquatic Trophic

Productivity model to a floodplain segment of the Methow River, Washington ...

Table 3. Environmental input data used to parameterize the Aquatic Trophic Productivity model to the

Twisp River floodplain, Washington

\section{Conversion Factors}

International System of Units to Inch/Pound

\begin{tabular}{|c|c|c|}
\hline Multiply & By & To obtain \\
\hline \multicolumn{3}{|c|}{ Length } \\
\hline meter $(\mathrm{m})$ & 39.37 & inch (in.) \\
\hline centimeter $(\mathrm{cm})$ & 0.3937 & inch (in.) \\
\hline kilometer $(\mathrm{km})$ & 0.6214 & mile (mi) \\
\hline \multicolumn{3}{|c|}{ Area } \\
\hline square meter $\left(\mathrm{m}^{2}\right)$ & 10.7639 & square foot $\left(\mathrm{ft}^{2}\right)$ \\
\hline cubic meter $\left(\mathrm{m}^{3}\right)$ & 61023.7441 & cubic inch $\left(\mathrm{in}^{3}\right)$ \\
\hline \multicolumn{3}{|c|}{ Flow rate } \\
\hline meter per second $(\mathrm{m} / \mathrm{s})$ & 3.281 & foot per second (ft/s) \\
\hline cubic meter per second $\left(\mathrm{m}^{3} / \mathrm{s}\right)$ & 35.31 & cubic foot per second $\left(\mathrm{ft}^{3} / \mathrm{s}\right)$ \\
\hline liter per second $(\mathrm{L} / \mathrm{s})$ & 15.85 & gallon per minute (gal/min) \\
\hline \multicolumn{3}{|c|}{ Mass } \\
\hline gram & 0.0353 & ounce, avoirdupois (oz) \\
\hline kilogram (kg) & 2.205 & pound, avoirdupois (lb) \\
\hline
\end{tabular}

Temperature in degrees Celsius $\left({ }^{\circ} \mathrm{C}\right)$ may be converted to degrees Fahrenheit $\left({ }^{\circ} \mathrm{F}\right)$ as:

$$
{ }^{\circ} \mathrm{F}=\left(1.8 \times{ }^{\circ} \mathrm{C}\right)+32 \text {. }
$$

Concentrations of chemical constituents in water are given in either milligrams per liter $(\mathrm{mg} / \mathrm{L})$ or micrograms per liter $(\mu \mathrm{g} / \mathrm{L})$. 
This page left intentionally blank 


\section{Aquatic Trophic Productivity Model: A Decision Support Model for River Restoration Planning in the Methow River, Washington}

Joseph R. Benjamin ${ }^{1}$ and J. Ryan Bellmore ${ }^{2}$

\section{Introduction}

The U.S. Geological Survey (USGS) has developed a dynamic food-web simulation model to provide decision support for Bureau of Reclamation (Reclamation) river restoration projects in the Methow River, Washington. This modeling effort was done to contribute to Reasonable and Prudent Alternative actions 56 and 57 of the 2014 Federal Columbia River Power System Biological Opinion (FCRPS BO), which calls for exploration of modeling as a means to help evaluate Endangered Species Act (ESA)-listed fish response to river restoration efforts. In the Methow River, these species of concern include Upper Columbia River (UCR) spring Chinook salmon (Oncorhynchus tshawytscha) and UCR summer steelhead (Oncorhynchus mykiss). Additionally, the Independent Scientific Advisory Board (ISAB) for the Columbia River has identified the need for modeling (Independent Scientific Advisory Board, 2011a) —including models that incorporate food-web dynamics (Independent Scientific Advisory Board, 2011b) - to better understand how restoration and management strategies might enhance salmon and steelhead populations.

Dynamic food-web models, even relatively simple ones, can be valuable tools for exploring responses to river restoration. Although these models have rarely been applied to rivers and streams (but see Mcintire and Colby, 1978; Power and others, 1995), they are commonly used for management decisions in terrestrial and ocean ecosystems (Christensen and Pauly, 1993; Evans and others, 2013). One of the main strengths of these models is that they are rooted in the fundamental laws of thermodynamics (that is, mass balance). Moreover, these models can be easily adapted to different contexts by adding or subtracting different species from the web and by mechanistically linking the dynamics of web members to local environmental conditions, such as water temperature, stream discharge, and channel hydraulics (Power and others, 1995; Doyle, 2006). Alternative management actions can then be evaluated by changing these environmental conditions to simulate potential outcomes following restoration.

In this report, we outline the structure of a stream food-web model constructed to explore how alternative river restoration strategies may affect stream fish populations. We have termed this model the "Aquatic Trophic Productivity model" (ATP). We present the model structure, followed by three case study applications of the model to segments of the Methow River watershed in northern Washington. For two case studies (middle Methow River and lower Twisp River floodplain), we ran a series of simulations to explore how food-web dynamics respond to four distinctly different, but

\footnotetext{
${ }^{1}$ U.S. Geological Survey

${ }^{2}$ U.S. Forest Service
} 
applied, strategies in the Methow River watershed: (1) reconnection of floodplain aquatic habitats, (2) riparian vegetation planting, (3) nutrient augmentation (that is, salmon carcass addition), and (4) enhancement of habitat suitability for fish. For the third case study, we conducted simulations to explore the potential fish and food-web response to habitat improvements conducted in 2012 at the Whitefish Island Side Channel, located in the middle Methow River.

\section{Study Watershed}

The modeling effort is focused on the Methow River, a fifth-order stream in north-central Washington that drains into the Columbia River at river kilometer (rkm) 843 in the Upper Columbia River Basin (fig. 1). The Methow River has two major tributaries, the Twisp River entering the Methow River at rkm 66 near the town of Twisp, Washington, and the Chewuch River that enters the Methow River at rkm 80 near the town of Winthrop, Washington. Anadromous fish travel through nine Columbia River dams between the Methow River and Pacific Ocean. In addition to ESA-listed Upper Columbia summer steelhead and Upper Columbia spring Chinook, the Methow has anadromous populations of summer Chinook salmon, coho salmon (O. kisutch), and Pacific lamprey (Entosphenus tridentatus). The watershed also contains several resident salmonids species that include, but are not limited to, mountain whitefish (Prosopium williamsoni), westslope cutthroat trout (O. clarki), bull trout (Salvenlinus confluentus), and brook trout (S. fontinalis).

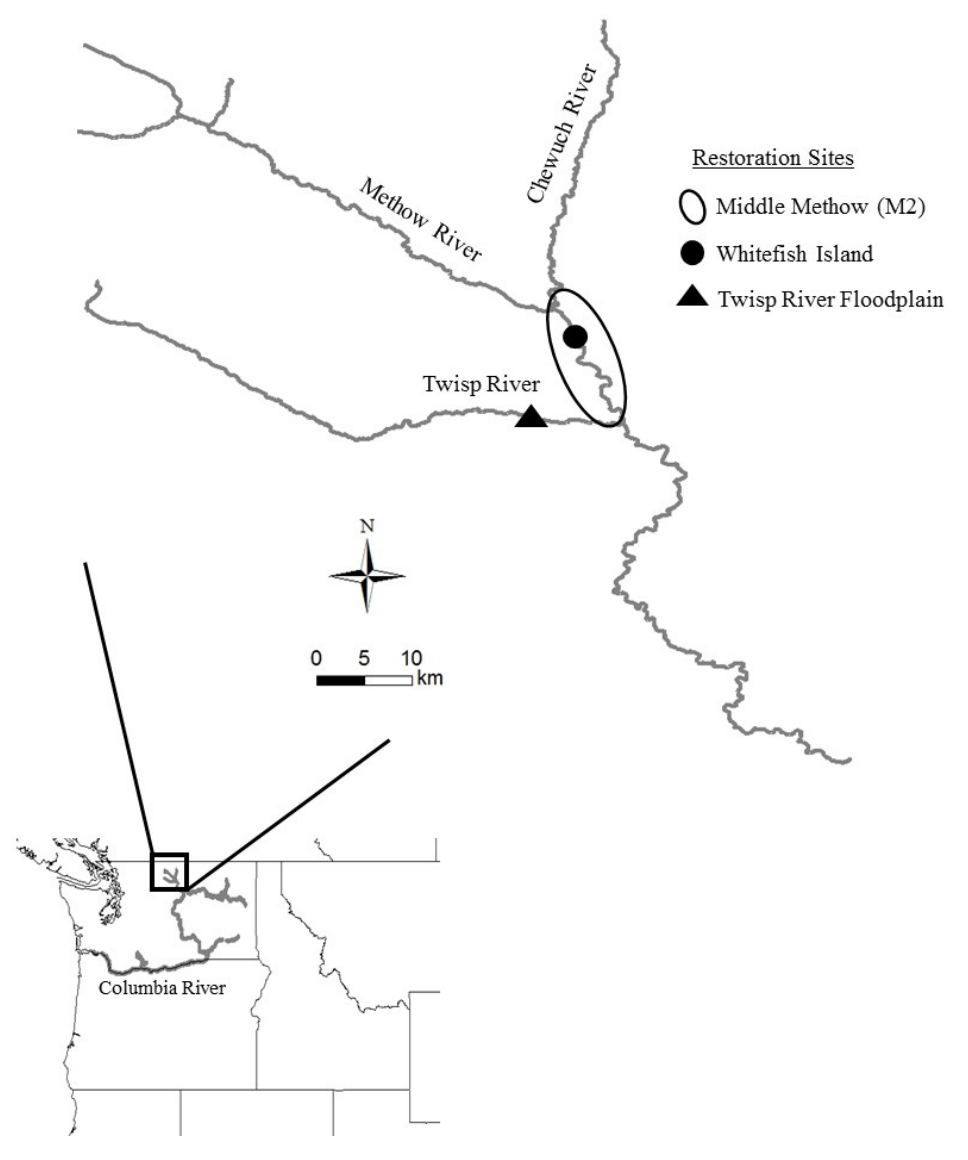

Figure 1. Map showing locations of restoration sites for the Methow River watershed, Washington. 


\section{Description of the Aquatic Trophic Productivity Model}

\section{Modelling Approach}

The ATP is a dynamic food-web simulation model, whereby the capacity of stream and river ecosystems to sustain fish is explicitly tied to transfers of organic matter between different components of a simplified river food web (fig. 2). This model mechanistically links the dynamics of the food-web and the resultant performance of different web members to (1) the physical and hydraulic conditions of the stream, (2) the structure and composition of the adjacent riparian zone, and (3) marine nutrient subsidies delivered by adult salmon. The modeling framework assumes that the general dynamics of river food webs can be predicted if the dynamics of these environmental factors are known. Following this assumption, the model can be used to explore how environmental changes wrought by restoration might affect the overall dynamics of the food web and the performance of specific web members.

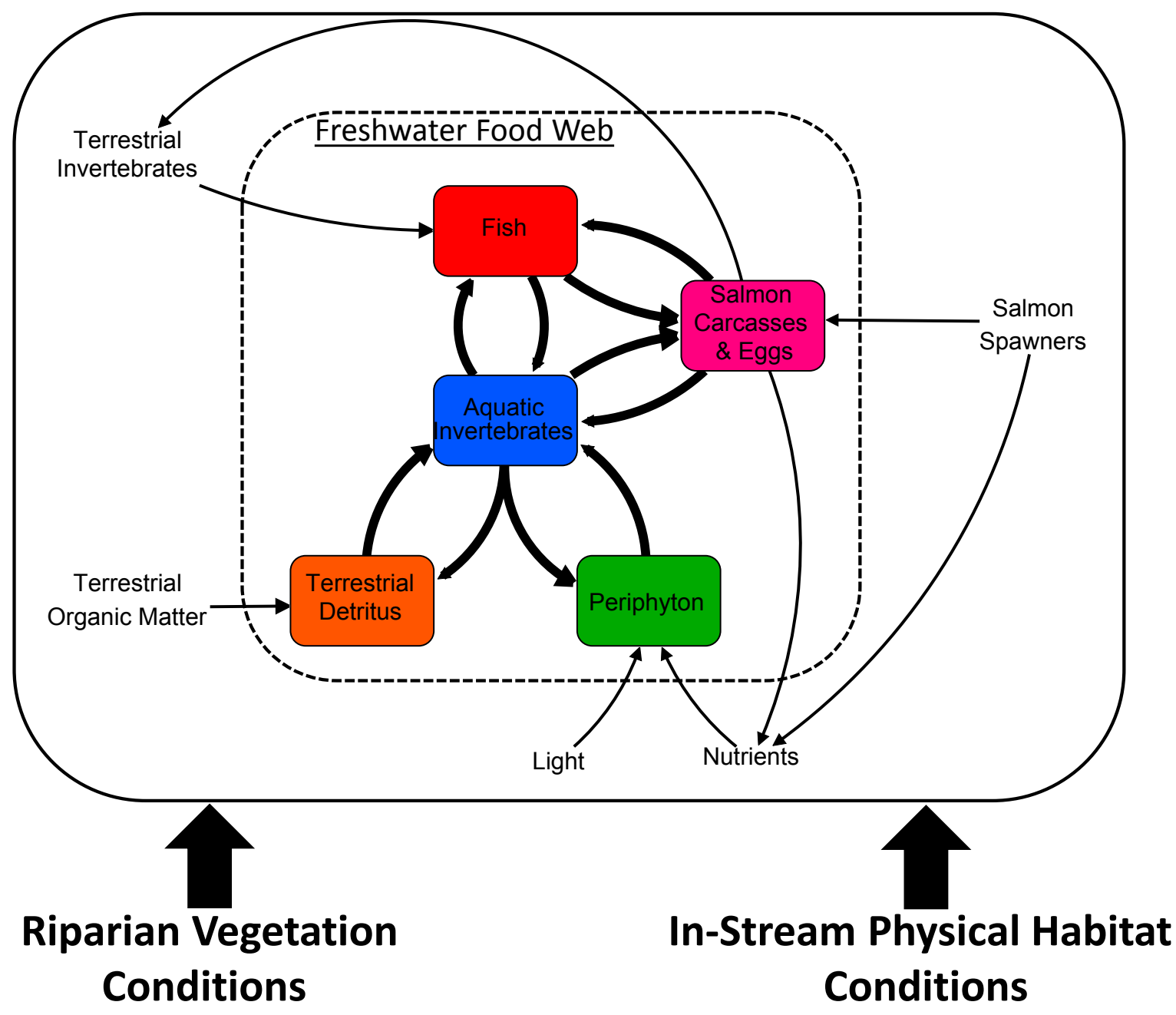

Figure 2. Conceptual diagram showing Aquatic Trophic Productivity model, illustrating biomass stocks of organisms and organic matter (rectangular boxes), consumer-resource interactions (thick arrows), inputs of energy, nutrients and organic matter from outside the system (thin arrows), and explicit linkages to in-stream physical habitat and adjacent riparian vegetation. 


\section{General Model Structure}

We take an ecosystem-based approach to structuring the river food web (Lindeman, 1942; Odum and Barrett, 2005), whereby the different biotic players are aggregated into stocks of biomass that represent the generalized trophic structure of river ecosystems (fig. 2). The backbone of the model contains four biomass stocks or state variables: (1) in-stream primary producers (periphyton; $P$ ), $(2)$ terrestrially derived organic matter (that is, leaf litter; $D)$, (3) aquatic invertebrates $(I)$, and (4) fish $(F)$. In the model, periphyton and terrestrial detritus are consumed by aquatic invertebrates, and aquatic invertebrates are consumed by fish. As with all ecosystems, the modeled food web is an open system, in that energy and materials (that is, subsidies) enter the system from external locations. In this case, these external inputs represent the raw ingredients that fuel the productivity of the food web, and include (1) light and nutrients, which provide the energy and materials necessary for periphyton production; (2) lateral inputs from the riparian zone, which provide detrital organic matter (leaf litter) and direct food resources for fish (terrestrial invertebrates); and (3), returning adult salmon, which represent a source of marine carbon and nutrients (marine derived nutrients; MDN) that are incorporated into the food web via nutrient uptake by periphyton and direct consumption of carcass material by fish and invertebrates (see details below).

The dynamics of each biomass stock in the model are governed by a series of simple mass balance equations (table 1). Biomass increases if the processes that contribute to biomass gains (for example, consumption and energy assimilation, upstream/lateral inputs, production) outweigh the processes that contribute to biomass losses (for example, predation, downstream export, respiration). For example, at the base of the aquatic food web, periphyton biomass $(P)$ increases via the processes of growth and upstream inputs, and decreases via consumption by invertebrates, microbial decay, and downstream export. In the sections that follow, we describe the functional form of these processes and illustrate how each is linked to environmental conditions of the river and the adjacent riparian zone. The model is run on a daily time step with units of grams of ash-free dry mass (g AFDM) so that the seasonal dynamics of all of biomass stocks can be tracked through time. In addition, seasonal dynamics of leaf litter inputs and spawning salmon are incorporated by allowing a pulse of these subsidies to occur. We used STELLA ${ }^{\circledR} 10.1$ (ISEE Systems, Lebanon, N.H., USA) to construct the model and run the simulations. 
Table 1. Biomass mass-balance equations for the state variables in the Aquatic Trophic Productivity model.

$\left[\alpha_{X Y}\right.$ is the proportion of prey type $\mathrm{X}$ consumed by predator $\mathrm{Y}$ that is assimilated. Subscript definitions: $F$, fish; $I$, aquatic invertebrates; $T$, terrestrial invertebrates; $C$, salmon carcass; $E$, salmon eggs; $P$, periphyton; $D$, terrestrial detritus]

\begin{tabular}{|c|c|}
\hline State Variable & Mass Balance Equation \\
\hline Fish, $F$ & $\begin{array}{r}\frac{d F}{d t}=\text { Consumption }_{I F} \alpha_{I F}+\text { Consumption }_{T F} \alpha_{T F}+\text { Consumption }_{C F} \alpha_{C F} \\
+ \text { Consumption }_{E F} \alpha_{E F}-\text { Respiration }_{F}-\text { Mortality }_{F}\end{array}$ \\
\hline Invertebrates, $I$ & $\begin{array}{l}\frac{d I}{d t}=\text { Consumption }_{P I} \alpha_{P I}+\text { Consumption }_{D I} \alpha_{D I}+\text { Consumption }_{C I} \alpha_{C I} \\
+ \text { Upstream }_{I}-\text { Consumption }_{I F}-\text { Respiration }_{I}-\text { Mortality }_{I} \\
\quad-\text { Export }_{I}\end{array}$ \\
\hline Periphyton, $P$ & $\frac{d P}{d t}=$ Production $_{P}+$ Upstream $_{P}-$ Consumption $_{P I}-$ Decay $_{I}-$ Export $_{I}$ \\
\hline Terrestrial detritus, $D$ & $\frac{d D}{d t}=$ Lateral $_{D}+$ Upstream $_{D}-$ Consumption $_{D I}-$ Decay $_{D}-$ Export $_{D}$ \\
\hline Salmon carcass, $C$ & 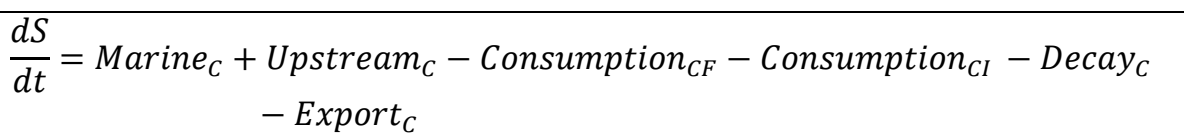 \\
\hline
\end{tabular}




\section{Prey Consumption and Assimilation}

Consumption represents the amount of prey biomass ingested by a predator. For a given predator $Y$, the consumption of prey type $X$ is modeled as

$$
\text { Consumption }_{X Y}=B_{Y}\left(\text { cons }_{\max , Y} f_{1}(\text { Temp }) f_{2}(\text { PreyAvailability, SelfLimit })\right) \cdot \text { selection }_{X Y}
$$

where

$$
\begin{aligned}
\text { cons }_{\max , Y} & \text { is the maximum rate of consumption for predator } \\
Y & \text { when temperatures conditions are optimum, predator biomass } \\
B_{Y} & \text { is low (no density dependence) and prey resources are not limiting; } \\
f_{1} \& f_{2} & \text { are functions that range from } 0 \text { to } 1 \text { and describe the limiting effects of water } \\
& \text { temperature }\left(\text { Temp },{ }^{\circ} \mathrm{C}\right), \text { prey availability and predator self-limitation; and } \\
\text { selection }_{X Y} & \text { is the proportion of predator, and } \\
Y^{\prime} \mathrm{s} & \text { consumption that is directed at prey type } X .
\end{aligned}
$$

The amount of consumed prey that is available for predator growth is calculated by multiplying consumption by a prey-specific assimilation efficiency $\left(\alpha_{X Y}\right.$, the proportion of prey $X$ biomass consumed by predator $Y$ that is assimilated).

The temperature limitation function $f_{1}($ Temp) is represented by an asymmetrical Gaussian distribution (Rutherford and others, 2000) and has the form

$$
\begin{aligned}
& f_{1}=\exp \left(-\left(\frac{T e m p-\text { Temp }_{\text {opt }}}{\text { Temp }_{\text {opt }}-T e m p_{\min } / \sqrt{\ln (100)}}\right)^{2}\right), \quad \text { if Temp }<\text { Temp } p_{\text {opt }}
\end{aligned}
$$

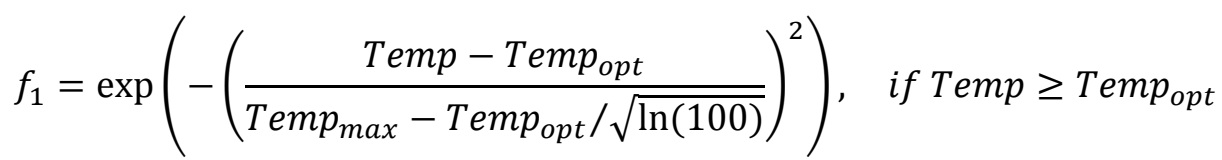

where

Temp $p_{\text {opt }}$ is the optimum temperature for consumption, and

Temp $p_{\text {max }}$ and $T e m p_{\text {min }}$ are the maximum and minimum threshold temperatures, respectively, where consumption is 1 percent of what can be achieved at the optimum temperature.

Using this formulation, consumption rate declines as water temperatures increase or decrease relative to the optimum temperature. 
A type II functional response is used to describe the limiting effect of prey availability and predator density $\left(f_{2}\right)$ as follows (Gotelli, 2001):

$$
f_{2}=\frac{\sum_{i}^{n} B_{i}-B_{i}^{*}}{\sum_{i}^{n}\left(B_{i}-B_{i}^{*}\right)+\left(k_{Y}+\gamma_{Y} B_{Y}\right)}
$$

where
$B_{i} \quad$ is the biomass of prey type $i$ in the environment,
$B_{i}^{*} \quad$ is the biomass of prey type $i$ that is unavailable to consumers (that is, refuge biomass, see below),
$n \quad$ is the total number of prey items available to predator $Y$,
$k_{Y} \quad$ is the density independent prey biomass half saturation level, and
$\gamma_{Y} \quad$ is a dimensionless self-interaction parameter $\left(\gamma_{Y}>0\right.$ for interference,
$<0$ for facilitation) that adjusts consumption rates for consumer biomass density $\left(B_{Y}\right)$.

In the model, consumers adjust foraging to maximize their energy intake by preferentially selecting prey items that are highly abundant and (or) of high quality. The proportion of predator $Y$ 's consumption directed at prey $X$ is calculated as follows:

$$
\text { selection }_{X Y}=\alpha_{X Y}\left(B_{X}-B_{X}^{*}\right) /\left(\sum_{i}^{n} \alpha_{i Y}\left(B_{i}-B_{i}^{*}\right)\right)
$$

In this formulation, the consumption rate of prey $X$ by predator $Y$ is a product of the quantity (available biomass) and quality (assimilation efficiency; $\alpha_{X Y}$ ) of prey type $X$, relative to the summation of the quantity and quality of each prey type $i$ available to predator $Y$. This predator switching mechanism releases prey from strong predation when their densities become low (sensu Holling Type III function response; Holling, 1959).

\section{Respiration, Decay, and Mortality}

Respiration is the process by which biomass is lost to satisfy the metabolic requirements of organisms (aquatic invertebrates and fish), whereas decay represents the loss of biomass (periphyton, terrestrial detritus, and carcasses) to microbial decomposition. Both respiration and decay were assumed to increase exponentially with water temperature $(T)$ as follows (Rutherford and others, 2000):

where

$$
\begin{gathered}
\text { Respiration }_{i}=B_{i} r_{\text {ref }, i} \theta_{i}^{T-T_{r e f}} \\
\text { Decay }_{i}=B_{i} d_{r e f, i} \theta_{i}^{T-T_{r e f}}
\end{gathered}
$$

$r_{r e f, i}$ and $d_{r e f, i} \quad$ are respiration and decay rates, respectively, for biomass stock $i$ at the reference temperature $T_{\text {ref }}\left(T_{\text {ref }}=20^{\circ} \mathrm{C}\right)$, and

$\theta_{i} \quad$ is a dimensionless temperature coefficient.

Mortality is an additional loss term for fish and invertebrate biomass, which is controlled by a constant mortality rate $\left(m_{i}\right)$. 


\section{Export}

Export represents the detachment/mobilization and subsequent downstream transport of benthic organisms (periphyton and aquatic invertebrates) and organic matter (terrestrial detritus and salmon carcass material). This includes downstream export due to (1) loss of biomass when benthic substrates are mobilized by scouring flows and, (2) losses of biomass on stable substrates due to water friction on the stream bed (Bellmore and others, 2014). The export of biomass stock $i$ is represented by

$$
\operatorname{Export}_{i}=\left(B_{i}-B_{i}^{*}\right) \times\left(e_{\text {shear }, i}\left(1-r_{\text {scour }}\right)+r_{\text {scour }}\right)
$$

where

$B_{i}^{*} \quad$ is a refuge biomass that is not susceptible to mobilization (for example, hyporheic invertebrates), and

$r_{\text {scour }}$ and $e_{\text {shear }, i}$ represent the rates of biomass loss to benthic substrate mobilization and shear velocity on the streambed, respectively.

Export due to scouring of the stream bed is the amount of bed that is newly mobilized by high flows at each time step and is calculated as follows:

$$
r_{\text {scour }}=\left\{\begin{array}{c}
\frac{\left(1-p_{\text {scour }, t-1}\right)-\left(1-p_{\text {scour }, t}\right)}{\left(1-p_{\text {scour }, t-1}\right)} \text { if } p_{\text {scour }, t}>p_{\text {scour }, t-1} \\
\text { else } 0
\end{array}\right\}
$$

where

$$
p_{\text {scour }, t} \quad \text { is the proportion of bed that is mobilized at a given time step. }
$$

This formulation allows for the rate of scour to be positive only when the proportion of the bed being scoured increases from one time step to the next. In other words, once flows subside and the proportion of bed scour stabilizes (or decreases), no additional biomass is removed from the system due to scour. For those portions of the bed that are not being mobilized, export increases due to friction velocity on the stream bed $\left(u_{*}\right)$ following a sigmoid function:

$$
e_{\text {shear }, i}=\left(\frac{0.01 e^{a_{i} u_{*}}}{0.01 e^{a_{i} u_{*}}+0.99}-0.01\right)
$$

where

$a_{i} \quad$ is a parameter that determines the sharpness at which the sigmoid curve approaches its maximum of 0.99 (that is, 99 percent biomass export).

See section, "Physical Controls" for a description of how friction velocity and proportion of bed scour are calculated. 


\section{Periphyton Production}

Production represents the process by which primary producer biomass (termed periphyton) is accrued on the stream bed via the photosynthetic conversion of radiation into biomass. Here we use a periphyton production formulation adapted from Bellmore and others (2014):

$$
\text { Production } \left._{P}=B_{P} g_{\max } f_{1}(\text { Temp }) f_{3}(\text { Density }) f_{4}(\text { Light }) f_{5} \text { (Nutrients }\right) f_{6} \text { (Velocity) }
$$

where

$g_{\max } \quad$ is the maximum rate (1/day) of periphyton growth when biomass $\left(B_{P}\right)$ is very low (no density dependence), resources are not limiting, and environmental conditions are ideal.

This maximum rate is multiplied by five dimensionless functions that range from 0 to 1 , and account for the limiting effects of water temperature $\left(f_{1}\right)$, periphyton density $\left(f_{3}\right)$, light $\left(f_{4}\right)$, nutrients $\left(f_{5}\right)$, and water velocity $\left(f_{6}\right)$. The temperature function, $f_{1}$, is the same as in equation 2 above, whereby growth declines when water temperature is either above or below a given optimum temperature. All other limiting factors are represented by Michaelis-Menton functions, where the effect of each factor on periphyton growth follows a type II functional response. The density function has the form

where

$$
f_{3}=1-\frac{B_{P}}{B_{P}+\left(1-p_{\text {scour }}\right) k_{P}}
$$

$k_{P} \quad$ is the biomass level $\left(B_{P}\right)$ where periphyton growth rate is half its maximum, and accounts for self-limitation within the periphyton community; that is, as the algal mat grows there is increased competition for nutrients and light (Hill and Harvey, 1990; Boston and Hill, 1991).

The half saturation value for biomass $\left(k_{p}\right)$ is adjusted at each time step to account for the proportion of the bed currently being scoured $\left(p_{\text {scour }}\right)$. Scoured surfaces are assumed unsuitable for periphyton growth during the scouring event. The limiting effect of light takes the form

$$
f_{4}=\frac{P A R_{\text {bed }}}{P A R_{\text {bed }}+k_{\text {par }}}
$$

where

$P A R_{\text {bed }} \quad$ is the amount of photosynthetically active radiation (PAR) reaching the stream bed at each time step, and

$k_{\text {par }} \quad$ is the half saturation level for PAR. 
The amount of light reaching the bed of the stream is determined from empirical estimates of abovecanopy PAR (PAR can $)$ following Julian and others (2008):

$$
P A R_{\text {bed }}=\left(P A R_{\text {can }} \cdot\left(1-p_{\text {shade }}\right) \cdot p_{\text {reflect }}\right) e^{-0.17 \cdot N T \cdot z}
$$

where

$p_{\text {shade }} \quad$ is the proportion of light lost to shading,

$p_{\text {reflect }} \quad$ is the proportion of PAR that enters the water after reflection,

NT is nephelometric turbidity, and

$z \quad$ is average water depth.

The nutrient function calculates the effect of a single limiting nutrient on periphyton growth, using either dissolved inorganic nitrogen $\left(D I N ; \mathrm{NO}_{2}+\mathrm{NO}_{3}+\mathrm{NH}_{4}\right)$ or soluble reactive phosphorus $(S R P)$, as follows:

$$
f_{5}=\operatorname{MIN}\left(\frac{[D I N]}{[D I N]+k_{D I N}}, \frac{[S R P]}{[S R P]+k_{S R P}}\right)
$$

where

$D I N$ and

SRP are the concentration $(\mathrm{mg} / \mathrm{L})$ of DIN and SRP in the water column, and

$k_{N}$ and

$k_{S R P} \quad$ are the half saturation levels for these two nutrients.

At any given time, only the nutrient that is most limiting effects periphyton growth. The final limitation function calculates the limiting effect of water velocity $(v)$ on periphyton growth (McIntire, 1973), as follows:

$$
f_{6}=\operatorname{MIN}\left(1,0.2+\frac{v}{v+k_{v}}\right)
$$

where

$k_{v} \quad$ is half saturation level for water velocity in meters per second $(\mathrm{m} / \mathrm{s})$.

This function assumes that low water velocities can limit nutrient uptake rates and export of metabolic wastes (McIntire, 1973; McIntire and Colby, 1978). 


\section{Lateral and Upstream Inputs}

Lateral inputs $\left(\right.$ Lateral $\left._{D}\right)$ of leaf litter from the riparian zone directly contribute to the in-stream stock of terrestrial detritus (D), which are consumed by aquatic invertebrates $(I)$. This process is an exogenous input to the model, and therefore no equation is provided. However, the magnitude and timing of this input can be calculated by considering the density, composition, and aerial coverage of riparian vegetation (Minshall and Rugenski, 2006). We assumed that leaf litter inputs are normally distributed through time, with a maximum input in mid-autumn.

Lateral inputs of terrestrial invertebrates serve as a direct food resource for stream fishes (Baxter and others, 2005). Unlike leaf litter inputs, however, we assume that terrestrial invertebrates are either immediately consumed by fish or exported downstream (that is, unconsumed terrestrial invertebrates are not retained). The availability of this subsidy at a given time step is modeled as follows:

$$
\text { Input }_{\text {Terr Inverts }}=\left(p_{\text {veg }} B_{\text {drop }}\right)+\left(B_{\text {winged }} * \text { CarcassStrandingMultiplier }\right)
$$

where

$$
\begin{aligned}
p_{\text {veg }} & \text { is the proportion of the stream covered by riparian vegetation, } \\
B_{\text {drop }} & \text { is the daily biomass input ( } \mathrm{g} \text { AFDM d }{ }^{-1} \text { ) of invertebrates dropping from vegetation, } \\
B_{\text {winged }} & \text { is the daily biomass input of winged invertebrates calculated from an empirical } \\
& \text { relationship with air temperature (Edwards and Huryn, 1995), and }
\end{aligned}
$$

CarcassStrandingMultiplier is a multiplier that adjusts inputs of winged insects by the amount of salmon carcasses stranded in terrestrial habitats (for example, gravel bars). The

CarcassStrandingMultiplier is calculated using a type II functional response, as follows:

$$
\text { CarcassStrandingMultiplier }=\frac{\left(M A X_{\text {stranding }}-1\right) B_{S, \text { stranded }}}{B_{S, \text { stranded }}+k_{S, \text { stranded }}}+1
$$

where

$M A X_{\text {stranding }}$

is the maximum possible effect of salmon on terrestrial invertebrate inputs (Scheuerell and others, 2007),

$k_{S, \text { stranded }} \quad$ is the stranded carcass biomass value where the response is half of the maximum, and $B_{S, \text { stranded }} \quad$ is the biomass of stranded salmon carcasses, calculated by multiplying the total biomass of deposited salmon carcasses by the proportion of carcass biomass stranded in terrestrial habitats $\left(p_{S, \text { stranded }}\right)$.

Upstream inputs $\left(\right.$ Upstream $\left._{i}\right)$ represent organic matter (leaf litter and periphyton) and organisms (aquatic invertebrates) transported into the modeled river segment from upstream river segments. We assume that upstream inputs (Upstream ${ }_{i}$ ) equal export from the same modeled river segment (see eq. 6) corrected for the ability of the system to retain this incoming organic matter or organisms; where the rate of retention is assumed to be one minus the export rate (see eq. 6). When multiple river sections are linked end-on-end upstream inputs to downstream reaches can be directly modeled (that is, upstream inputs equal downstream export from the segment immediately upstream). 


\section{Effects of Salmon on the Food Web}

The magnitude of marine inputs of nutrients and organic matter (both carcasses and eggs) are proportional to the number of adult salmon spawners that return to the system. The model tracks salmon through four stages: (1) arrival of salmon in the modeled river segment, (2) spawning, (3) post-spawn salmon, and (4) mortality. We assumed the arrival of salmon to be normally distributed around an average arrival time (August $1 \pm 6$ days; mean $\pm \mathrm{SD}$ ), after which salmon remain in the modelled river segment a specified number of days prior to spawning ( 82 days for the case studies below; see Bellmore and others, 2014 for more information). Although a proportion of all salmon carcasses are stranded in terrestrial habitats, the proportion that remains in the river is assumed to be immediately available for consumption by both fish and invertebrates $\left(\right.$ Marine $\left._{S}\right)$.

The contribution of dissolved nitrogen $\left[D I N_{\text {salmon }}\right]$ and phosphorus $\left[S R P_{\text {salmon }}\right]$ from salmon excretion (in milligrams per liter) is calculated as (Bellmore and others, 2014)

$$
\left[D I N_{\text {salmon }}\right]=\frac{B_{\text {salmon } D I N_{\text {excret }}}}{Q 86,400},\left[S R P_{\text {salmon }}\right]=\frac{B_{\text {salmon }} S R P_{\text {excret }}}{Q 86,400}
$$

where

$$
\begin{array}{ll}
B_{\text {salmon }} & \begin{array}{l}
\text { is the total biomass of live salmon in the spawning reach, } \\
\text { aIN excret and } S R P_{\text {excret }}
\end{array} \\
\text { are mass-specific daily nutrient excretion rates (in mg of nutrient/g of } \\
\text { salmon/day), and } \\
\text { is discharge (in liters per second), which is multiplied by the number of } \\
\text { seconds in a day, to calculate the total volume of water moving through the } \\
\text { spawning segment per day. }
\end{array}
$$

After mortality, the contribution of nutrients from carcasses is determined by replacing live salmon biomass and nutrient excretion rates, with carcass biomass $\left(B_{\text {carcass }}\right)$ and associated nutrient leaching rates $\left(D I N_{\text {leach }}, S R P_{\text {leach }}\right)$. Contributions of nitrogen and phosphorus from both live and dead salmon are added to background nutrient concentrations in the water column to calculate total nutrient concentrations available to periphyton (see eq. 13).

Salmon can detach/mobilize periphyton, detritus, and aquatic invertebrates from the streambed during redd construction (Janetski and others, 2009). Salmon induced disturbance of benthic substrata is equal to the proportion of the total wetted area excavated by spawning

$$
p_{\text {disturb, salmon }}=\frac{R_{\text {success }} A_{\text {redd }}}{A_{\text {wet }}}
$$

where
$R_{\text {success }}$
is the number of redd sites that are successfully used after accounting for redd superimposition (overlapping redd positioning),

$$
\begin{array}{r}
A_{\text {redd }} \\
A_{\text {wet }}
\end{array}
$$$$
\text { is average redd area }\left(\mathrm{m}^{2}\right) \text {, and }
$$$$
\text { is the total wetted area of the modeled segment. }
$$ 
The proportion of the streambed excavated by spawners is added to the proportion of the bed scoured by hydraulic forces (see section, "Physical Controls"), which subsequently influences export rates for periphyton, detritus, and aquatic invertebrates (see eq. 6). The number of successful redds (that is, redds that are not superimposed) is given by the function (Maunder, 1997)

$$
R_{\text {success }}=\left(K_{\text {redd }}\right)\left(1-\exp \left(-\frac{\text { Spawn }_{\text {female }}}{K_{\text {redd }}}\right)\right)
$$

where

$$
\begin{aligned}
K_{\text {redd }} & \text { is redd carrying capacity, and } \\
\operatorname{Spawn}_{\text {female }} & \text { is the number of female spawners. }
\end{aligned}
$$

$K_{\text {redd }}$ is calculated by dividing the area of suitable spawning habitat in the model segment $\left(A_{\text {suitable }}\right)$ by average redd area $\left(A_{\text {redd }}\right)$. Using this formulation, superimposition increases if either the numbers of spawners increases or the amount of suitable spawning habitat decreases. Suitable spawning habitat is the proportion of stream bed that contained substratum of an appropriate grain size for redd building (1$15 \mathrm{~cm}$ in diameter) that is not being scoured by hydraulic forces at the time of spawning. When redds are superimposed, the eggs that were deposited in the first redd are assumed to become immediately available for consumption by fish.

\section{Physical Controls}

Built-in graphical functions are used to relate channel discharge to average wetted width and average water depth. In current model runs, these hydraulic relationships have been obtained by summarizing information from more detailed two-dimensional hydraulic models (fig. 3). Water velocity is solved for using the continuity equation. Friction velocity $\left(u_{*}\right)$ is calculated as follows (Gordon and others, 2004)

$$
u_{*}=\sqrt{g S R}
$$

where

$g \quad$ is acceleration due to gravity,

$S \quad$ is channel slope, and

$R \quad$ is the hydraulic radius of the channel. 


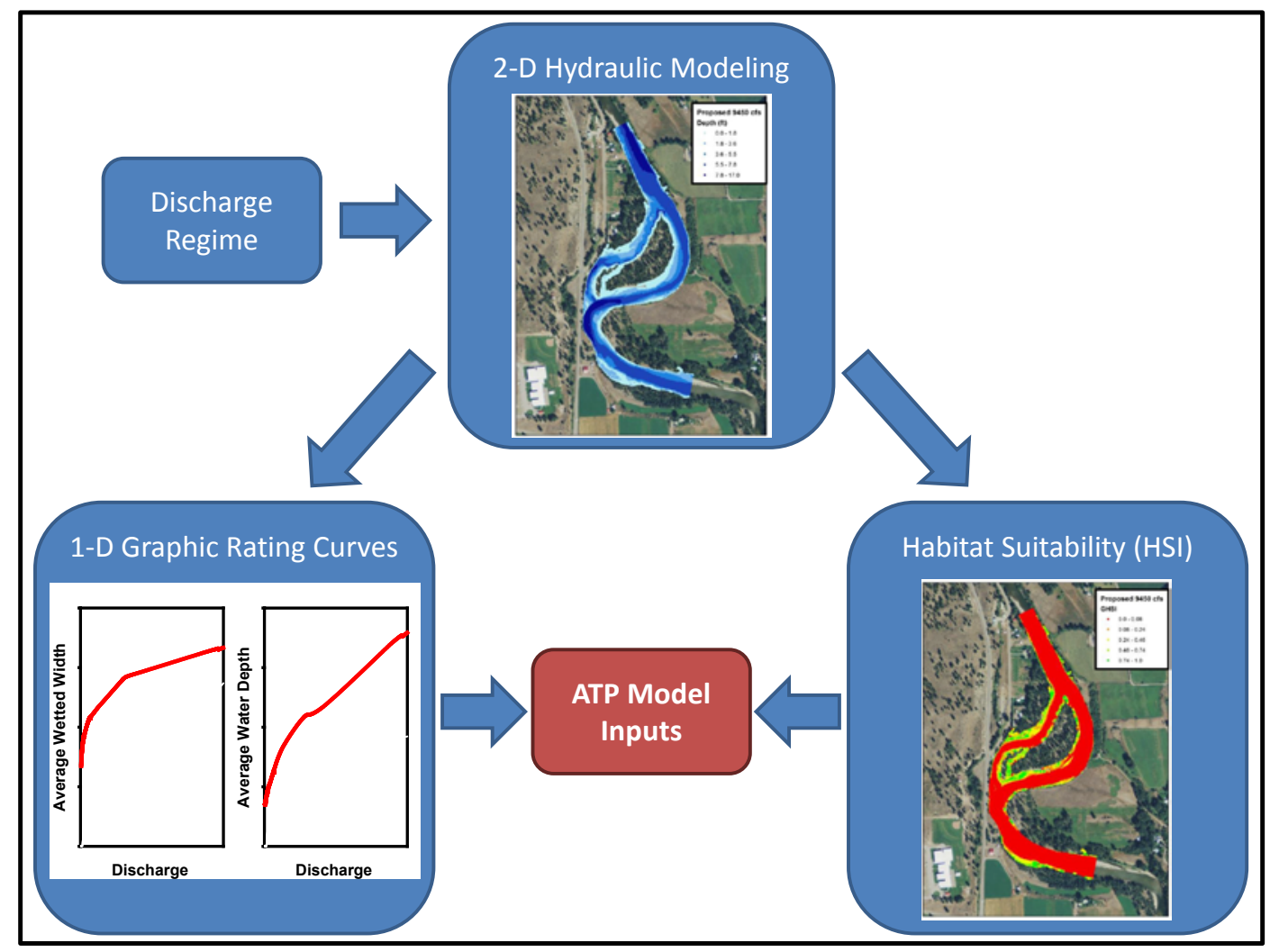

Figure 3. Diagram showing hydraulic inputs to the Aquatic Trophic Productivity model. One-dimensional (1-D) rating curves that describe the relation between discharge and reach averaged water depth and wetted width, and the proportion of habitat suitable for fish based on habitat suitability indices (HSIs) for water depth and velocity. These hydraulic model inputs are calculated by summarizing the output of a two-dimensional (2-D) hydraulic model run at a range of discharges that represent the annual hydrograph of the modeled reach.

The proportion of the bed being scoured at any given time step $\left(p_{\text {scour }}\right)$ is determined by first calculating the diameter of substrate at the threshold of motion (critical substrate size, $D_{\text {crit }}$ ) for a given water depth and slope (Gordon and others, 2004)

$$
D_{\text {crit }}=\frac{d \cdot S}{\left(\rho_{s}-1\right) \cdot \tau^{*}}
$$

where

$\rho_{s} \quad$ is substrate density $\left(2.65 \mathrm{~kg} \mathrm{~m}^{-3}\right)$, and

$\tau^{*} \quad$ is the Shields number (0.045) following Henderson (1966, p. 415). 
This critical substrate size $\left(D_{\text {crit }}\right)$ is then compared against a cumulative substrate size distribution for the stream bed to calculate the proportion of the stream bed that contained substrates smaller than the critical size (see Bellmore and others, 2014); this represents the portion of the stream bed scoured $\left(p_{\text {scour }}\right)$ by hydraulic forces alone. Within the ATP model, we do not account for scouring of redds owing to high flows.

The proportion of wetted area that is suitable for fish is calculated by comparing the distribution of depths and velocities from two-dimensional hydraulic models to the depths and velocities preferred by the fish species of interest (that is, habitat suitability indices or HSI; fig. 3). For current model runs, we have used habitat suitability indices developed for juvenile Chinook salmon (Raleigh and others, 1986).

\section{Parameterizing and Corroborating the Model}

A literature search was conducted to determined values for all model parameters (for example, half-saturation values, respiration and consumption rates, and assimilation efficiencies; appendix A). Fish bioenergetic parameters were coded for juvenile Chinook salmon (Hanson and others, 1997). In cases where no literature values existed, we adjusted parameter values to produce model runs that were stable (that is, biomass stocks maintained positive values) and that matched reasonably well with empirically measured biomass values (Bellmore and others, 2013; Zuckerman, 2015). To do this, we parameterized the model with environmental conditions from the middle Methow River (M2; see below for details). We selected this segment because (1) environmental data necessary to parameterize the model was available and (2) empirical food-web data existed to compare with model simulations.

The model produced estimates for periphyton, invertebrate, and fish biomass that were similar to those measured in empirical studies (Bellmore and others, 2013; Zuckerman, 2015; fig. 4). Seasonal patterns of biomass were also consistent with expectations (fig. 5). The biomass of terrestrial detritus increases in autumn corresponding to leaf abscission, and then declined throughout the winter and into the spring as this detrital material was decomposed, consumed by invertebrates, and exported downstream. Periphyton biomass was lowest in the winter, increased in the spring with warmer water temperatures and greater light availability, declined during high flows when turbidity and bed scour were high, and then peaked in late summer. This pattern of periphyton dynamics is frequently observed in snowmelt dominated systems such as the Methow River (Minshall and others, 1992). The peak in aquatic invertebrate biomass lagged slightly behind the peak periphyton biomass, and the peak in fish biomass lagged slightly behind that of invertebrates. The biomass dynamics of fish, and to a lesser degree, invertebrates, were strongly mediated by water temperature, which was well below the optimum temperature (for example, $16^{\circ} \mathrm{C}$ for fish) for these organisms much of the year. 


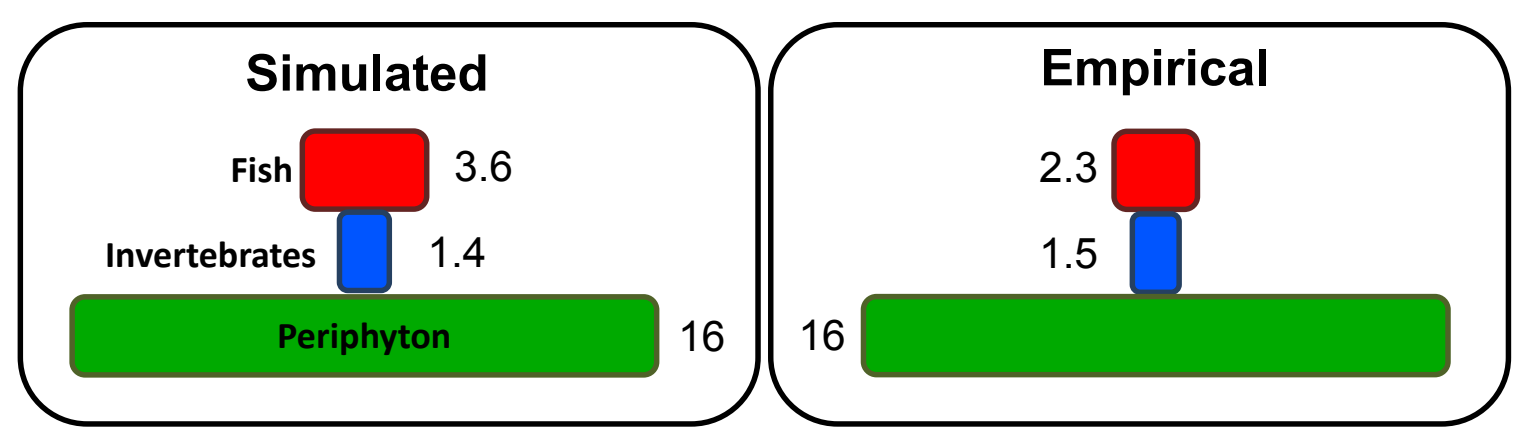

Figure 4. Diagram showing trophic stacks comparing simulated average annual biomasses (grams of ash-free dry mass per square meter) to empirical biomass data for the middle portion (river kilometer 66-80) of the Methow River (M2). Empirical data were from Bellmore and others (2013), who estimated fish and invertebrate biomass, and Zuckerman (2015) who estimated periphyton biomass for the modeled river segment.

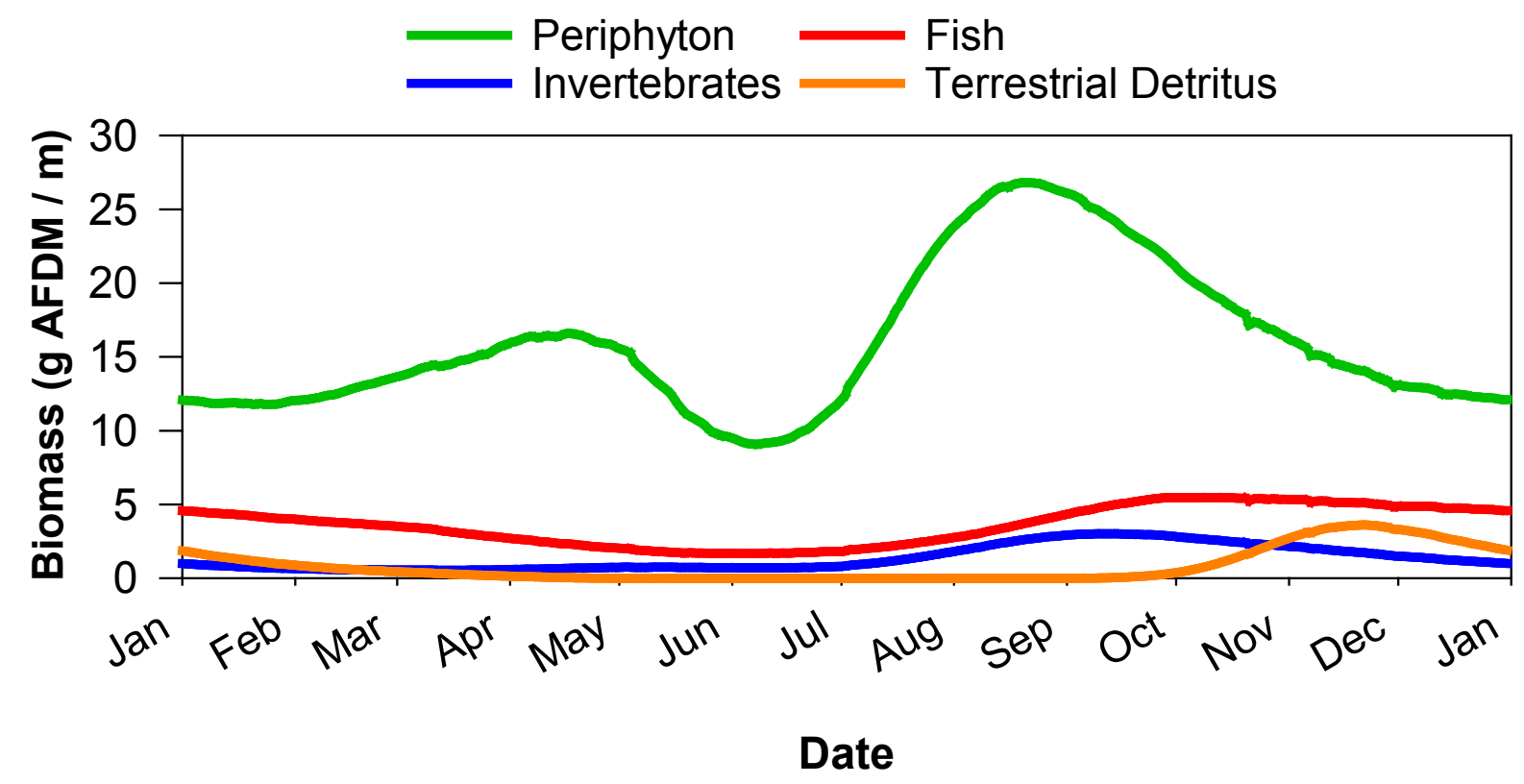

Figure 5. Graph showing simulated biomass dynamics for periphyton, terrestrial detritus, aquatic invertebrates, and fish for the middle portion (river kilometer 66-80) of the Methow River. 


\section{Model Sensitivity Analysis}

To identify parameters that produce the most uncertainty in model simulations, we conducted a global sensitivity analysis (GSA). For this analysis, we identified 30 model parameters that can directly influence biomass gains and losses for fish $(F)$, invertebrates $(I)$, periphyton $(P)$, and terrestrial detritus $(D)$. Briefly, using a uniform distribution, we created 8,000 combinations of different parameter values by randomly selecting $(8,000$ times) values for each parameter within specified "sensitivity bounds." The widths of these sensitivity bounds were adjusted to account for perceived uncertainty in parameter values: \pm 25 percent for literature derived values and \pm 50 percent for parameter values that were assumed. These 8,000 parameter combinations were run through the model using Sensi-Specs in STELLA $^{\circledR} 10.1$ (ISEE Systems, Lebanon, New Hampshire) to produce 8,000 separate estimates of biomass for fish, invertebrates, periphyton, and terrestrial detritus. The relative importance of each parameter for controlling each of these biomass stocks was ranked using a random forest analysis (following Harper and others, 2011), which estimates parameter importance by combining predictions from multiple classification trees through bootstrap sampling (Cutler and others, 2007). Importance parameters were measured using mean node impurity values, which were normalized by the sum of the total. This analysis was conducted in R using the 'randomForest' package (Liaw and Wiener, 2002).

Based on the global sensitivity analysis, four parameters produced much of the uncertainty in periphyton, aquatic invertebrate, and fish biomass (fig. 6). These parameters included aquatic invertebrate assimilation efficiency for periphyton $\left(\alpha_{P I}\right)$, aquatic invertebrate maximum consumption rate $\left(\right.$ cons $\left._{\max , I}\right)$, maximum growth rate for periphyton $\left(g_{\max }\right)$, and the shape parameter for periphyton export $\left(a_{P}\right)$. The self-interaction parameter for fish $\left(\gamma_{F}\right)$ produced additional uncertainty for aquatic invertebrates. For periphyton, the half saturation for periphyton density $\left(B_{P}\right)$ and the self-interaction term for invertebrates $\left(\gamma_{I}\right)$ were also important. The shape parameter for detritus export $\left(a_{D}\right)$ strongly controlled the uncertainty in terrestrial detritus biomass. 


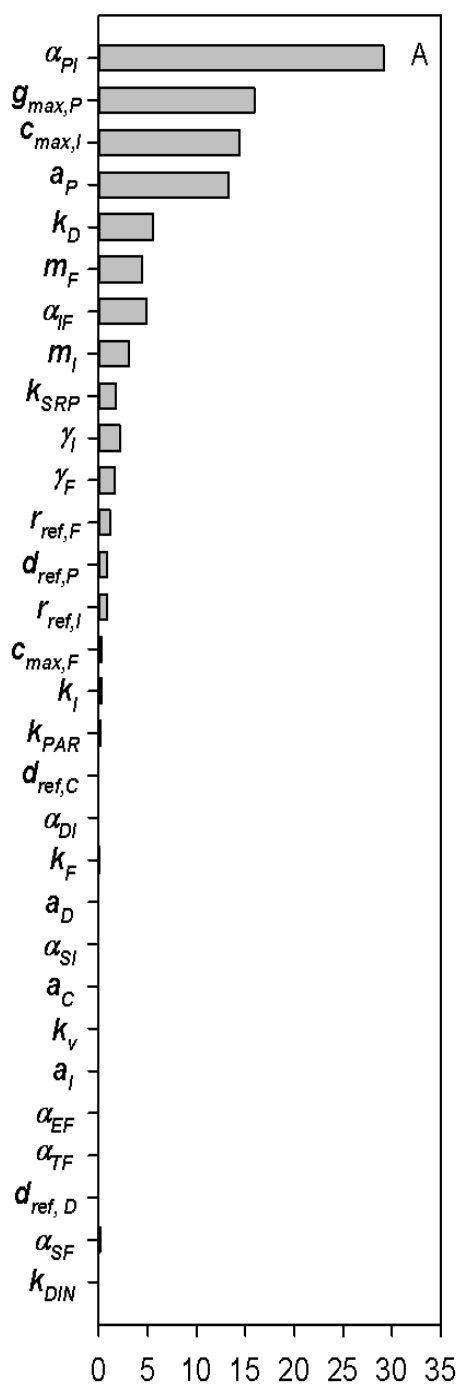

Percent relative importance

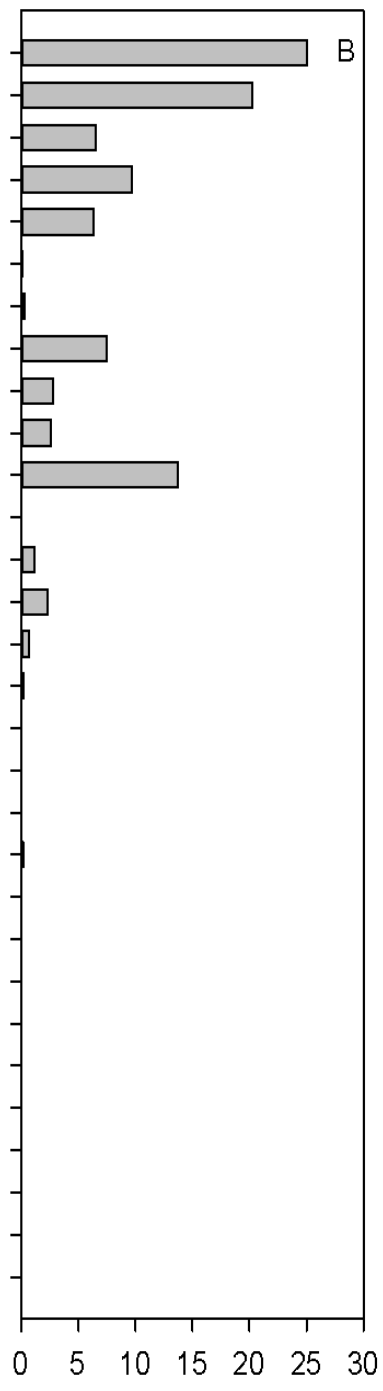

Percent relative importance

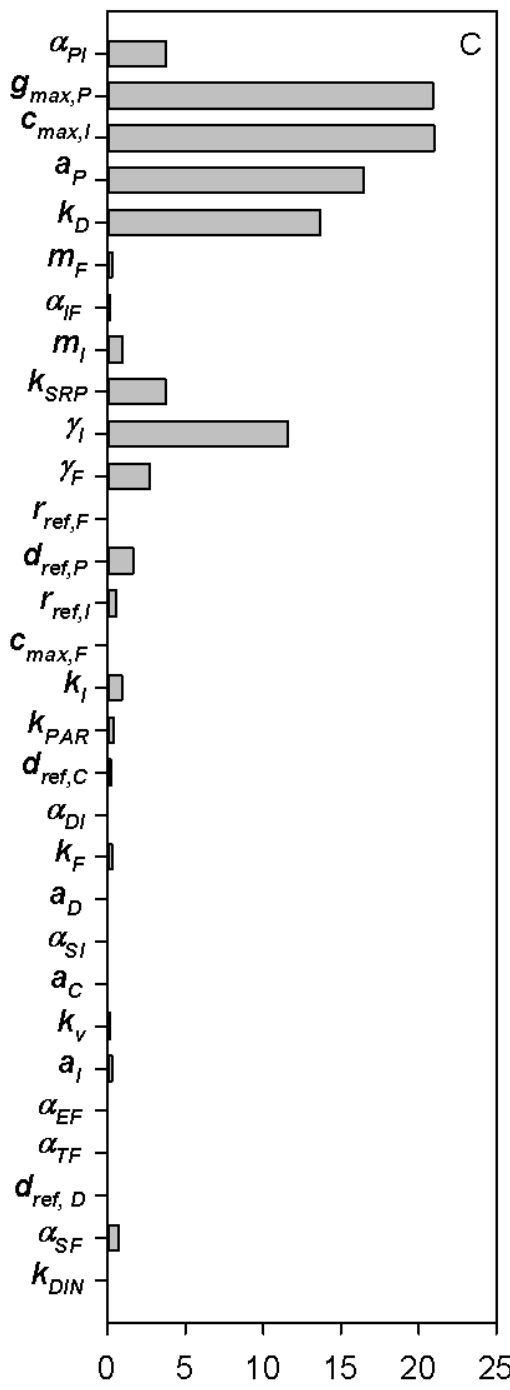

Percent relative importance

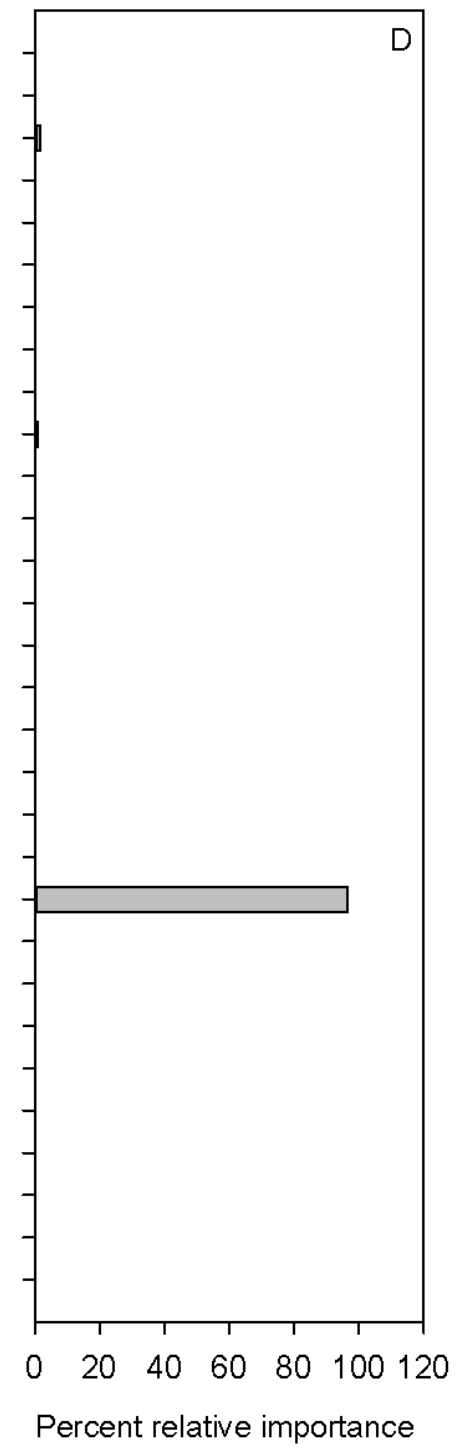

Figure 6. Graphs showing relative importance parameters from global sensitivity analysis for biomass of $(A)$ fish, $(B)$ aquatic invertebrates, $(C)$ periphyton, and $(D)$ terrestrial detritus. 


\section{Figure 6 Explanation}

$\alpha_{\mathrm{PI}}$, proportion of ingested periphyton biomass that is assimilated by aquatic invertebrates $(\mathrm{g} / \mathrm{g})$;

$\mathrm{g}_{\max , \mathrm{P}}$, maximum rate of growth of periphyton when temperature is optimum $([\mathrm{g} / \mathrm{g}] / \mathrm{d})$;

$\mathrm{c}_{\max , \mathrm{I}}$, maximum rate of consumption of aquatic invertebrates when temperature is optimum $([\mathrm{g} / \mathrm{g}] / \mathrm{d}) /$

$a_{P}$, shape parameter for export rate equation;

$k_{D}$, density half saturation for periphyton $\left(\mathrm{g} \mathrm{AFDM} / \mathrm{m}^{2}\right)$;

$m_{F}$, daily mortality rate of fish (g/g/day)/;

$\alpha_{\mathrm{IF}}$, proportion of ingested aquatic invertebrate biomass that is assimilated by fish (g/g);

$m_{I}$, daily mortality rate of aquatic invertebrates $([\mathrm{g} / \mathrm{g}] / \mathrm{d})$;

$k_{S R P}$, soluble reactive phosphorus (SRP) half saturation level for periphyton $(\mathrm{mg} / \mathrm{L})$;

$\gamma_{I}$, dimensionless self-interaction parameter for aquatic invertebrates;

$\gamma_{F}$, dimensionless self-interaction parameter for fish;

$r_{r e f, F}$, rate of respiration of fish at $25^{\circ} \mathrm{C}([\mathrm{g} / \mathrm{g}] / \mathrm{d})$;

$d_{r e f, P}$, rate of decay of periphyton at $20^{\circ} \mathrm{C}([\mathrm{g} / \mathrm{g}] / \mathrm{d})$;

$r_{\text {ref,I }}$, rate of respiration of aquatic invertebrates at $20^{\circ} \mathrm{C}([\mathrm{g} / \mathrm{g}] / \mathrm{d})$;

$\mathrm{c}_{\max , \mathrm{F}}$, maximum rate of consumption of fish when temperature is optimum $([\mathrm{g} / \mathrm{g}] / \mathrm{d})$;

$k_{I}$, prey biomass half saturation level for aquatic invertebrates $\left(\mathrm{g} \mathrm{AFDM} / \mathrm{m}^{2}\right)$;

$k_{P A R}$, photosynthetically active radiation (PAR) half saturation level for periphyton ([mol $\left.\left./ \mathrm{m}^{2}\right] / \mathrm{d}^{-1}\right)$;

$d_{r e f, C}$, rate of salmon carcass decay at $20^{\circ} \mathrm{C}([\mathrm{g} / \mathrm{g}] / \mathrm{d})$;

$\alpha_{\mathrm{DI}}$, proportion of ingested terrestrial detritus biomass that is assimilated by aquatic invertebrates $(\mathrm{g} / \mathrm{g})$;

$k_{F}$, prey biomass half saturation level for fish $\left(\mathrm{g} \mathrm{AFDM} / \mathrm{m}^{2}\right)$;

$a_{D}$, shape parameter for terrestrial detritus export rate equation;

$\alpha_{\mathrm{SI}}$, proportion of ingested salmon carcass biomass that is assimilated by aquatic invertebrates $(\mathrm{g} / \mathrm{g})$;

$a_{C}$, shape parameter for salmon carcass export rate equation;

$k_{v}$, water velocity half saturation level for fish $(\mathrm{m} / \mathrm{s})$;

$a_{I}$, shape parameter for aquatic invertebrate export rate equation;

$\alpha_{\mathrm{EF}}$, proportion of ingested salmon egg biomass that is assimilated by fish $(\mathrm{g} / \mathrm{g})$;

$\alpha_{\mathrm{TF}}$, proportion of ingested terrestrial invertebrate biomass that is assimilated by fish (g/g);

$d_{r e f, D}$, rate of decay of terrestrial detritus at $20{ }^{\circ} \mathrm{C}([\mathrm{g} / \mathrm{g}] / \mathrm{d})$;

$\alpha_{\mathrm{SF}}$, proportion of ingested salmon carcass biomass that is assimilated $(\mathrm{g} / \mathrm{g})$; and

$k_{D I N}$, dissolved inorganic nitrogen (DIN) half saturation level for periphyton $(\mathrm{mg} / \mathrm{L})$. 


\section{Case Study 1: The Middle Part of the Methow River (M2 Segment)}

\section{Introduction and Site Description}

The middle part (rkm 66-80) of the Methow River, also known as the "M2 segment," is a location of ongoing river restoration efforts aimed at enhancing habitat conditions for ESA-listed spring Chinook Salmon and summer steelhead (fig. 1). This relatively unconfined river-floodplain segment lies between the two largest communities in the Methow Valley, Twisp and Winthrop. Much of the surface of the floodplain has been developed for agricultural and residence use, resulting in deforestation and disconnection of the river from adjacent floodplain habitat because of diking (Bureau of Reclamation, 2010). Due to this change, opportunities exist to make habitat and riparian improvements to enhance conditions for juvenile anadromous fishes that both spawn and rear within this reach. Here, we use the ATP model to evaluate how this river segment might respond to alternative restoration actions.

\section{Aquatic Trophic Productivity Model Runs}

We explored the response of the modeled river segment to (1) riparian vegetation restoration, (2) nutrient augmentation via salmon carcass addition, (3) reconnection of floodplain or side-channel habitat, and (4) increased proportion of habitat (water depths and velocities) that is suitable for juvenile salmonids by increasing HSI values. We also conducted a simulation to evaluate the combined impact of all four actions. We adjusted the magnitude of each treatment to represent the perceived restoration potential of the reach based on geomorphic and vegetation assessments as well as historic conditions (Mullen and others, 1992; Bureau of Reclamation, 2010). All simulation were run for 3,650 days (10 years), starting on January 1. Results are reported for the final 365 days of the model simulation, after the model had equilibrated to initial conditions, which took approximately 1,095 days (3 years). Results are presented in grams of AFDM per meter of stream length. To quantify uncertainty around the mean output values (that is, produce error bars) in modeled responses for each treatment scenario, we ran 500 simulations using the same range of values as was used in the sensitivity analysis. The number of days simulated, time to equilibration, and days reported are similar for all case studies.

To represent the potential effects of riparian vegetation restoration on stream food webs, we instantaneously increased the aerial coverage of vegetation (composed of black cottonwood; Populus trichocarpa) by 50 percent - from 5 percent aerial coverage of the channel to 7.5 percent cover. Corresponding to the increase in vegetation cover we also increased stream shading by 50 percent above background. The addition of riparian vegetation only influenced the modeled food web by modifying inputs of terrestrial organic matter (leaf litter and invertebrates) and solar radiation (PAR). Although riparian restoration can also influence bank stability, in-stream cover, water temperature, and stream nutrients, this simulation was focused on the direct effects of riparian vegetation restoration on inputs of organic matter and energy to the system.

For nutrient augmentation, we evaluated the effect of adding salmon carcasses to the channel at a magnitude similar to potential historic salmon spawning abundances (20X greater than the current number of spawners; Mullen and others, 1992). This equated to an addition of 4,000 salmon carcasses to the modeled river segment, which were added each year of the ten year model simulation. Each carcass weighed five kilograms and all carcasses were added to the stream in a single pulse on September 21. 
To simulate the potential effect of floodplain restoration, we added a side channel parallel to the entire length of the main channel. The environmental conditions of this channel were parameterized to match those of a side channel that was recently restored and reconnected within the modeled river segment of the Methow River (Bureau of Reclamation, 2012). The only environmental conditions that were modified from those in the main channel were discharge, channel hydraulics, riparian vegetation cover, and shading. Once connected, a percentage of the discharge from the main channel (ranging from 2 percent during low flow to 23 percent at bankfull flows) was routed into the side channel. Channel hydraulics were adjusted to represent the distinctly different hydraulic conditions of the side channel (that is, narrow bank-full width and shallower depth) based on information from a two-dimensional hydraulic model. Because the channel was narrower, the proportion of the channel covered by vegetation (and associated stream shading) also was higher than in the main channel.

To improve suitable depth and velocity habitat for fish, we increased the proportion of habitat suitable for juvenile fish (calculated from depth and velocity HSI curves) by 20 percent. In other words, this allowed 20 percent more of the habitat to be accessible to fish. Typically, restoration to improve suitable depth and velocity habitat for fish is done by adding large wood structures to the stream to increase pool area. Although our simulations do not account for the addition of wood directly, by adjusting the HSI we assumed this would account for changes in hydraulics and associated habitat suitability these woody structures might provide.

\section{Environmental Inputs and Model Parameterization}

The sources and values of environmental input data used to parameterize the model are shown in table 2 . The values for temporally dynamic environmental inputs are presented in figure 7 . Graphic functions that related discharge to reach-averaged wetted width and water depth were constructed by summarizing information from a previously constructed two-dimensional hydraulic model (Bureau of Reclamation, 2012). The amount and composition of riparian vegetation was converted into estimates of leaf litter input using published relationships between tree diameter and foliage biomass (Jenkins and others, 2004). 


\section{Table 2. Values and sources of environmental input data used to parameterize the Aquatic Trophic Productivity model to a floodplain segment of the Methow River, Washington.}

$\left[\mathrm{m}^{3} / \mathrm{s}\right.$, cubic meter per second; ${ }^{\circ} \mathrm{C}$, degrees Celsius; NOAA, National Oceanic and Atmospheric Administration; NTU, nephelometric turbidity units; g AFDM $/ \mathrm{m}^{2}$, grams of ash-free dry mass per square meter; $\mathrm{mg} / \mathrm{L}$, milligram per liter; $\mathrm{m} / \mathrm{m}$, meter per meter; $\left(\mathrm{mol} / \mathrm{m}^{2}\right) / \mathrm{d}$, mole per square meter per day; -, not applicable]

\begin{tabular}{|c|c|c|c|c|}
\hline Environmental input & Units & Variable type & $\begin{array}{l}\text { Used } \\
\text { values }\end{array}$ & Source \\
\hline Discharge & $\mathrm{m}^{3} / \mathrm{s}$ & $\begin{array}{r}\text { Temporally } \\
\text { dynamic }\end{array}$ & Figure 7 & $\begin{array}{l}\text { National Water Information System, USGS } 12448500 \\
\text { Methow River at Winthrop, WA; daily average } \\
\text { from 1912-2012; } \\
\text { http://waterdata.usgs.gov/nwis - accessed February } \\
2013\end{array}$ \\
\hline Water temperature $(T)$ & ${ }^{\circ} \mathrm{C}$ & $\begin{array}{r}\text { Temporally } \\
\text { dynamic }\end{array}$ & Figure 7 & Zuckerman (2015) \\
\hline Air temperature & ${ }^{\circ} \mathrm{C}$ & $\begin{array}{r}\text { Temporally } \\
\text { dynamic }\end{array}$ & Figure 7 & NOAA, Winthrop 1 WSW, WA US \\
\hline Nephelometric turbidity $(N T)$ & NTU & $\begin{array}{r}\text { Temporally } \\
\text { dynamic }\end{array}$ & Figure 7 & $\begin{array}{l}\text { Washington Department of Ecology, 48A140 Methow } \\
\text { River at Twisp, WA; monthly average 1995-2012; } \\
\text { https://fortress.wa.gov/ecy/eap/riverwq - accessed } \\
\text { February } 2013\end{array}$ \\
\hline Nitrogen $(\mathrm{N})$ & $\mathrm{mg} / \mathrm{L}$ & $\begin{array}{r}\text { Temporally } \\
\text { dynamic }\end{array}$ & Figure 7 & Same source as turbidity \\
\hline $\begin{array}{l}\text { Soluble reactive phosphorus } \\
\text { (SRP) }\end{array}$ & $\mathrm{mg} / \mathrm{L}$ & $\begin{array}{r}\text { Temporally } \\
\text { dynamic }\end{array}$ & Figure 7 & Same source as turbidity \\
\hline Leaf litter input (LateralD) & $\mathrm{g} \mathrm{AFDM} / \mathrm{m}^{2}$ & $\begin{array}{r}\text { Temporally } \\
\text { dynamic }\end{array}$ & Figure 7 & Bureau of Reclamation (2010) \\
\hline $\begin{array}{l}\text { Invertebrate drop from riparian } \\
\text { vegetation }\left(\mathrm{B}_{\text {drop }}\right)\end{array}$ & g AFDM $/ \mathrm{m}^{2}$ & $\begin{array}{r}\text { Temporally } \\
\text { dynamic }\end{array}$ & Figure 7 & Bellmore and others (2013) \\
\hline Shading $\left(p_{\text {shade }}\right)$ & - & $\begin{array}{r}\text { Temporally } \\
\text { dynamic }\end{array}$ & Figure 7 & J.R. Bellmore, unpub. data; 2009 \\
\hline $\begin{array}{l}\text { Photosynthetically active } \\
\text { radiation }\left(P A R_{\text {can }}\right)\end{array}$ & $\mathrm{mol} / \mathrm{m}^{2} / \mathrm{d}$ & $\begin{array}{r}\text { Temporally } \\
\text { dynamic }\end{array}$ & Figure 7 & $\begin{array}{l}\text { U.S. Department of Agriculture, UV-B Monitoring and } \\
\text { Research Program, Pullman, WA; daily average } \\
\text { 2004-12; http://uvb.nrel.colostate.edu/UVB - } \\
\text { accessed February } 2013\end{array}$ \\
\hline $\begin{array}{l}\text { Relations between discharge } \\
\text { and wetted width }\end{array}$ & - & Graphical function & - & Bureau of Reclamation (2012) \\
\hline $\begin{array}{l}\text { Relations between discharge } \\
\text { and water depth }\end{array}$ & - & Graphical function & - & Bureau of Reclamation (2012) \\
\hline Reach length & $\mathrm{m}$ & Constant & 16,000 & Bureau of Reclamation (2010) \\
\hline Channel slope $(S)$ & $\mathrm{m} / \mathrm{m}$ & Constant & 0.005 & Bureau of Reclamation (2010) \\
\hline $\begin{array}{l}\text { Proportion of stream covered by } \\
\text { vegetation }\left(p_{\text {veg }}\right)\end{array}$ & - & Constant & 0.05 & Bureau of Reclamation (2010) \\
\hline Number of returning salmon & \# & Constant & 200 & Hillman and others (2014) \\
\hline Substrate size distribution & $\mathrm{m}$ & $\begin{array}{l}\text { Cumulative } \\
\text { distribution }\end{array}$ & ${ }^{1} 0.11$ & J.R. Bellmore, unpub. data; 2009 \\
\hline
\end{tabular}

${ }^{1}$ Median substrate size (D50) of distribution. 

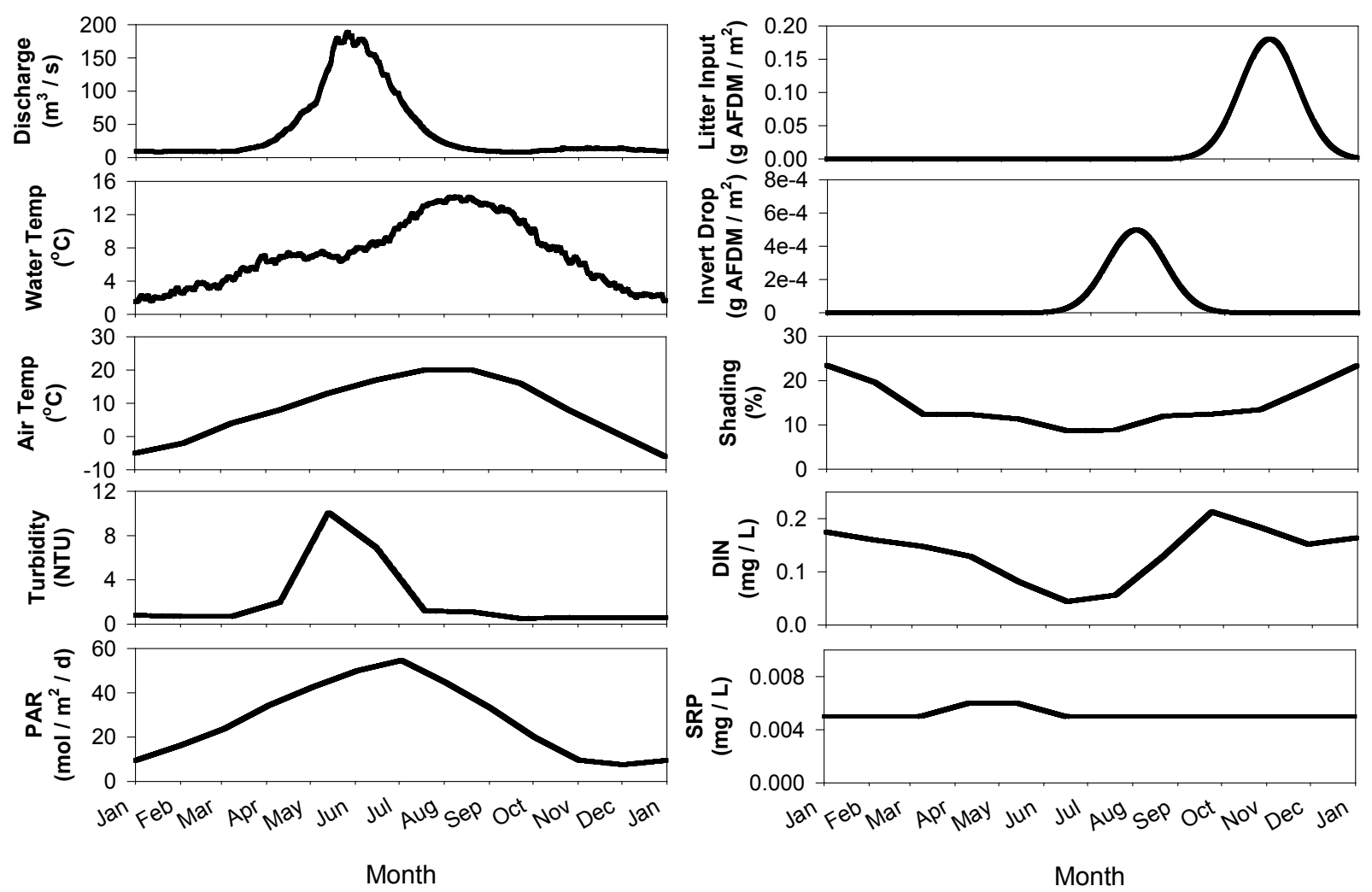

Figure 7. Graph showing temporally dynamic environmental inputs used to parameterize the Aquatic Trophic Productivity model to the middle portion (river kilometer 66-80) of the Methow River, Washington. PAR, photosynthetically active radiation; Litter input, lateral input of leafs from riparian vegetation (LateralD); Invert Drop, aerial input of terrestrial invertebrates from overhanging riparian vegetation $\left(B_{\text {drop }}\right)$; DIN, dissolved inorganic nitrogen; and SRP, soluble reactive phosphorus.

\section{Results and Discussion}

The simulated response to river restoration varied among the four treatment types, across the four biomass stocks, and through time (fig. 8). Riparian vegetation restoration increased the availability of in-stream terrestrial detritus during and shortly following leaf abscission. However, the increase in detritus did not propagate up the food web to aquatic invertebrates and fish. Instead, fish and invertebrates decreased - almost imperceptibly_-because of a slight decrease in periphyton biomass (1 percent decrease in average annual biomass) owing to additional riparian shading. The lack of an effect was largely due to the width of the river section (on average, $40 \mathrm{~m}$ wetted width at base flow). This is consistent with the basic tenants of the river continuum concept (Vannote and others, 1980), which predict there to be reduced interaction between rivers and their riparian zones as channel width increases. Moreover, invertebrate production was largely driven by autochthonous energy sources, which limited the benefits of terrestrial detritus inputs on higher trophic levels. 
In contrast to the vegetation treatment response, salmon carcass addition did increase fish biomass. In autumn, fish biomass increased sharply following carcass addition and remained above background most of the year. Aquatic invertebrates also increased following carcass addition, but returned to background by January. Periphyton biomass did not increase in response to carcass addition. The observed increase in fish biomass with carcass addition was primarily due to the direct consumption of labile carcass material. Fish preferentially selected for and foraged on carcass material in our model simulations because of the high quality of salmon carcass tissue relative to invertebrate prey (Gende and others, 2002). Carcass material was also directly consumed by aquatic invertebrates, which increased their biomass and provided further prey resources for fish. Periphyton biomass did not increase, in part, because of greater consumption by the subsidized aquatic invertebrate population. More importantly, the river was too large (discharge of $8,000 \mathrm{~L} / \mathrm{s}$ ) for the nutrients excreted by salmon and leached out of carcasses $(0.07 \mathrm{mg} / \mathrm{s})$ to increase nutrient concentrations enough to measurably stimulate periphyton production. In a separate empirical study however, we did find that live salmon spawners - even at low densities - could increase primary production in the Methow River (Benjamin and others, 2016).

The biomass of terrestrial detritus, periphyton, aquatic invertebrates, and fish all increased in response to adding a side channel adjacent the main channel (fig. 8). The benefits to fish occurred in multiple pathways. Firstly, side channel addition increased the capacity of the modeled river segment to retain basal organic matter by routing some of the flow from the main channel into a lower energy (that is, lower stream power) side channel. This resulted in more basal organic matter being retained and assimilated in situ instead of being transported downstream. Secondly, side channel addition increased the total input of terrestrial leaf litter and invertebrates to the modeled river segment. This increase was a function of the secondary ribbon of riparian vegetation bordering the added side channel. Finally, adding a side channel increased the total wetted area of the river segment (by an average of 23 percent), and therefore, on a per-meter basis there was simply more habitat to support fish, invertebrates, and periphyton.

Improving habitat suitability increased fish biomass similar to that observed with side channel addition. The increase in fish biomass was owing to more habitat being available for fish to occupy. This increase in fish biomass, however, resulted in a slight decrease in invertebrate biomass because of additional fish consumption.

When all four treatments were simulated together (vegetation + carcass + side channel + HSI), the response was generally additive. That is, the magnitude of the response was approximately equal to the sum of the individual responses. 

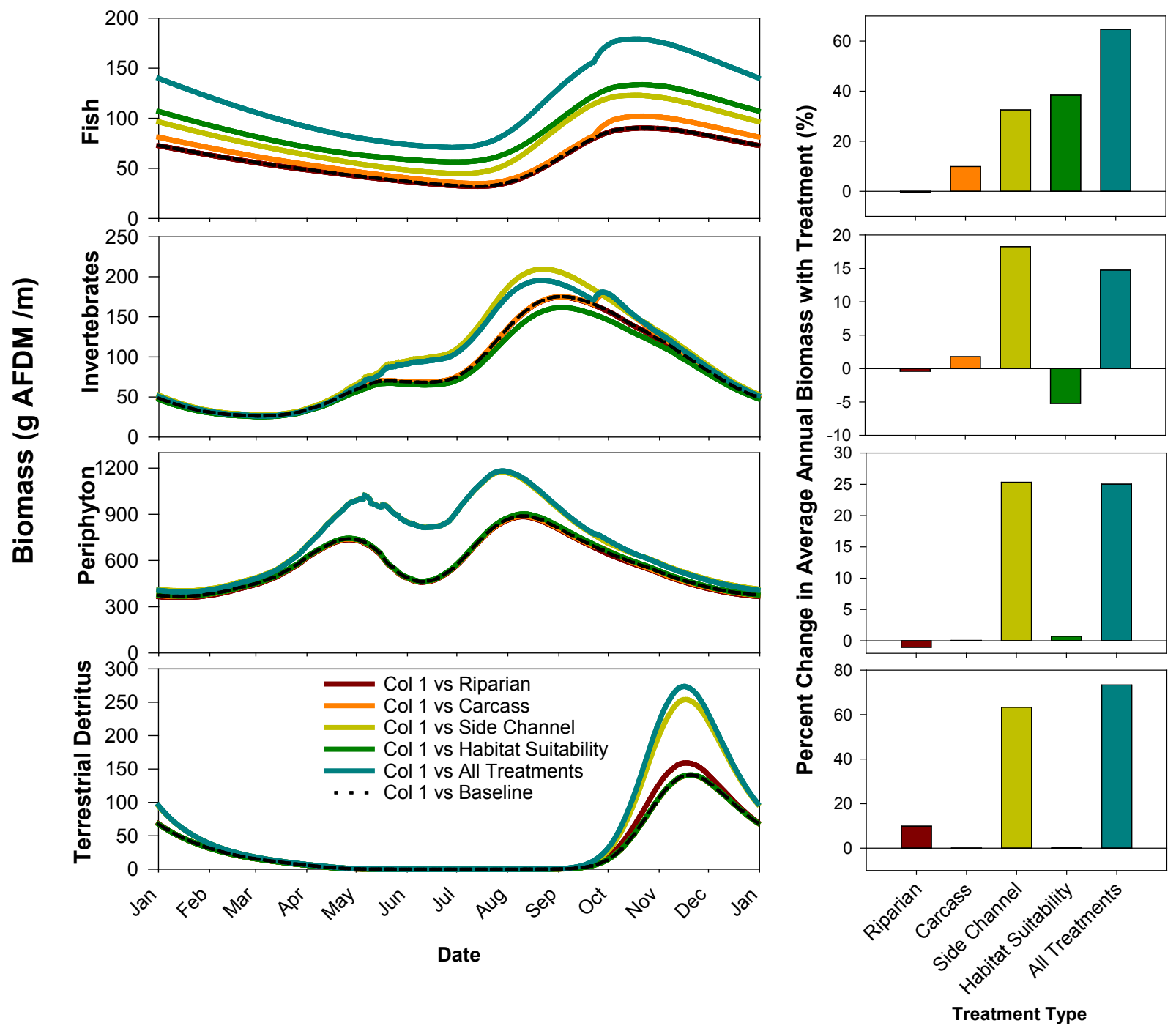

Figure 8. Graphs showing effects of alternative restoration strategies on the biomass dynamics of terrestrial detritus, periphyton, aquatic invertebrates, and fish relative to background conditions (left), and the percent change in average annual biomass from background associated with each treatment (right) in the middle portion (river kilometer 66-80) of the Methow River. g AFDM/m, grams per meter of ash-free-dry-mass. 
We converted biomass to the number of juvenile salmonines to estimate the carrying capacity of the $\mathrm{M} 2$ reach. The number of juvenile salmonines was estimated by dividing the total fish biomass by the average size of a Chinook salmon smolt (10 g; Snow and others, 2013). The pattern in the relative change of mean juvenile numbers was identical to that of mean fish biomass. Given this, we provide a different perspective to look at the reach capacity to sustain juvenile salmon by presenting the median or 50th percentile estimated from the uncertainty analyses (fig. 9). Ranked from lowest to highest, the relative change in fish numbers per meter to each of the treatments was -0.2 fish per meter (fish $/ \mathrm{m} ; 50$ th percentile) for vegetation restoration, $5 \mathrm{fish} / \mathrm{m}$ for carcass supplementation, $19 \mathrm{fish} / \mathrm{m}$ for side channel addition, $26 \mathrm{fish} / \mathrm{m}$ for habitat suitability improvement, and $51 \mathrm{fish} / \mathrm{m}$ for all treatments combined. These rankings were robust to parameter uncertainty in the model, evaluated by model sensitivity analysis. Moreover, for all treatments except riparian restoration, the model simulated positive fish responses across a broad range of parameter uncertainty - a finding that illustrates that the model simulation results are relatively insensitive to our assumptions about the value of specific parameters.

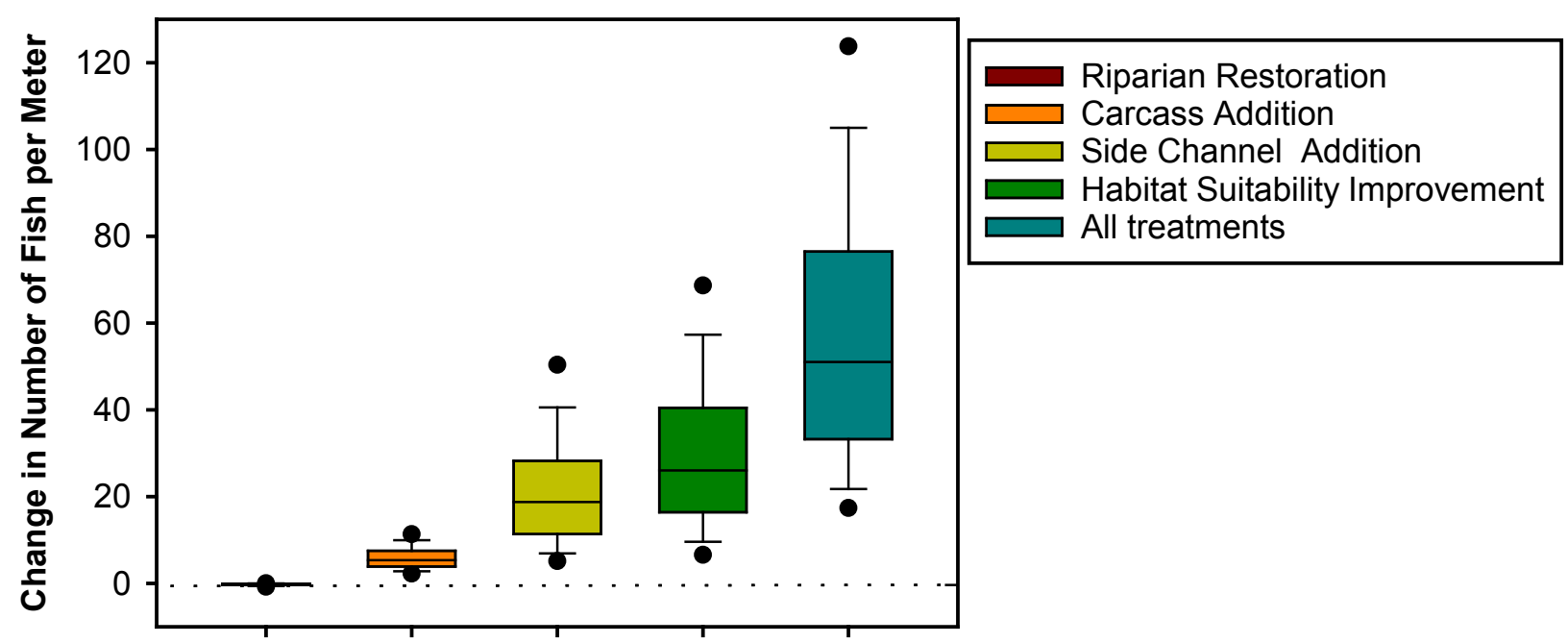

Figure 9. Box-and-whisker plot showing the range of restoration responses for middle Methow River (M2) section in terms of change in fish numbers observed across a 500 run model sensitivity analysis. The center line in each box is the 50th percentile, and the boundaries of the boxes contain modeled responses that are within the 25th and 75th percentile, whereas the whiskers contain response that are within the 10th and 90th percentile. Circular symbols show the 5th and 95th percentile of the modeled responses. 
In the Methow River, where restoration is targeted at increasing the capacity of the stream to sustain healthy fish populations, our simulations suggested that some actions may be more likely to produce desired outcomes than others. Improvements to habitat suitability for fish and side channel reconnection produced the greatest positive response for fish, suggesting that these efforts may be the most effective in the M2 section relative to carcass addition and riparian planting. These findings also lend support to several ongoing restoration efforts in the Methow River that are directly targeted at adding woody structures to improve fish habitat and re-establishing connectivity with relict side channels (Bellmore and others, 2013; Martens and Connolly, 2014). Model simulations also suggest that subsidizing the food web with salmon carcass material could produce positive fish responses, but the amount of carcasses needed (4,000 in our simulations) to create an effect may not be feasible. In contrast, increasing riparian forest cover had very minimal effects on fish in the modeled river segment owing to the large size of the river segment. That said, our simulations did not include other benefits of riparian vegetation such as labile nutrients (leached from abscised leaves) and large woody debris that can influence river food webs and habitat suitability for fish, respectively (Meyer and others, 1998; Gregory and others, 2003).

\section{Case Study 2: Lower Twisp River Floodplain}

\section{Introduction and Site Description}

The Twisp River is a fourth order tributary entering the Methow River at the town of Twisp in northern Washington (fig. 1). The Twisp River is a snowmelt dominated river, with peak flows occurring during May or June and mean monthly discharge ranging from 1 to $34 \mathrm{~m}^{3} / \mathrm{s}$. Species of concern include spring Chinook salmon, steelhead, and bull trout, which spawn and rear in most of the river. Habitat changes from anthropogenic events include road construction, bank hardening, and conversion of riparian areas to agricultural and residential use.

Reclamation is collaborating with the Methow Salmon Recovery Foundation, Upper Salmon Recovery Funding Board, and other state and Federal agencies on a restoration project in a section of the Twisp River at approximately river kilometer 8. This section is known as the Twisp River Floodplain Project (Inter-fluve, 2015). Goals of this project are to improve hydraulic connectivity and channel complexity within a 1.6-km section for the benefit of ESA-listed fish species. To accomplish these goals, actions will include removing irrigation ditches and reconnecting side channels and wetlands, adding large woody debris, and planting riparian vegetation. A separate project by the Yakama Nation also proposes to add salmon carcass or analog material to the stream to enhance food base productivity near this reach (Jorgensen, 2013).

\section{Aquatic Trophic Productivity Model Runs}

We used the ATP model to evaluate a suite of restoration options that have been identified for the Twisp River Floodplain Project (increasing riparian vegetation, reconnecting a side channel, and improving habitat suitability for fish) and for the Twisp River in general (salmon carcass addition). Unless otherwise noted, all model simulations for the Twisp River Floodplain Project are similar to those presented for the middle Methow River (M2). 
To represent the potential effects of riparian vegetation restoration on stream food webs, we increased the aerial coverage of vegetation by 20 percent and potential shade by 10 percent following objectives for this river section (Inter-fluve, 2015). This scenario only simulates mature trees along the riparian corridor, which changes instream food webs by modifying the inputs of terrestrial organic matter (leaf litter and invertebrates) and solar radiation (PAR). This scenario does not account for other functions of riparian trees such as providing bank stability, instream cover, and changes in water temperature. This simulation also does not account for trees falling into the wetted channel that change geomorphology and, subsequently, fish habitat.

We simulated the response to river food webs following the reconnection of a $160 \mathrm{~m}$ side channel, as proposed for this section (Inter-fluve, 2015). The only environmental conditions that were modified from conditions in the main channel were discharge, channel hydraulics, riparian vegetation cover, and shading. Once connected, 10 percent of the discharge from the main channel was routed into the side channel. Hydraulics were adjusted under the assumption that the side channel had a narrow bank-full width and shallower depth compared to the main channel.

To improve suitable depth and velocity habitat for fish, we increased the HSI by 20 percent following objectives for this reach (Inter-fluve, 2015). This allowed 20 percent more of the habitat to be accessible to fish. Typically, restoration to improve suitable depth and velocity habitat for fish is done by adding large wood structures to the stream to increase pool area. Although our simulations do not account for the addition of wood directly, by adjusting the HSI we assumed this would account for changes in hydraulics and associated habitat suitability these woody structures might provide.

In addition to the scenarios above that are proposed for the Twisp River Floodplain Project, we evaluated the effect of adding salmon carcasses. Although this is not a current objective for this river section, others have proposed nutrient augmentation in the form of salmon carcasses for a larger section of Twisp River (Jorgensen, 2013). Chinook salmon spawning densities for this section of the Twisp River range from 7 to 15 individuals (Snow and others, 2013). We added carcasses at a magnitude similar to potential historic salmon spawning abundances (20 times greater than the current number of spawners; Mullen and others, 1992). This equated to an addition of 140 salmon carcasses to the Twisp River Floodplain segment, which were added each year of the 10-year model simulation. We chose the lower end of the range to be conservative in the potential response. Each carcass weighed $5 \mathrm{~kg}$, and all carcasses were added to the stream in a single pulse on September 21.

\section{Environmental Inputs and Model Parameterization}

Most of the environmental input data was specific to the Twisp River Floodplain Project (fig. 10, table 3). However, some inputs such as air temperature and PAR were the same as those used for the middle Methow River (M2) section. 

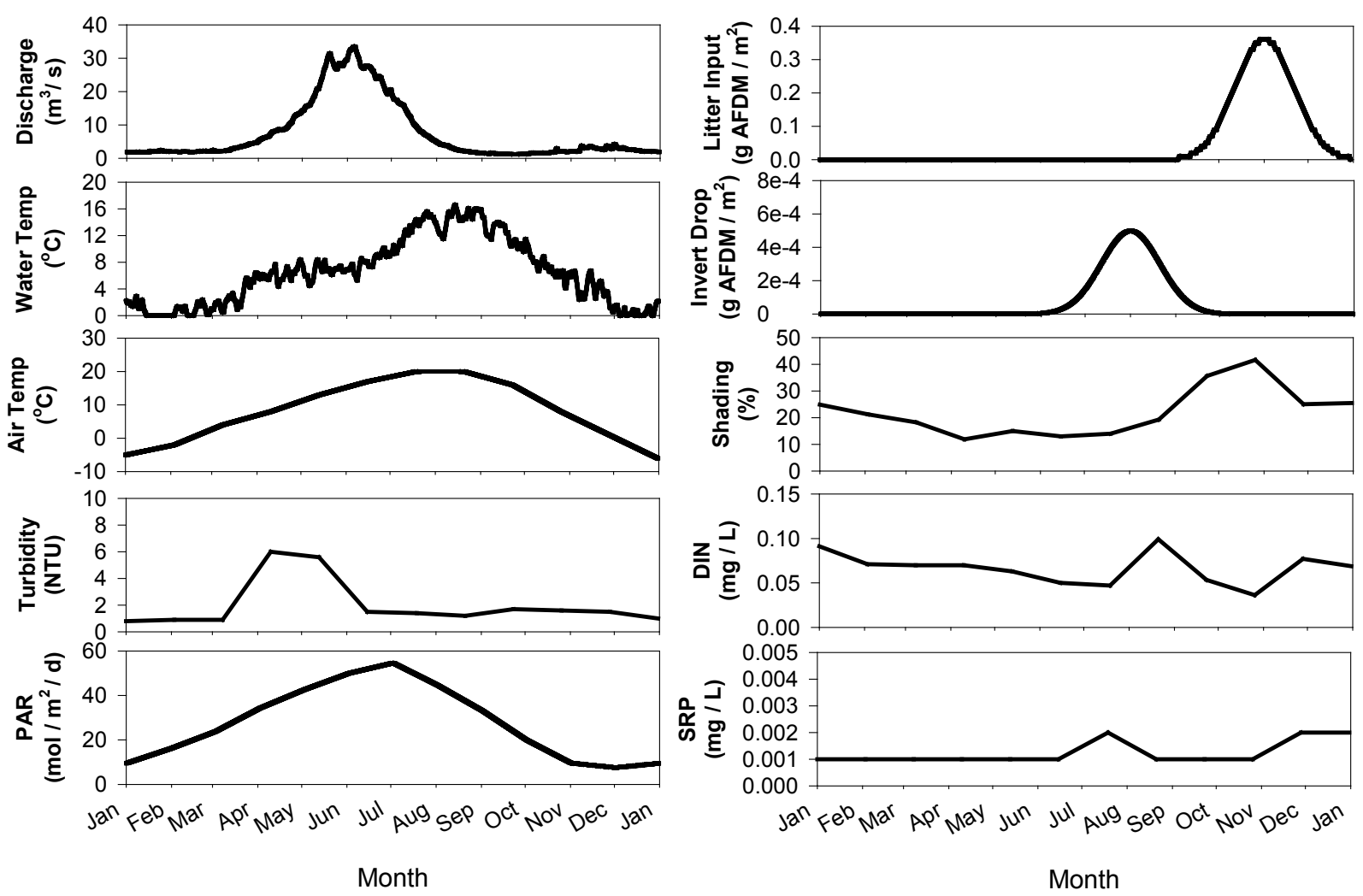

Figure 10. Graphs showing temporally dynamic environmental inputs used to parameterize the Aquatic Trophic Productivity model to a floodplain segment of the Twisp River floodplain, Washington. PAR, photosynthetically active radiation; Litter input, lateral input of leafs from riparian vegetation (Lateral $\left.{ }_{D}\right)$; Invert Drop, aerial input of terrestrial invertebrates from overhanging riparian vegetation ( $\left.B_{\text {drop }}\right)$; DIN, dissolved inorganic nitrogen; and SRP, soluble reactive phosphorus. 
Table 3. Environmental input data used to parameterize the Aquatic Trophic Productivity model to the Twisp River floodplain, Washington.

$\left[{ }^{\circ} \mathrm{C}\right.$, degrees Celsius; g AFDM $/ \mathrm{m}^{2}$, grams of ash-free dry mass per square meter; $\mathrm{m}^{3} / \mathrm{s}$, cubic meter per second; NTU, nephelometric turbidity units; $\mathrm{m}$, meter; $\mathrm{mg} / \mathrm{L}$, milligram per liter; $\mathrm{m} / \mathrm{m}$, meter per meter; $\left(\mathrm{mol} / \mathrm{m}^{2}\right) / \mathrm{d}$, mole per square meter per day; \#, number; -, not applicable]

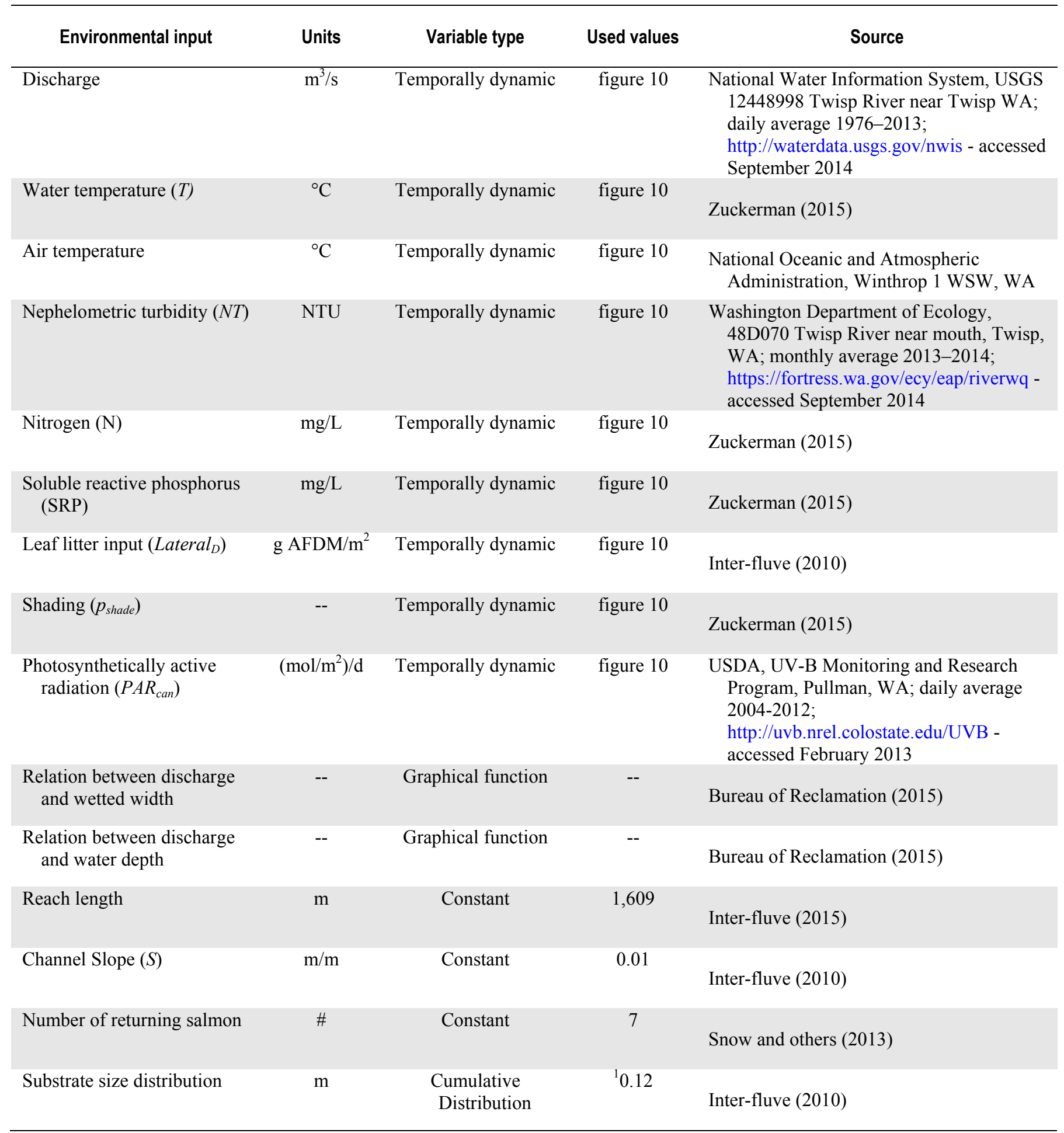

${ }^{1}$ Median substrate size (D50) of distribution. 


\section{Results and Discussion}

The simulated response to restoration in the Twisp River Floodplain section varied among the four treatment types, across the four biomass stocks, and through time (fig. 11). Mechanisms behind responses were similar to those reported for the middle Methow River section (M2; Case Study 1). Riparian vegetation restoration increased the availability of in-stream terrestrial detritus during and shortly following leaf abscission. However, the increase in detritus did not propagate up the food web to aquatic invertebrates and fish and resulted in a slightly negative $(<-1$ percent $)$ response. The salmon carcass addition had the greatest effect on fish, increasing biomass by 34 percent (fig. 11). In autumn, fish biomass increased sharply following carcass addition and remained above background levels for the remainder of the year. Aquatic invertebrates also increased following carcass addition, but returned to background levels by January. Periphyton biomass, however, did not increase in response to carcass addition. Side channel reconnection also increased fish biomass (by 5 percent), but this increase was small relative to the increase observed with carcass addition. That said, side channel addition had a greater positive effect on terrestrial detritus, periphyton, and aquatic invertebrates than any of the other treatments. Increasing fish habitat suitability of velocity and depth led to an 8 percent increase in fish biomass and subsequently a 3 percent decrease in aquatic invertebrate biomass owing to greater consumption of invertebrates by fish. When all four treatments were simulated together (vegetation + carcass + side channel + HSI), the response for each stock was generally additive; that is, the magnitude of the response for each stock was roughly equivalent to the sum of the individual response magnitudes.

To estimate the capacity of juvenile salmonines in the Twisp River Floodplain restoration site, the total fish biomass was divided by the average size of a Chinook salmon smolt ( $10 \mathrm{~g}$; Snow and others, 2013). The pattern in the relative change of mean juvenile numbers was identical to that of mean fish biomass. Given this, we provide a different perspective to look at the reach capacity to sustain juvenile salmon by presenting the median or 50th percentile estimated from the uncertainty analyses (fig. 12). Ranked from lowest to highest, the relative change in fish numbers per meter for each of the treatments was riparian restoration (no change), side channel addition (1 fish/m), habitat suitability improvement (1 fish/m), carcass addition ( $5 \mathrm{fish} / \mathrm{m})$, and all treatments combined (6 fish/m). These rankings were robust to parameter uncertainty in the model, evaluated by model sensitivity analysis. Moreover, based the 500 simulations using random combinations of input parameters, carcass addition and all treatments combined are more likely to succeed than other treatments because the distribution of values for these scenarios did not overlap zero.

Our simulations for the Twisp River Floodplain project suggest that nutrient enhancement may be a more appropriate restoration alternative relative to changes in physical habitat. In this river section, the addition of carcasses appeared to have the greatest positive response for fish owing to direct consumption. This result may not be surprising given the oligotrophic conditions of the Twisp River (Jorgensen, 2013). Simulations of reconnecting a side channel and improving habitat suitability of depth and velocity also had a positive response. However, the outcome of these may not be as certain. These findings indicate that planned restoration actions for this section of river will have positive results, but may not be the most effective means to improve fish numbers. Although the ATP did not simulate changes in fish biomass following riparian planting, this does not mean this restoration action would be ineffective. The benefit of riparian vegetation for fish cover, which has been shown to influence fish survival (Penaluna and others, 2015), has yet to be included in the model. 

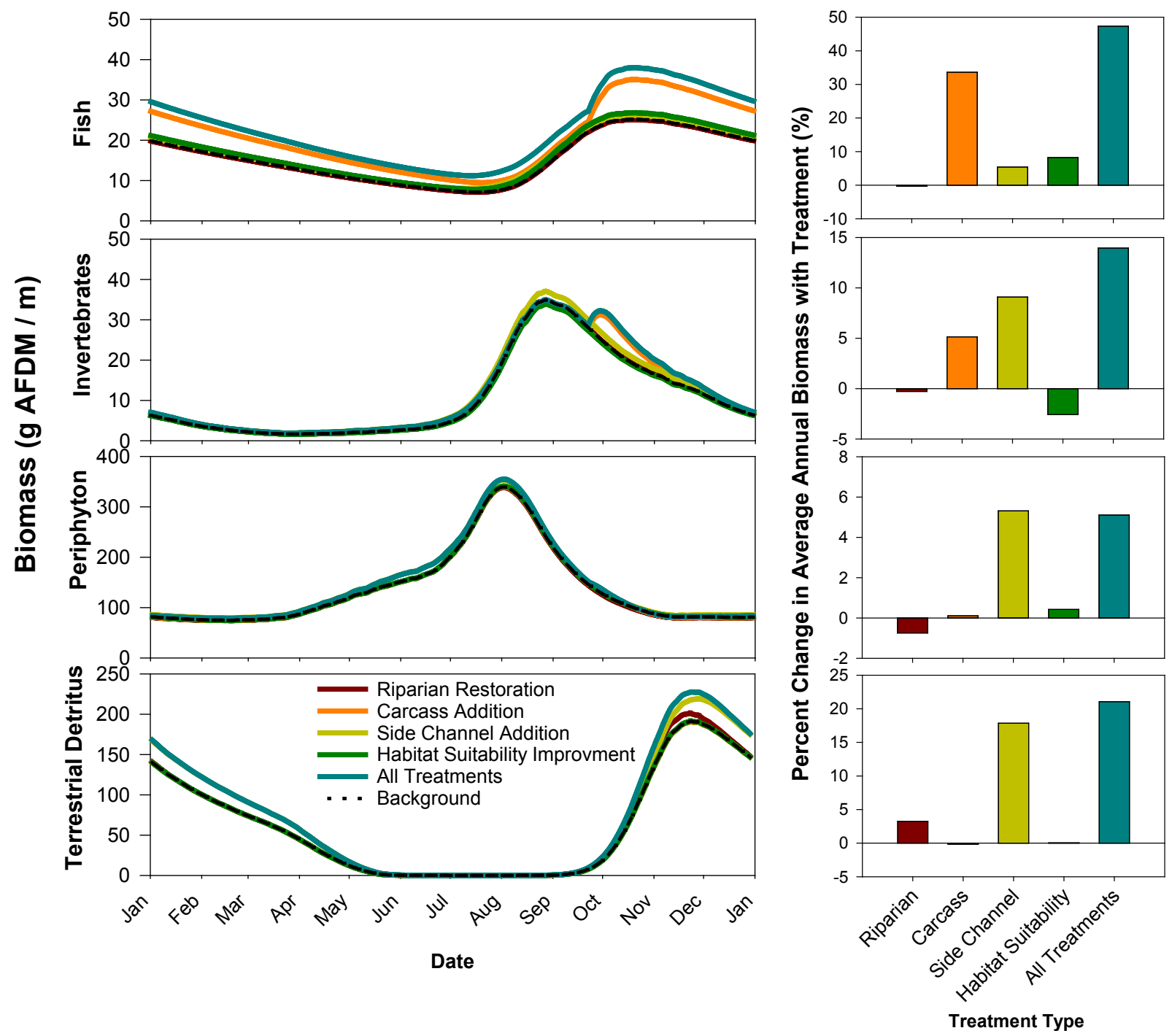

Figure 11. Graphs showing effects of alternative restoration strategies on the biomass dynamics of terrestrial detritus, periphyton, aquatic invertebrates and fish relative to background conditions (left), and the percent change in average annual biomass from background associated with each treatment (right) in the Twisp River floodplain. All units are in grams per meter of ash-free-dry-mass (g AFDM/m). 


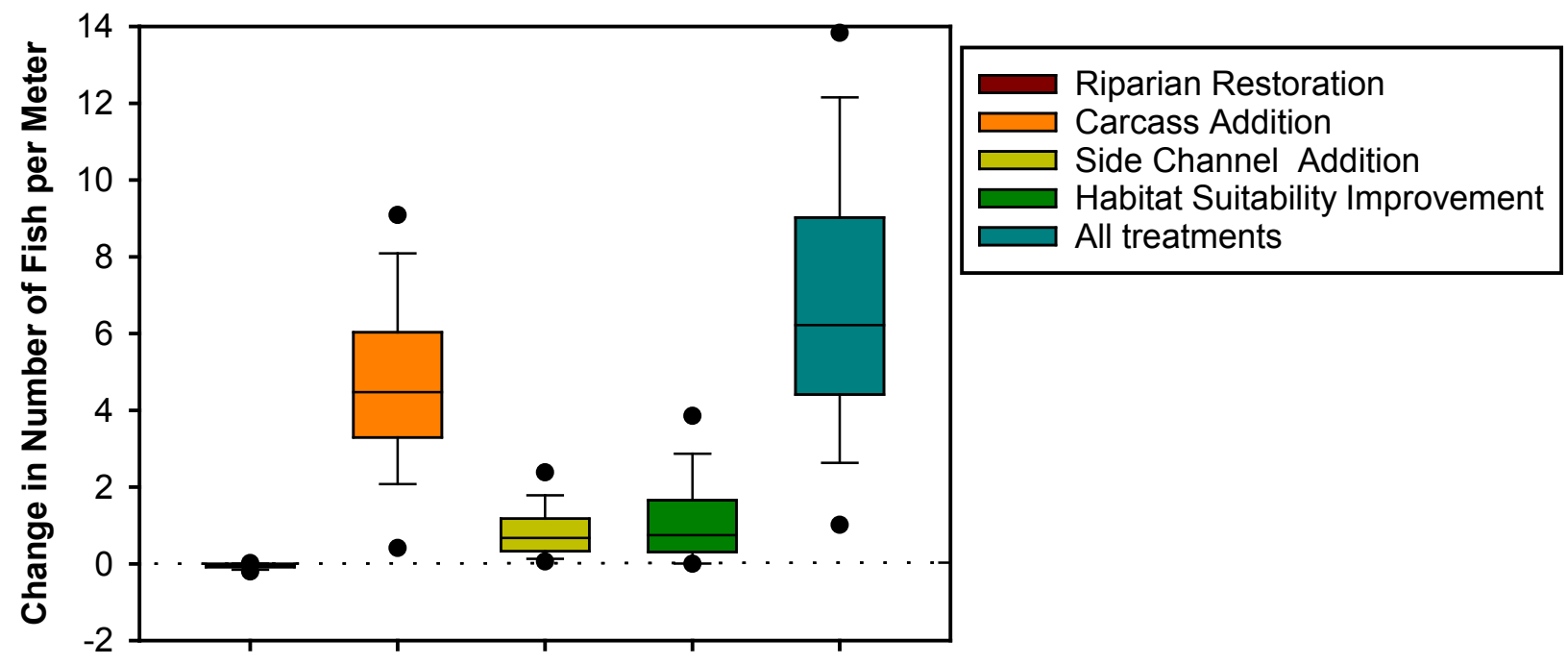

Figure 12. Box-and-whisker plot showing the range of restoration responses for Twisp River floodplain in terms of change in fish numbers observed across a 500-run model sensitivity analysis. The center line in each box is the 50th percentile and the boundaries of the boxes contain modeled responses that are within the 25th and 75th percentile, whereas the whiskers contain response that are within the 10th and 90 th percentile. Circular symbols show the 5th and 95th percentile of the modeled responses. 


\section{Case Study 3: Whitefish Island Side Channel}

\section{Introduction and Site Description}

In 2012, habitat improvements were made at the Whitefish Island side channel, which is a 457m-long channel located adjacent to the main stem of the Methow River between the towns of Twisp and Winthrop. Prior to habitat improvement, aquatic habitat in the Whitefish Island side channel consisted of a series of isolated pools that were disconnected from the main channel approximately 9 months of the year (except during higher flows; fig. 13). In the current, post-treatment state, the side channel maintains surface water connection with the main channel throughout the year, except for extremely low flows $\left(<4 \mathrm{~m}^{3} / \mathrm{s}\right)$. Additionally, the reconnected side channel exhibits much greater wetted area and water depth than the pre-treatment channel. Moreover, log jams and wood assemblies were added during the treatment, which provide additional structural and hydraulic complexity for rearing juvenile fish.
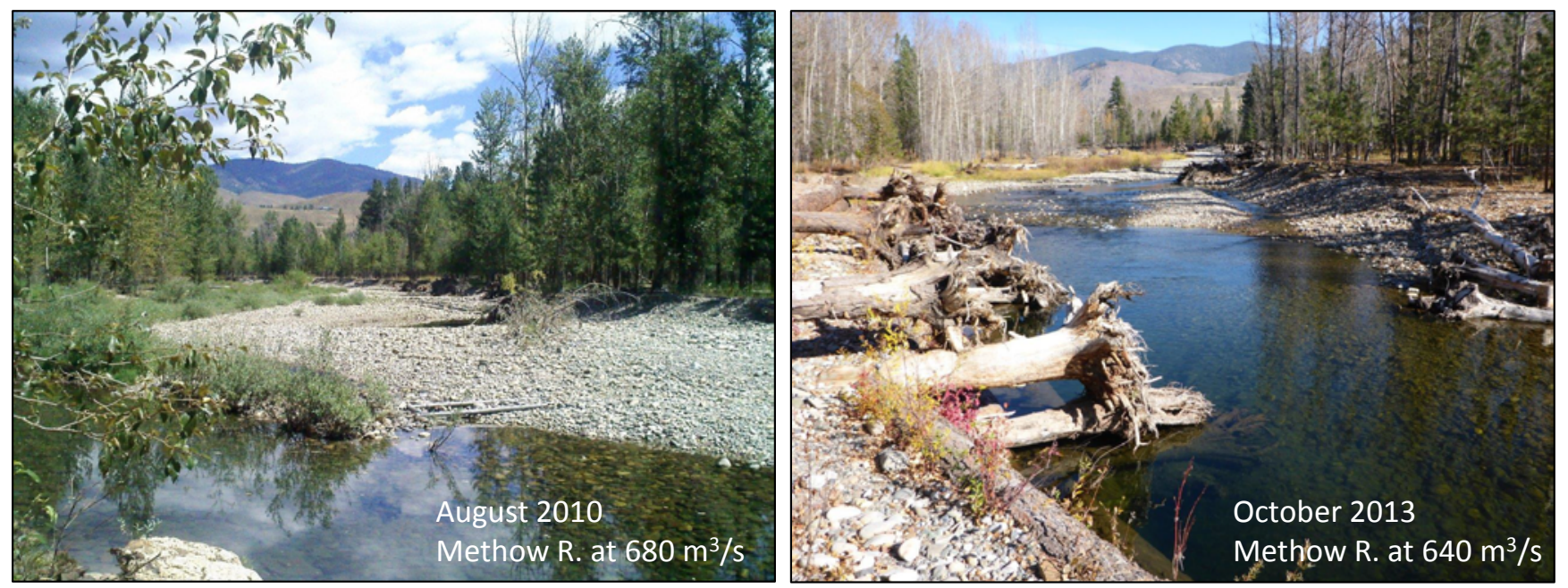

Figure 13. Photographs showing Whitefish Island side channel prior to restoration (left; photograph taken by Brian Fisher, Methow Salmon Recovery Foundation) and after restoration (right; photograph taken by Ronald Gross, Bureau of Reclamation). 


\section{Aquatic Trophic Productivity Model Runs}

Although restoration had already occurred, we applied the ATP model to explore how this habitat improvement action may have changed food-web dynamics and the capacity of the side channel to support fish production. Three model simulations were done: (1) pre-restoration, which represents the pre-treatment conditions; (2) post-restoration scenario 1, which simulates the expected effects of restoration on changes in side channel discharge, wetted area, and hydraulics (that is, average water depth and velocity); and (3) post-restoration scenario 2, which is identical to scenario 1, and has the added effect of doubling the proportion of wetted habitat suitable for juvenile fish.

\section{Model Parameterization}

Hydraulic information for the model was derived from a previously constructed Bureau of Reclamation hydraulic model as well as USGS habitat surveys (Bureau of Reclamation, 2012; Martens and others, 2014). Average daily water temperatures for input to the model were summarized from temperature loggers deployed and maintained by the Methow Salmon Recovery Foundation. Water nutrients and turbidity were taken from a nearby Washington Department of Ecology monitoring site. Riparian vegetation coverage was estimated by analyzing aerial site photographs, and stream shading was calculated from Solar-Pathfinder ${ }^{\mathrm{TM}}$ surveys. Substrate distributions were calculated from a Wolman pebble count.

Because habitat suitability information is not currently available for the pre-restoration condition, we assumed that 25 percent of the wetted area contained habitat suitable for juvenile fish prior to restoration. For the first post-restoration scenario (scenario 1), we held habitat suitability at 25 percent. For scenario 2, we increased HSI from 25 to 50 percent to reflect the likely increase in habitat quality that may be associated with the complexity features, such as large woody debris, added to the channel. Uncertainty in modeled responses for each treatment scenario was quantified by running a separate 500 simulation sensitivity analysis, which incorporated uncertainty in model parameter values.

\section{Results and Discussion}

ATP model simulations simulated a positive and large magnitude response to Whitefish Island side channel restoration across all trophic levels (fig. 14). Relative to pre-treatment, fish biomass increased by 362 percent with post-restoration scenario 1 and 726 percent with scenario 2 (fig. 14). These estimates in fish biomass incorporate all fish, target (for example, Chinook salmon) and nontarget (for example, sculpin, brook trout). Assuming only Chinook salmon reside in this side channel, we estimated that capacity would increase by approximately 3,500 smolts (average size $=10 \mathrm{~g}$ ) with scenario 1, and 7,000 juveniles with scenario 2. This increase in Chinook smolt capacity is within the range of that estimated by the USGS in a preliminary fish survey conducted post-restoration (Kyle Martens, oral personal commun., Washington State Department of Natural Resources, September 2015). 

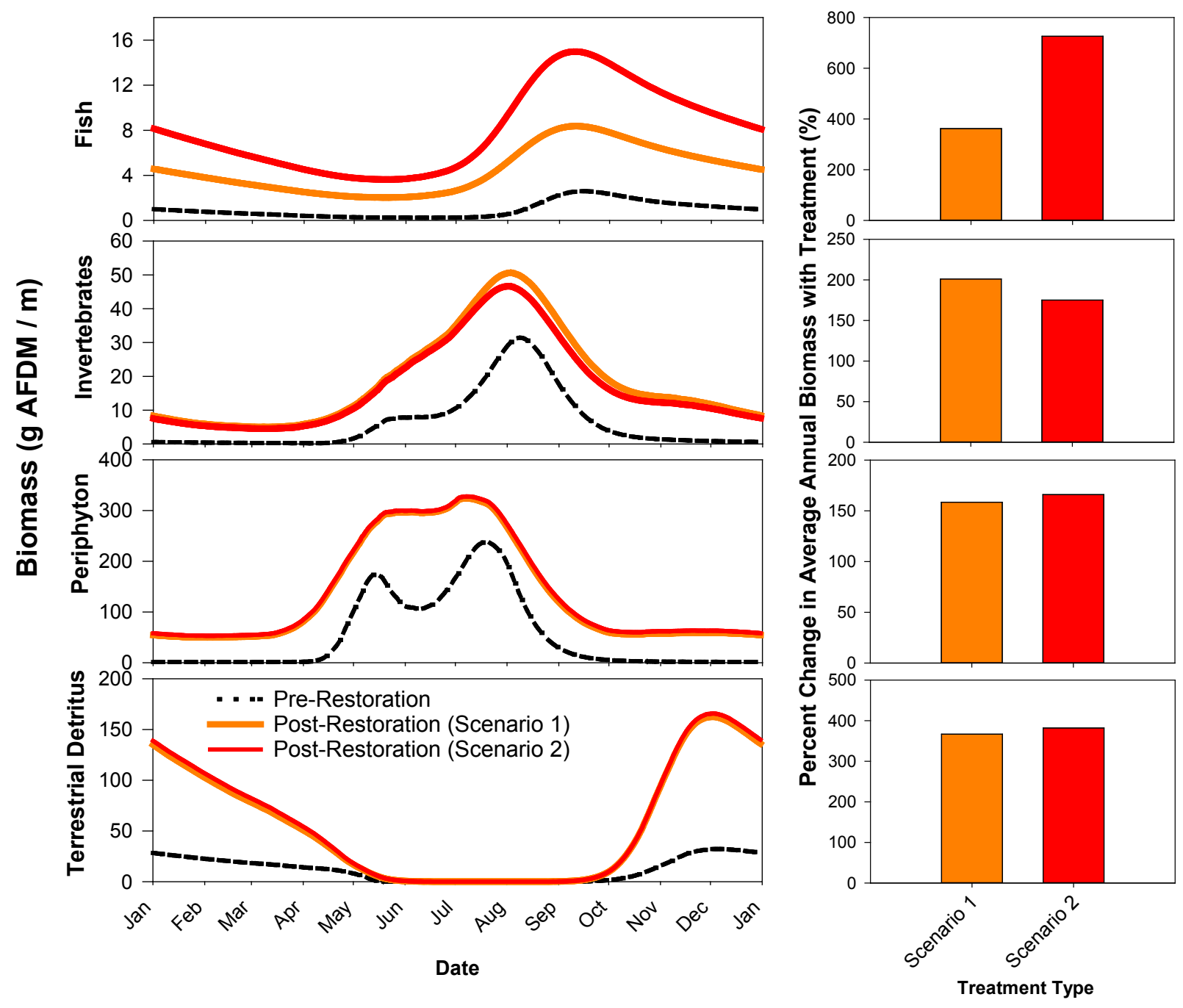

Figure 14. Graphs showing effects of restoration on the biomass dynamics of terrestrial detritus, periphyton, aquatic invertebrates, and fish relative to background conditions (left), and the percent change in average annual biomass from background associated with each treatment (right). All units are in grams of ash-free-dry-mass per meter (g AFDM/m). 
The model simulated positive responses to restoration regardless of parameter uncertainty (fig. 15). More than 95 percent of the 500 model runs conducted in the sensitivity analysis produced positive responses to restoration.

For scenario 1 , the simulated increase in fish biomass was primarily owing to the 5-fold increase in wetted area following restoration. Additionally, following restoration, there was a year-round influx of food resources drifting into the side channel from the upstream main-channel segment, which increased food availability for fish. For scenario 2 , the increase in habitat quality allowed fish more opportunities to access and use these additional food resources. In fact, the additional predation pressure by fish in scenario 2 reduced invertebrate biomass below what was observed with scenario 1 . Overall, these simulations suggest that the habitat improvements that have occurred at Whitefish Island may indeed significantly increase the capacity for the side channel to sustain juvenile salmonids.

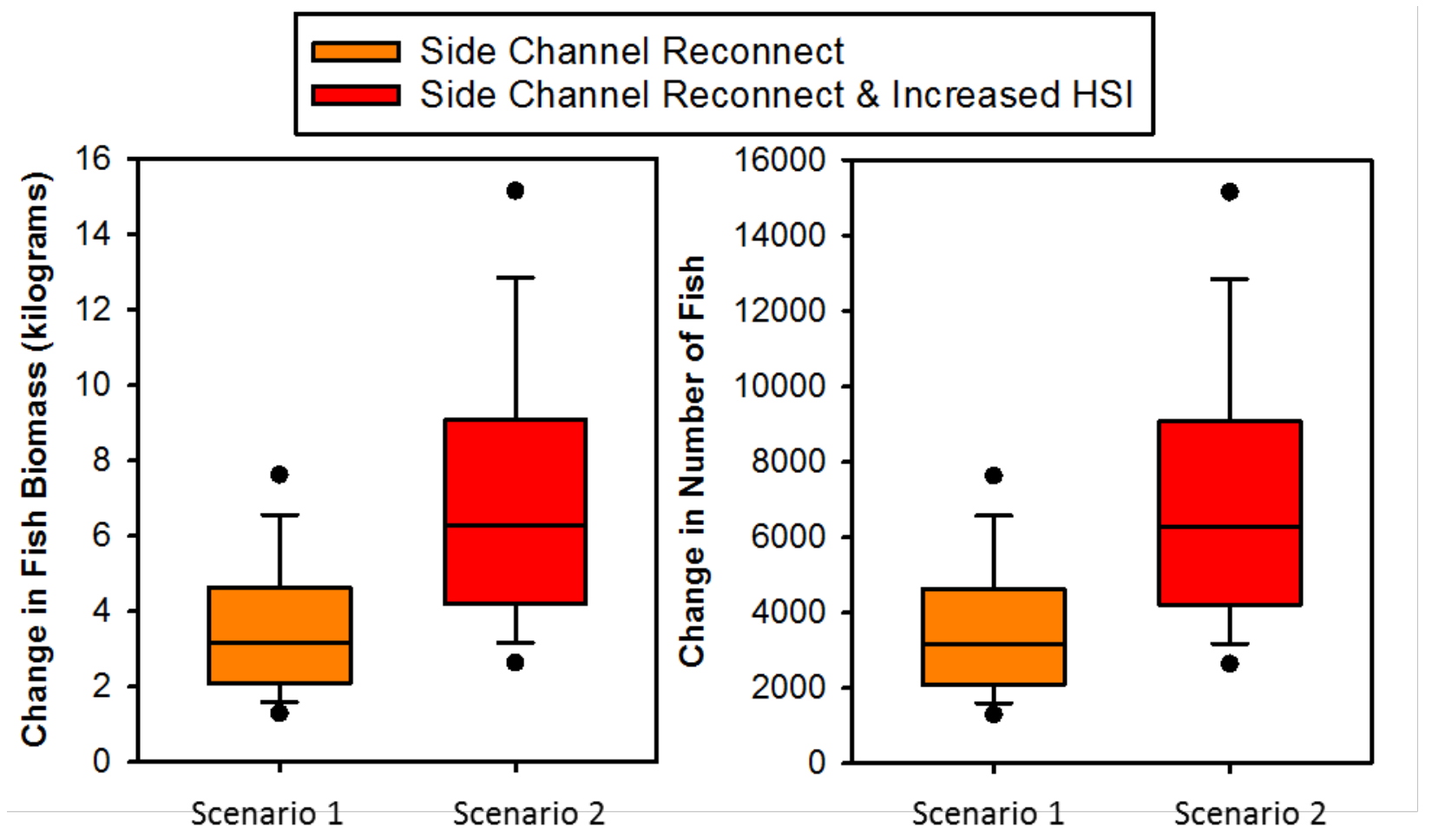

Figure 15. Box-and-whisker plots showing the range of restoration responses for Whitefish Island side channel in terms of change in total fish biomass (left) and change in fish numbers (right) observed across a 500-run model sensitivity analysis. The boundaries of the boxes contain modeled responses that are within the 25th and 75th percentile, whereas the whiskers contain response that are within the 10th and 90th percentile. Circular symbols show the 5th and 95th percentile of the modeled responses. 


\section{Conclusions}

We constructed a model and explicitly linked food-web dynamics to environmental factors known to influence stream food webs. Our simulations illustrate that food-web models can be used to explore responses to a variety of river restoration actions, from those that represent relatively direct manipulations of the food web (for example, salmon carcass addition), to those that are focused on modifying the physical template of the river upon which these webs of interaction emerge (for example, floodplain reconnection). Model simulation results emphasize that restoration actions can influence stream ecosystems through multiple pathways, and that responses to restoration are context dependent. For example, the M2 segment of the middle Methow River was most sensitive to reconnection of side channel habitat and improvements in habitat suitability. In contrast, the lower Twisp River floodplain was most sensitive to stimulation of the food web by addition of salmon carcass material. These results illustrate that different locations in the river network will not respond equally to the same restoration strategy and that local environmental conditions and limiting factors should to be considered when selecting which strategy or strategies are most appropriate. Thus, the ATP model can be used to discern appropriate restoration actions among reaches within a watershed, and should be used as one component, among a suite of tools, for regional decision making.

Results from the ATP model do provide learning opportunities to inform adaptive management. For example, results that are perceived as "wrong" may point out an aspect of the ecosystem that is not clearly understood or where additional information is needed. Thus, data collected by subsequent monitoring of restoration treatments can be used to refine model parameters, the structure of the model, and even the underlying knowledge and assumptions on which the model is based. Over time, this interaction between modeling, experimentation (that is, restoration actions), and monitoring can lead to adaptive learning and increased ability to make better predictions (Power, 2001). Moreover, models also provide a mechanistic understanding of why given responses occur (or do not occur), which is important for promoting understanding, identifying knowledge gaps, and informing empirical studies (Power, 2001; Ford, 2010).

Overall, our food-web model was a vast simplification from that of real stream food webs. That said, models are, by definition, simplifications of more complex systems (Ford, 2010). Although our model was simple in nature, its dynamics were realistic and the biomass values it produced matched reasonably well with those measured empirically (Bellmore and others, 2013; Zuckerman, 2015). We made a compromise between simplicity and complexity. For simplicity - and to make the model most applicable across a broad range of sites - we focused on the basic structure of a simple stream food web. For complexity, we added numerous mechanisms by which environmental conditions interact with specific components of the food web to influence dynamics. This allowed the model to be customized to the unique environmental conditions in different river reaches and different watersheds. Regardless of how well these models are customized to specific contexts, they will still be abstractions of reality. As such, model simulation results should not be interpreted as truth, but instead as hypotheses about what might happen as the context of the system changes. Nonetheless, the hypotheses generated by these models provide a defensible means to structure decision making. 
In conclusion, we show that food-web models generally, and the ATP model specifically, can be critically important for guiding river restoration and management. River ecosystems are inherently interconnected and complex. Although restoration assessments frequently focus on the direct effects of restoration on species of interest, restoration also influences the larger biological system in which these species participate. Understanding responses to restoration will require accounting for these complexities, and the ATP model provides a means for doing so. Linking these approaches to restoration planning, however, will require that researchers and modelers work directly with managers, restoration practitioners, and other stakeholders, and incorporate their local knowledge into the modeling process early and often. It should be clear, however, that the goal of this interaction is not to provide perfect predictions, but to foster a deeper understanding of the dynamics and complexity of the system, which can lead to better restoration planning, and potentially, the ability to prioritize approaches.

\section{Acknowledgments}

We thank Chris Jordan, Mitch Mumma, Kathryn Puckett, and Andrea Woodward for providing helpful reviews on earlier versions of this manuscript. Andy Ford and Dave McIntire provided numerous tips and recommendations during model development. Conversations with Colden Baxter, Jennifer Bountry, Scott Collins, Pat Connolly, Dan Dombroski, Alex Fremier, Stan Gregory, John Jorgensen, Francine Mejia, Michael Newsom, Russ Perry, Jason Romine, Dana Warren, Dana Weigel, and Adrianne Zuckerman also contributed to the report. We also thank the HJ Andrews Experimental Forest.

\section{References Cited}

Abdul-Aziz, O.I., Wilson, B.N., and Gulliver, J.S., 2010, Two-zone model for stream and river ecosystems: Hydrobiologia, v. 638, p. 85-107.

Abelho, M., 2001, From litterfall to breakdown in streams - A review: Scientific World Journal, v. 1, p. 656-680.

Baxter, C.V., Fausch, K.D., and Saunders, W.C., 2005, Tangled webs-Reciprocal flows of invertebrate prey link streams and riparian zones: Freshwater Biology, v. 50, p. 201-220.

Bellmore, J.R., Baxter, C.V., Martens, K.D., and Connolly, P.J., 2013, The floodplain food web mosaic - A study of its importance to salmon and steelhead with implications for their recovery: Ecological Applications, v. 23, p. 189-207.

Bellmore, J.R., Fremier, A.K., Mejia, F., and Newsom, M., 2014, The response of stream periphyton to Pacific salmon-Using a model to understand the role of environmental context: Freshwater Biology, v. 59, p. 1,437-1,451.

Benjamin, J.R., Bellmore, J.R., and Watson, G.A., 2016, Response of ecosystem metabolism to low densities of spawning Chinook salmon: Freshwater Science, v. 35, p. TBD.

Benjamin, J.R., Connolly, P.J., Romine, J.G., and Perry, R.W., 2013, Potential effects of changes in temperature and food resources on life history trajectories of juvenile Oncorhynchus mykiss: Canadian Journal of Fisheries and Aquatic Sciences, v. 142, p. 208-220.

Boston, H.L., and Hill, W.R., 1991, Photosynthesis-light relations of stream periphyton communities: Limnology and Oceanography, v. 36, p. 644-656.

Boulêtreau, S., Garabétian, F., Sauvage, S., and Sánchez-Pérez, J., 2006, Assessing the importance of a self-generated detachment process in river biofilm models: Freshwater Biology, v. 51, p. 901-912. 
Bureau of Reclamation, 2010, Middle Methow reach assessment-Methow River, Okanogan County, Washington: Bureau of Reclamation, 200 p.

Bureau of Reclamation, 2012, Methow River Numerical Hydraulic Modeling Study_Whitefish Island Project Area: Bureau of Reclamation, SRH Report 2012-14.

Bureau of Reclamation, 2015, Methow hydraulics for trophic model: Bureau of Reclamation, FY2015 Progress Report, SRH-2016-02.

Butterwick, C., Heaney, S.I., and Talling, J.F., 2004, Diversity in the influence of temperature on the growth rates of freshwater algae, and its ecological relevance: Freshwater Biology, v. 50, p. 291-300.

Chapra, S.C., 1997, Surface water-quality modeling: New York, WCB/McGraw-Hill, 844 p.

Chidami, S., and Amyot, M., 2008, Fish decomposition in boreal lakes and biogeochemical implications: Limnology and Oceanography, v. 53, p. 1,988-1,996.

Christensen, V., and Pauly, D., 1993, Trophic models of aquatic ecosystems-ICLARM Conference Proceedings 26: International Center for Living Aquatic Resources Management, 390 p.

Cross, W.F., Baxter, C.V., Donner, K.C., Rosi-Marshall, E.J., Kennedy, T.A., Hall, R.O., Wellard Kelly, H.A., and Rogers, R.S., 2011, Ecosystem ecology meets adaptive management—Food web response to a controlled flood on the Colorado River, Glen Canyon: Ecological Applications, v. 21, p. 2,016-2,033.

Cutler, D.R., Edwards, T.C., Beard, K.H., Cutler, A., Hess, K.T., Gibson, J., and Lawler, J.J., 2007, Random forests for classification in ecology: Ecology, v. 88, p. 2,783-2,792.

D’Angelo, D.J., Gregory, S.V., Ashkenas, L.R., and Meyer, J.L., 1997, Physical and biological linkages within a stream geomorphic hierarchy-A modeling approach: Journal of the North American Benthological Society, v. 16, p. 480-502.

DeNicola, D.M., 1990, Periphyton responses to temperature at different ecological levels, in Stevenson, R.J., Bothwell, M.L., and Lowe, R.L., eds., Algal ecology_Freshwater benthic ecosystems: San Diego, California, Academic Press, p. 150-176.

Doyle, M.W., 2006, A heuristic model for potential geomorphic influences on trophic interactions in streams: Geomorphology, v. 77, p. 235-248.

Edwards, E.D., and Huryn, A.D., 1995, Annual contribution of terrestrial invertebrates to a New Zealand trout stream: New Zealand Journal of Marine and Freshwater Research, v. 29, p. 467-477.

Evans, M.R., Bithell, M., Cornell, S.J., Dall, S.R.X., Díaz, S., Emmott, S., Ernande, B., Grimm, V., Hodgson, D.J., Lewis, S.L., Mace, G.M., Morecroft, M., Moustakas, A., Murphy, E., Newbold, T., Norris, K.J., Petchey, O., Smith, M., Travis, J.M.J., and Benton, T.G., 2013, Predictive systems ecology_Proceedings of the Royal Society of London B: Biological Sciences, v. 280, 20131452.

Ford, A., 2010, Modeling the environment (2nd ed.): Washington, D.C., Island Press, 380 p.

Fovet, O., Belaud, G., Litrico, X., Charpentier, S., Bertrand, C., Dauta, A., and Hugodot, C., 2010, Modelling periphyton in irrigation canals: Ecological Modelling, v. 221, p. 1,153-1,161.

Gende, S.M., Edwards, E.D., Willson, M.F., and Wipfli, M.S., 2002, Pacific salmon in aquatic and terrestrial ecosystems: BioScience, v. 52, p. 917-928.

Gordon, N.D., McMahon, T.A., Finlayson, B.L., Gippel, C.J., and Nathan, R.J., 2004, Stream Hydrology-An introduction for ecologists (2nd ed.): West Sussex, United Kingdom, John Wiley and Sons, $431 \mathrm{p}$.

Gotelli, N.J., 2001, A Primer of Ecology (3rd ed.): Sunderland, Massachusetts, Sinauer Associates, 206 p.

Grafius, E., and Anderson, N.H., 1979, Population dynamics, bioenergetics, and role of Lepidostoma quercina Ross (Trichoptera: Lepidostomatidae) in an Oregon woodland stream: Ecology, v. 60, p. 433-441. 
Gregory, S., Boyer, K., and Gurnell, A., 2003, The ecology and managment of wood in world rivers:

Bethesda, Maryland, American Fisheries Society, Symposium 37, 431 p.

Hamilton, D.P., and Schladow, S.G., 1997, Prediction of water quality in lakes and reservoirs:

Ecological Modelling, v. 96, p. 91-110.

Hanson, P.C., Johnson, T.B., Schindler, D.E., and Kitchell, J.F., 1997, Fish bioenergetics 3.0:

University of Wisconsin Sea Grant Institute, Sea Grant Technical Report WISCU-T-97-001.

Harper, E.B., Stella, J.C., and Fremier, A.K., 2011, Global sensitivity analysis for complex ecological models - A case study of riparian cottonwood population dynamics: Ecological Applications, v. 21, p. $1,225-1,240$.

Henderson, F.M., 1966, Open channel flow: New York, U.S.A., Macmillan Publishing Co, Inc.

Hill, W.R., Fanta, S.E., and Roberts, B.J., 2009, Quantifying phosphorus and light effects in stream algae: Limnology and Oceanography, v. 54, p. 368-380.

Hill, W.R., and Harvey, B.C., 1990, Periphyton responses to higher trophic levels and light in a shaded stream: Canadian Journal of Fisheries and Aquatic Sciences, v. 47, p. 2,307-2,314.

Hillman, T.W., Miller, M., Moran, C., Tonesth, M., Hughes, M., Murdoch, A., Keller, L., Willard, C., Ishida, B., Kamphaus, C., and Pearsons, T., 2014, Monitoring and evaluation of the Cheland and Grant County PUDs hatchery programs - 2013 annual report: Report to the HCP and PRCC Hatchery Committees.

Holling, C.S., 1959, Some characteristics of simple types of predation and parasitism: The Canadian Entomologist, v. 91, p. 385-389.

Independent Scientific Advisory Board, 2011a, Using a comprehensive landscape approach for more effective conservation and restoration: Independent Scientific Advisory Board, ISAB 2011-4, 179 p.

Independent Scientific Advisory Board, 2011b, Columbia River food webs-Developing a broader scientific foundation for fish and wildlife restoration: Independent Scientific Advisory Board, ISAB 2011-1, 350 p.

Inter-fluve, 2010, Lower Twisp River reach assessment: Prepared for Yakama Nation Fisheries Program, $115 \mathrm{p}$.

Inter-fluve, 2015, Twisp River flood plain habitat enhancement, Inter-fluve: Final design report prepared for Bureau of Reclamation, $53 \mathrm{p}$.

Janetski, D.J., Chaloner, D.T., Tiegs, S.D., and Lamberti, G.A., 2009, Pacific salmon effects on stream ecosystems-Aquantitative synthesis: Oecologia, v. 159, p. 583-595.

Jenkins, J.C., Chojnacky, D.C., Heath, L.S., and Birdsey, R.A., 2004, Comprehensive database of diameter-based biomass regressions for North American tree species: U.S. Forest Service, General Technical Report NE-319.

Jorgensen, J., 2013, Upper Columbia nutrient supplementation project 2008-471-00: Yakama Nation Fisheries, $104 \mathrm{p}$.

Jørgensen, S.E., Nielsen, S.N., and Jørgensen, L.A., 1991, Handbook of ecological parameters and ecotoxicology: New York, Elsevier, 1,263 p.

Julian, J.P., Stanley, E.H., and Doyle, M.W., 2008, Basin-scale consequences of agricultural land use on benthic light availability and primary production along a sixth-order temperate river: Ecosystems, $\mathrm{v}$. 11, p. 1,091-1,105.

Liaw, A., and Wiener, M., 2002, Classification and regression by randomForest: R news, v. 2, p. 18-22. Lindeman, R.L., 1942, The trophic-dynamic aspect of ecology: Ecology, v. 23. p. 399-417.

Martens, K.D., and Connolly, P.J., 2014, Juvenile anadromous salmonid production in Upper Columbia River side channels with different levels of hydrological connection: Transactions of the American Fisheries Society, v. 143, p. 757-767. 
Martens, K.D., Tibbits, W.T., Watson, G.A., Newsom, M.A., and Connolly, P.J., 2014, Methow and Columbia Rivers studies, Washington-Summary of data collection, comparison of database structure and habitat protocols, and impact of additional PIT tag interrogation systems to survival estimates, 2008-2012: U.S. Geological Survey Open-File Report 2014-1016, 92 p.

Martínez, A., Larrañaga, A., Pérez, J., Descals, E., and Pozo, J., 2014, Temperature affects leaf litter decomposition in low-order forest streams: field and microcosm approaches: FEMS Microbiology Ecology, v. 87, p. 257-267.

Maunder, M.N., 1997, Investigation of density dependence in salmon spawner-Egg relationships using queuing theory: Ecological Modelling, v. 104, p. 189-197.

McCullough, D.A., and Minshall, G.W., 1979, Bioenergetics of lotic filter-feeding insects Simulium spp. (Diptera) and Hydropsyche occidentalis (Trichoptera) and their function in controlling organic transport in streams: Ecology, v. 60, p. 585-596.

McIntire, C.D., 1973, Periphyton dynamics in laboratory streams-A simulation model and its implications: Ecological Monographs, v. 43, p. 399-420.

McIntire, C.D., 1996, A tutorial and teaching guide for the use of a lotic ecosystem model: Corvallis, Oregon State University, $271 \mathrm{p}$.

McIntire, C.D., and Colby, J.A., 1978, A hierarchical model of lotic ecosystems: Ecological Monographs, v. 48, p. 167-190.

Meyer, J.L., Wallace, J.B., and Eggert, S.L., 1998, Leaf litter as a source of dissolved organic carbon in streams: Ecosystems, v. 1, p. 240-249.

Minshall, G.W., Petersen, R.C., Bott, T.L., Cushing, C.E., Cummins, K.W., Vannote, R.L., and Sedell, J.R., 1992, Stream ecosystem dynamics of the Salmon River, Idaho-An 8th order system: Journal of the North American Benthological Society, v.11, p. 111-137.

Minshall, G.W., and Rugenski, A., 2006, Riparian processes and interactions, in Hauer, F.R., and Lamberti, G.A., eds., Methods in Stream Ecology (2nd ed.): San Diego, California, Academic Press, p. 721-742.

Mullen, J.W., Williams, K.R., Rhodus, G., Hillman, T.W., and McIntyre, J.D., 1992, Production and habitat of salmonids in Mid-Columbia River tributary streams: U.S. Fish and Wildlife Service, 187 p.

Odum, E.P., and Barrett, G.W., 2005, Fundamentals of Ecology (5th ed.): Belmont, California, Thomson Brooks/Cole, 598 p.

Penaluna, B.E., Dunham, J.B., and Noakes, D.L.G., 2015, Instream cover and shade mediate avian predation on trout in semi-natural streams: Ecology of Freshwater Fish, doi: 10.111.eff.122221.

Post, D.M., and Walters, A.W., 2009, Nutrient excretion rates of anadromous alewives during their spawning migration: Transactions of the American Fisheries Society, v. 138, p. 264-268.

Power, M.E., 2001, Field biology, food web models, and management - Challenges of context and scale: Oikos, v. 94, p. 118-29.

Power, M.E., Parker, G., Dietrich, W.E., and Sun, A., 1995, How does floodplain width affect floodplain river ecology?-A preliminary exploration using simulations: Geomorphology, v. 13, p. 301-317.

Quinn, J.M., Steele, G.L., Hickey, C.W., and Vickers, M.L., 1994, Upper thermal tolerances of twelve New Zealand stream invertebrate species: New Zealand Journal of Marine and Freshwater Research, v. 28, p. 391-397.

Quinn, T.P., 2005, The behavior and ecology of Pacific salmon and trout: Seattle, Washington, University of Washington Press, 378 p. 
Raleigh, R.F., Miller, W.J., and Nelson, P.C., 1986, Habitat suitability index models and instream flow suitability curves - Chinook salmon: U.S. Fish and Wildlife Service Biological Report 82 (10.122), $64 \mathrm{p}$.

Rutherford, J.C., Scarsbrook, M.R., and Broekhuizen, N., 2000, Grazer control of stream algaeModeling temperature and flood effects: Journal of Environmental Engineering, v. 126, p. 331-339.

Scheuerell, M.D., Moore, J.W., Schindler, D.E., and Harvey, C.J., 2007, Varying effects of anadromous sockeye salmon on the trophic ecology of two species of resident salmonids in southwest Alaska: Freshwater Biology, v. 52, p. 1,944-1,956.

Schuwirth, N., Acuña, V., and Reichert, P., 2011, Development of a mechanistic model (ERIMO-I) for analyzing the temporal dynamics of the benthic community of an intermittent Mediterranean stream: Ecological Modelling, v. 222, p. 91-104.

Snow, C., Frady, C., Repp, A., Murdoch, A., Small, M. P., and Dean, C., 2013, Monitoring and evaluation of wells and Methow hatchery programs - 2012 annual report: Twisp, Washington State Department of Fish and Wildlife, $210 \mathrm{p}$.

Uehlinger, U., Bührer, H., and Reichert, P., 1996, Periphyton dynamics in a floodprone prealpine river-Evaluation of significant processes by modelling: Freshwater Biology, v. 36, p. 249-263.

Vannote, R.L., Minshall, G.W., Cummins, K.W., Sedell, J.R., and Cushing, C.E., 1980, The river continuum concept: Canadian Journal of Fisheries and Aquatic Sciences, v. 37, p. 130-137.

Wood, C.M., 1995, Excretion, in Groot, C., Margolis, Leo, and Clarks, W.C., eds., Physiological ecology of Pacific salmon: Vancouver, Canada, University of British Columbia Press, p. 381-438.

Zuckerman, A., 2015, Seasonal variation in empirical and modeled periphyton at the watershed scale: Moscow, University of Idaho, M.S. thesis, 98 p. 


\section{Appendix A. Parameters Used in the Aquatic Trophic Productivity Model, Including a Description of Each Parameter, the Value Used in Model Runs, the Range of Values Applied to Sensitivity Analyses, and Literature Source(s)}

[g/g, gram per gram; $(\mathrm{g} / \mathrm{g}) / \mathrm{d}$, gram per gram per day; ${ }^{\circ} \mathrm{C}$, degrees Celsius; g AFDM $/ \mathrm{m}^{2}$, grams of ash-free dry mass per square meter; NTU, nephelometric turbidity unit; $\mathrm{m}$, meter; $\mathrm{m} / \mathrm{s}$, meter per second; $(\mathrm{mg} / \mathrm{g}) / \mathrm{d}$; milligram per gram per day; $\mathrm{mg} / \mathrm{L}$, milligram per liter; $\left(\mathrm{mol} / \mathrm{m}^{2}\right) / \mathrm{d}$, mole per square meter per day; $\mathrm{kg} / \mathrm{m}^{3}, \mathrm{kilogram}$ per cubic meter]

\begin{tabular}{|c|c|c|c|c|c|c|}
\hline $\begin{array}{l}\text { Model } \\
\text { sector }\end{array}$ & Parameter & Parameter description & Units & Value & $\begin{array}{c}\text { Sensitivity } \\
\text { range }\end{array}$ & Sources \\
\hline \multirow[t]{13}{*}{ Fish (F) } & $\alpha_{\mathrm{IF}}$ & $\begin{array}{l}\text { proportion of ingested aquatic invertebrate } \\
\text { biomass that is assimilated }\end{array}$ & $\mathrm{g} / \mathrm{g}$ & 0.75 & $\begin{array}{c}0.5625- \\
0.9375\end{array}$ & (Cross and others, 2011) \\
\hline & $\alpha_{\mathrm{TF}}$ & $\begin{array}{l}\text { proportion of ingested terrestrial } \\
\text { invertebrate biomass that is assimilated }\end{array}$ & $g / g$ & 0.70 & $0.525-0.875$ & (Cross and others, 2011) \\
\hline & $\alpha_{\mathrm{CF}}$ & $\begin{array}{l}\text { proportion of ingested salmon carcass } \\
\text { biomass that is assimilated }\end{array}$ & $g / g$ & 0.90 & $0.675-0.99$ & Assumed \\
\hline & $\alpha_{\mathrm{EF}}$ & $\begin{array}{l}\text { proportion of ingested salmon egg biomass } \\
\text { that is assimilated }\end{array}$ & $\mathrm{g} / \mathrm{g}$ & 0.95 & $0.71-0.99$ & Assumed \\
\hline & $\mathrm{c}_{\max , \mathrm{F}}$ & $\begin{array}{l}\text { maximum rate of consumption when } \\
\text { temperature is optimum }\end{array}$ & $(\mathrm{g} / \mathrm{g}) / \mathrm{d}$ & 0.16 & $0.12-0.20$ & (Benjamin and others, 2013) \\
\hline & Temp $_{\mathrm{opt}, \mathrm{F}}$ & optimum temperature for fish consumption & ${ }^{\circ} \mathrm{C}$ & 16.0 & & (Hanson and others, 1997) \\
\hline & $\mathrm{Temp}_{\max , \mathrm{F}}$ & maximum temperature for fish consumption & ${ }^{\circ} \mathrm{C}$ & 25.0 & & (Hanson and others, 1997) \\
\hline & $\mathrm{Temp}_{\min , \mathrm{F}}$ & minimum temperature for fish consumption & ${ }^{\circ} \mathrm{C}$ & -5.0 & & (Hanson and others, 1997) \\
\hline & $\gamma_{F}$ & dimensionless self-interaction parameter & unitless & 3.0 & $1.5-4.5$ & Assumed \\
\hline & $k_{F}$ & prey biomass half saturation level & $\mathrm{g} \mathrm{AFDM} / \mathrm{m}$ & 1.5 & $0.75-2.25$ & Assumed \\
\hline & $r_{r e f, F}$ & rate of respiration at $25^{\circ} \mathrm{C}$ & $(\mathrm{g} / \mathrm{g}) / \mathrm{d}$ & 0.012 & $0.009-0.015$ & (Hanson and others, 1997) \\
\hline & $\theta_{\mathrm{F}}$ & $\begin{array}{l}\text { temperature coefficient describing shape of } \\
\text { exponential relationship between } \\
\text { temperature and respiration rate }\end{array}$ & unitless & 1.07 & & (Hanson and others, 1997) \\
\hline & $m_{F}$ & daily mortality rate & $(g / g) / d$ & 0.00274 & $\begin{array}{r}0.00137- \\
0.00411 \\
\end{array}$ & Assumed \\
\hline \multirow[t]{3}{*}{$\begin{array}{l}\text { Aquatic } \\
\text { inverte- } \\
\text { brates (I) }\end{array}$} & $\alpha_{\mathrm{PI}}$ & $\begin{array}{l}\text { proportion of ingested periphyton biomass } \\
\text { that is assimilated }\end{array}$ & $\mathrm{g} / \mathrm{g}$ & 0.40 & $\begin{array}{l}0.02625- \\
0.04375\end{array}$ & $\begin{array}{l}\text { (Grafius and Anderson, 1979; } \\
\text { McCullough and Minshall, 1979; } \\
\text { Mcintire, 1996; Rutherford and others, } \\
\text { 2000; Cross and others, 2011) }\end{array}$ \\
\hline & $\alpha_{\mathrm{DI}}$ & $\begin{array}{l}\text { proportion of ingested terrestrial detritus } \\
\text { biomass that is assimilated }\end{array}$ & $\mathrm{g} / \mathrm{g}$ & 0.20 & $\begin{array}{l}0.01125- \\
0.01875\end{array}$ & (Mcintire, 1996; Cross and others, 2011) \\
\hline & $\alpha_{\mathrm{CI}}$ & $\begin{array}{l}\text { proportion of ingested salmon carcass } \\
\text { biomass that is assimilated }\end{array}$ & $\mathrm{g} / \mathrm{g}$ & 0.70 & $\begin{array}{l}0.18975- \\
0.31625\end{array}$ & (Cross and others, 2011) \\
\hline
\end{tabular}




\begin{tabular}{|c|c|c|c|c|c|c|}
\hline $\begin{array}{l}\text { Model } \\
\text { sector }\end{array}$ & Parameter & Parameter description & Units & Value & $\begin{array}{l}\text { Sensitivity } \\
\text { range }\end{array}$ & Sources \\
\hline & $\mathrm{c}_{\max , \mathrm{I}}$ & $\begin{array}{l}\text { maximum rate of consumption when } \\
\text { temperature is optimum }\end{array}$ & $(\mathrm{g} / \mathrm{g}) / \mathrm{d}$ & 0.5 & $0.375-0.625$ & $\begin{array}{l}\text { (Grafius and Anderson, 1979; Mcintire, } \\
\text { 1996; D'Angelo and others, 1997; } \\
\text { Rutherford and others, 2000) }\end{array}$ \\
\hline & Temp $_{\text {opt,I }}$ & $\begin{array}{l}\text { optimum temperature for invertebrate } \\
\text { consumption }\end{array}$ & ${ }^{\circ} \mathrm{C}$ & 15.0 & & $\begin{array}{l}\text { (Mcintire, 1996; Rutherford and others, } \\
\text { 2000) }\end{array}$ \\
\hline & Temp $_{\max , I}$ & $\begin{array}{l}\text { maximum temperature for invertebrate } \\
\text { consumption }\end{array}$ & ${ }^{\circ} \mathrm{C}$ & 26.0 & & (Quinn and others, 1994) \\
\hline & Temp $_{\min , \mathrm{I}}$ & $\begin{array}{l}\text { minimum temperature for invertebrate } \\
\text { consumption }\end{array}$ & ${ }^{\circ} \mathrm{C}$ & -10.0 & & Assumed \\
\hline & $\gamma_{I}$ & dimensionless self-interaction parameter & unitless & 8.0 & $4-12$ & Assumed \\
\hline & $k_{I}$ & prey biomass half saturation level & $\mathrm{g} \mathrm{AFDM} / \mathrm{m}^{2}$ & 5.0 & $2.5-7.5$ & Assumed \\
\hline & $r_{r e f, I}$ & rate of respiration at $20^{\circ} \mathrm{C}$ & $(\mathrm{g} / \mathrm{g}) / \mathrm{d}$ & 0.05 & $\begin{array}{l}0.0375- \\
0.0625\end{array}$ & $\begin{array}{l}\text { (Mcintire, 1996; D'Angelo and others, } \\
\text { 1997; Rutherford and others, 2000) }\end{array}$ \\
\hline & $m_{I}$ & daily mortality rate & $(g / g) / d$ & 0.0167 & $\begin{array}{l}0.00835- \\
0.02505\end{array}$ & Assumed \\
\hline & $\theta_{\mathrm{I}}$ & $\begin{array}{l}\text { temperature coefficient describing shape of } \\
\text { exponential relationship between } \\
\text { temperature and respiration rate }\end{array}$ & unitless & 1.05 & & (Rutherford and others, 2000) \\
\hline & $a_{I}$ & shape parameter for export rate equation & unitless & 7 & $3.5-10.5$ & Assumed \\
\hline & $B_{I}{ }^{*}$ & $\begin{array}{l}\text { refuge biomass that is invulnerable to } \\
\text { predation and export }\end{array}$ & $\mathrm{g} \mathrm{AFDM} / \mathrm{m}^{2}$ & 0.05 & & Assumed \\
\hline \multirow[t]{10}{*}{ Periphyton (P) } & $\mathrm{g}_{\text {max }, P}$ & $\begin{array}{l}\text { maximum rate of growth when temperature } \\
\text { is optimum }\end{array}$ & $(\mathrm{g} / \mathrm{g}) / \mathrm{d}$ & 1.1 & $0.825-1.375$ & $\begin{array}{l}\text { (Boulêtreau and others, 2006; Fovet and } \\
\text { others, 2010; Schuwirth and others, 2011) }\end{array}$ \\
\hline & Temp $_{\text {opt,P }}$ & optimum temperature for periphyton growth & ${ }^{\circ} \mathrm{C}$ & 20.0 & & $\begin{array}{l}\text { (DeNicola, 1990; Rutherford and others, } \\
\text { 2000; Butterwick and others, 2004) }\end{array}$ \\
\hline & Temp $_{\max , \mathrm{P}}$ & $\begin{array}{l}\text { maximum temperature for periphyton } \\
\text { growth }\end{array}$ & ${ }^{\circ} \mathrm{C}$ & 30.0 & & $\begin{array}{l}\text { (DeNicola, 1990; Rutherford and others, } \\
\text { 2000; Butterwick and others, 2004) }\end{array}$ \\
\hline & Temp $_{\min , \mathrm{P}}$ & $\begin{array}{l}\text { minimum temperature for periphyton } \\
\text { growth }\end{array}$ & ${ }^{\circ} \mathrm{C}$ & -10.0 & & $\begin{array}{l}\text { (DeNicola, 1990; Rutherford and others, } \\
\text { 2000; Butterwick and others, 2004) }\end{array}$ \\
\hline & $k_{D}$ & density half saturation for periphyton & $\mathrm{g} \mathrm{AFDM} / \mathrm{m}^{2}$ & 4.0 & $3-5$ & $\begin{array}{l}\text { (McIntire, 1973; Rutherford and others, } \\
\text { 2000; Boulêtreau and others, 2006; } \\
\text { Schuwirth and others, 2011) }\end{array}$ \\
\hline & $k_{P A R}$ & PAR half saturation level & $\left(\mathrm{mol} / \mathrm{m}^{2}\right) / \mathrm{d}$ & 5.0 & $3.75-6.25$ & $\begin{array}{l}\text { (Uehlinger and others, 1996; Hill and } \\
\text { others, 2009) }\end{array}$ \\
\hline & $k_{D I N}$ & $\begin{array}{l}\text { dissolved inorganic nitrogen (DIN) half } \\
\text { saturation level }\end{array}$ & $\mathrm{mg} / \mathrm{L}$ & 0.02 & $0.015-0.025$ & $\begin{array}{l}\text { (Jørgensen and others, 1991; Chapra, } \\
\text { 1997; Rutherford and others, 2000) }\end{array}$ \\
\hline & $k_{S R P}$ & $\begin{array}{l}\text { soluble reactive phosphorus (SRP) half } \\
\text { saturation level }\end{array}$ & $\mathrm{mg} / \mathrm{L}$ & 0.005 & $\begin{array}{l}0.00375- \\
0.00625\end{array}$ & $\begin{array}{l}\text { (Jørgensen and others, 1991; Chapra, } \\
\text { 1997; Rutherford and others, 2000) }\end{array}$ \\
\hline & $k_{v}$ & water velocity half saturation level & $\mathrm{m} / \mathrm{s}$ & 0.18 & $0.135-0.225$ & (McIntire, 1973; Mcintire, 1996) \\
\hline & $d_{r e f, P}$ & rate of decay at $20^{\circ} \mathrm{C}$ & $(g / g) / d$ & 0.035 & $\begin{array}{l}0.027- \\
0.044\end{array}$ & $\begin{array}{l}\text { (Hamilton and Schladow, 1997; } \\
\text { Rutherford and others, 2000) }\end{array}$ \\
\hline
\end{tabular}




\begin{tabular}{|c|c|c|c|c|c|c|}
\hline $\begin{array}{l}\text { Model } \\
\text { sector }\end{array}$ & Parameter & Parameter description & Units & Value & $\begin{array}{c}\text { Sensitivity } \\
\text { range }\end{array}$ & Sources \\
\hline & $\theta_{\mathrm{P}}$ & $\begin{array}{l}\text { temperature coefficient describing shape of } \\
\text { exponential relationship between } \\
\text { temperature and respiration rate }\end{array}$ & unitless & 1.08 & & $\begin{array}{l}\text { (Chapra, 1997; Abdul-Aziz and others, } \\
\text { 2010) }\end{array}$ \\
\hline & $a_{P}$ & shape parameter for export rate equation & unitless & 10 & $5-15$ & Assumed \\
\hline & $B_{P}{ }^{*}$ & $\begin{array}{l}\text { refuge biomass that is invulnerable to } \\
\text { predation and export }\end{array}$ & $\mathrm{g} \mathrm{AFDM} / \mathrm{m}^{2}$ & 0.5 & & Assumed \\
\hline \multirow[t]{3}{*}{$\begin{array}{l}\text { Terrestrial } \\
\text { detritus (D) }\end{array}$} & $d_{r e f, D}$ & rate of decay at $20^{\circ} \mathrm{C}$ & $(g / g) / d$ & 0.015 & $\begin{array}{l}0.011- \\
0.019\end{array}$ & $\begin{array}{l}\text { (Abelho, 2001; Martínez and others, } \\
\text { 2014) }\end{array}$ \\
\hline & $\theta_{\mathrm{D}}$ & $\begin{array}{l}\text { temperature coefficient describing shape of } \\
\text { exponential relationship between } \\
\text { temperature and respiration rate }\end{array}$ & unitless & 1.08 & & $\begin{array}{l}\text { (Abelho, 2001; Martínez and others, } \\
\text { 2014) }\end{array}$ \\
\hline & $a_{D}$ & shape parameter for export rate equation & unitless & 18 & $9-27$ & Assumed \\
\hline \multirow[t]{15}{*}{$\begin{array}{l}\text { Salmon carcass } \\
\text { (C) }\end{array}$} & $d_{r e f, C}$ & rate of salmon carcass decay at $20^{\circ} \mathrm{C}$ & $(\mathrm{g} / \mathrm{g}) / \mathrm{d}$ & 0.253 & $\begin{array}{l}0.190- \\
0.316\end{array}$ & (Chidami and Amyot, 2008) \\
\hline & $\theta_{\mathrm{C}}$ & $\begin{array}{l}\text { temperature coefficient describing shape of } \\
\text { exponential relationship between } \\
\text { temperature and respiration rate }\end{array}$ & unitless & 1.25 & & (Chidami and Amyot, 2008) \\
\hline & $a_{C}$ & shape parameter for export rate equation & unitless & 14 & $7-21$ & Assumed \\
\hline & $B_{C}{ }^{*}$ & $\begin{array}{l}\text { refuge biomass that is invulnerable to } \\
\text { predation and export }\end{array}$ & $\mathrm{g} \mathrm{AFDM} / \mathrm{m}^{2}$ & 0 & & Assumed \\
\hline & $D I N_{\text {excret }}$ & $\begin{array}{l}\text { rate of dissolved inorganic nitrogen } \\
\text { excretion from adult salmon }\end{array}$ & $(\mathrm{mg} / \mathrm{g}) / \mathrm{d}$ & 0.161 & & (Wood, 1995; Post and Walters, 2009) \\
\hline & $S R P_{\text {excret }}$ & $\begin{array}{l}\text { rate of soluble reactive phosphorus excretion } \\
\text { from adult salmon }\end{array}$ & $(\mathrm{mg} / \mathrm{g}) / \mathrm{d}$ & 0.032 & & (Wood, 1995; Post and Walters, 2009) \\
\hline & $D I N_{\text {leach }}$ & $\begin{array}{l}\text { rate of dissolved nitrogen leaching from } \\
\text { salmon carcasses }\end{array}$ & $(\mathrm{mg} / \mathrm{g}) / \mathrm{d}$ & 0.016 & & $\begin{array}{l}\text { Assumed value (1/10th of excretion } \\
\text { value) }\end{array}$ \\
\hline & $S R P_{\text {leach }}$ & $\begin{array}{l}\text { rate of soluble reactive phosphorus leaching } \\
\text { from salmon carcasses }\end{array}$ & $(\mathrm{mg} / \mathrm{g}) / \mathrm{d}$ & 0.003 & & $\begin{array}{l}\text { Assumed value (1/10th of excretion } \\
\text { value) }\end{array}$ \\
\hline & - & mass of individual salmon egg & g AFDM & 0.03 & & (Quinn, 2005) \\
\hline & - & pre spawn mortality & unitless & 0.1 & & (Quinn, 2005) \\
\hline & - & salmon body mass & g AFDM & 1000 & & (Quinn, 2005) \\
\hline & $\mathrm{A}_{\text {redd }}$ & area of individual salmon redd & $1 / \mathrm{m}^{2}$ & 4.5 & & (Quinn, 2005) \\
\hline & - & female fecundity & \# & 3,900 & & (Quinn, 2005) \\
\hline & - & minimum suitable spawning substrate size & $\mathrm{m}$ & 0.01 & & (Quinn, 2005) \\
\hline & - & maximum suitable spawning substrate size & $\mathrm{m}$ & 0.15 & & (Quinn, 2005) \\
\hline \multirow[t]{2}{*}{$\begin{array}{l}\text { Terrestrial } \\
\text { invertebrates }\end{array}$} & $\mathrm{B}_{\text {winged }}$ & input of winged terrestrial invertebrates & $\mathrm{g} \mathrm{AFDM} / \mathrm{m}^{2}$ & $\begin{array}{l}\text { calculate } \\
\text { d }\end{array}$ & & (Edwards and Huryn, 1995) \\
\hline & $\begin{array}{l}\text { MAX } \\
g\end{array}$ & $\begin{array}{l}\text { maximum potential increase in winged } \\
\text { terrestrial invertebrate input with salmon }\end{array}$ & unitless & 3 & & Assumed \\
\hline
\end{tabular}




\begin{tabular}{|c|c|c|c|c|c|c|}
\hline $\begin{array}{l}\text { Model } \\
\text { sector }\end{array}$ & Parameter & Parameter description & Units & Value & $\begin{array}{l}\text { Sensitivity } \\
\text { range }\end{array}$ & Sources \\
\hline & & carcass stranding & & & & \\
\hline & $k_{S, \text { stranding }}$ & $\begin{array}{l}\text { stranded carcass biomass value where the } \\
\text { response is half of the maximum }\end{array}$ & $\mathrm{g}$ AFDM $/ \mathrm{m}^{2}$ & 0.2 & & Assumed \\
\hline & $p_{C, \text { strand }}$ & $\begin{array}{l}\text { proportion of salmon carcass biomass that is } \\
\text { stranded in terrestrial habitats }\end{array}$ & unitless & 0.2 & & Assumed \\
\hline \multirow[t]{2}{*}{ Light } & $p_{\text {reflect }}$ & $\begin{array}{l}\text { proportion of PAR that enters water after } \\
\text { reflection }\end{array}$ & unitless & 0.88 & & (Julian and others, 2008) \\
\hline & $\theta_{\mathrm{NTU}}$ & $\begin{array}{l}\text { nephelometric turbidity coefficient for light } \\
\text { attenuation }\end{array}$ & unitless & 0.17 & & (Julian and others, 2008) \\
\hline \multirow{4}{*}{$\begin{array}{l}\text { Physical } \\
\text { conditions }\end{array}$} & $g$ & acceleration due to gravity & $\mathrm{m} / \mathrm{s}$ & 9.81 & & (Gordon and others, 2004) \\
\hline & $\rho_{\mathrm{w}}$ & water density & $\mathrm{kg} / \mathrm{m}^{3}$ & 1000 & & (Gordon and others, 2004) \\
\hline & $\rho_{\mathrm{s}}$ & density of substrate & $\mathrm{kg} / \mathrm{m}^{3}$ & 2.65 & & (Gordon and others, 2004) \\
\hline & $\tau^{*}$ & shields number & unitless & 0.0045 & & (Gordon and others, 2004) \\
\hline
\end{tabular}




\section{Appendix B. STELLA ${ }^{\circledR}$ diagrams and code for the Aquatic Trophic Productivity (ATP) model.}

Note: In some instances, coding was similar for multiple trophic levels. For these situations, only one diagram is shown and other similar trophic levels are noted. However, all the coding is presented. Values presented in the code are for the Lower Twisp River Floodplain (Case Study 2).

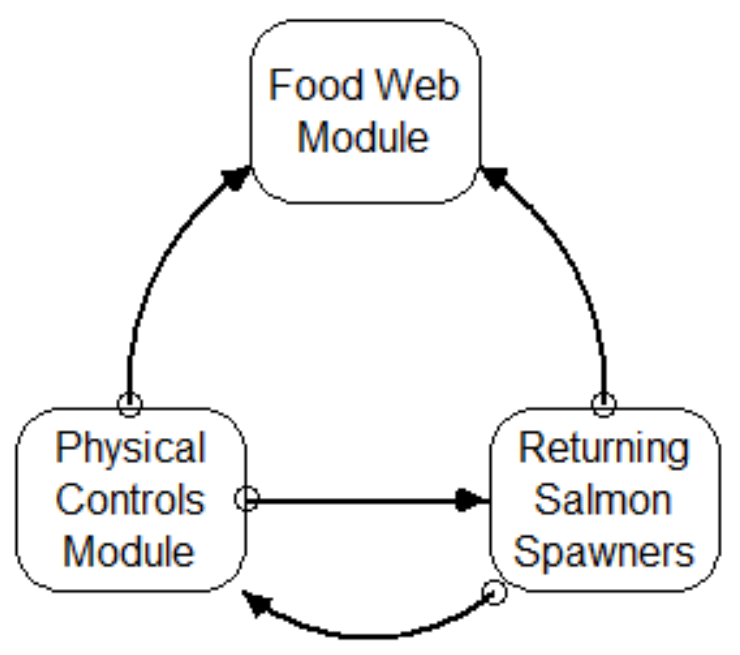

Figure B1. Linkage among the three main modules in the ATP model. 


\section{Physical Controls Module}

\section{Channel Hydraulics Calculations}

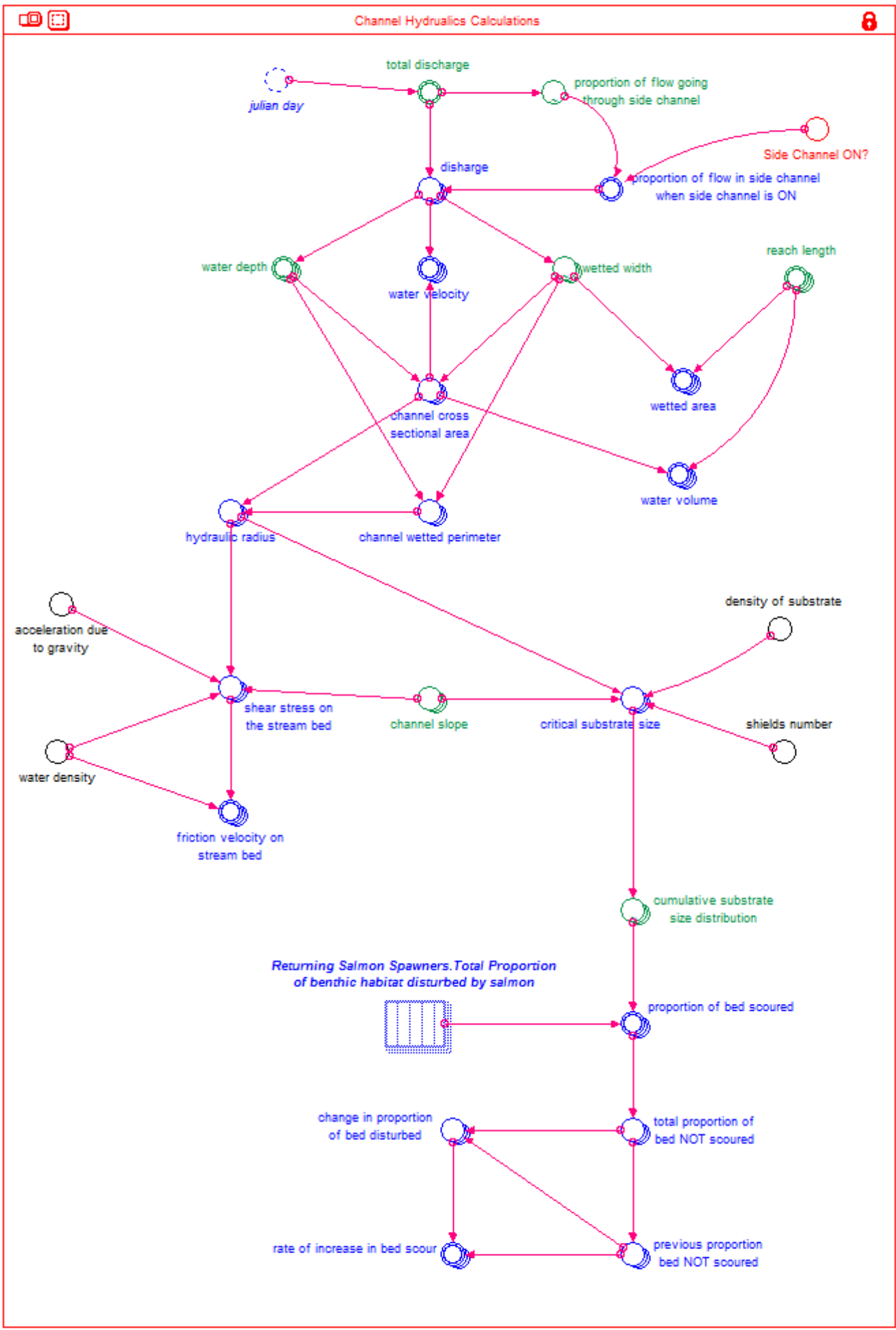

Figure B2. Channel Hydraulics calculations in the Physical Controls Module. Diagram is as it appears in STELLA ${ }^{\circledR}$. 
○ acceleration_due_to_gravity $=9.81$

○ change_in_proportion_of_bed_disturbed[Habitat_Patch_Type] = previous_proportion_bed_NOT_scouredtotal_proportion_of bed_ NOT_scoured

○ channel_cross_sectional_area[Habitat_Patch_Type] $=$ water_depth*wetted_width

○ channel_slope[main_channel] $=0.01$

○ channel_slope[side_channel] $=0.01$

$\circ$ channel_slope[upstream_channel] $=0.01$

○ channel_wetted_perimeter[Habitat_Patch_Type] $=$ wetted_width $+(2 *$ water_depth $)$

○ critical_substrate_size[Habitat_Patch_Type] $=($ hydraulic_radius $*$ channel_slope $) /($ density_of_substrate1)*shie-1ds_number)

○ density_of_substrate $=2.65$

○ disharge[main_channel] $=$ total_discharge* $(1-$

proportion_of_flow_in_side_channel_when_side_channel_is_ON)

- disharge[side_channel] $=$

(total_discharge* ${ }^{*}$ proportion_of_flow_in_side_channel_when_side_channel_is_ON)

○ disharge[upstream_channel] $=\overline{\text { total_discharge }}$

○ friction_velocity_on_stream_bed[Habitat_Patch_Type] = sqrt(shear_stress_on_the_stream_bed/water_density)

- hydraulic_radius[Habitat_Patch_Type] $=$ IF(channel_wetted_perimeter=0)THEN(0)ELSE(channel_cross_sectional_area/channel_wetted_perimeter)

○ previous_proportion_bed_NOT_scoured[Habitat_Patch_Type] $=$ HISTORY(total_proportion_of_bed_NOT_scoured, TIME-1)

○ proportion_of_bed_scoured[Habitat_Patch_Type] $=$ cumulative_substrate_size_distribution+Returning_Salmon_Spawners.Total_Proportion_of_benthic_habita t_disturbed_by_salmon

o proportion_of_flow_in_side_channel_when_side_channel_is_ON = proportion_of_flow_going_through_side_channel*'Side_Channel_ON?

$\circ$ rate_of_increase in_bed_scour[Habitat_Patch_Type] $=\overline{\mathrm{I}} \mathrm{F}$ (change in proportion_of bed_disturbed $>0$ ) THEN $(($ change_in_proportion_of_bed_disturbed/previous_proportion_bed_NOT_scoured $))$ ELSE 0

○ reach_length[main_channel] $=16 \overline{10}$

$\circ$ reach_length[side_channel] $=161$

$\circ \quad$ reach_length[upstream_channel] $=1610$

- shear_stress_on_the_stream_bed[Habitat_Patch_Type] $=$ acceleration_due_to_gravity*hydraulic_radius*wäwer_density*channel_slope

○ shields number $=0.045$

○ Side_Channel_ON? $=0$

○ total_proportion_of_bed_NOT_scoured[Habitat_Patch_Type] $=1$-proportion_of_bed_scoured

○ water_density $=1000$

○ water_velocity[Habitat_Patch_Type] $=$ IF(channel_cross_sectional_area=0)THEN(0)ELSE(disharge/channel_cross_sectional_area)

○ water_volume[Häitat_Patch_Type] = channel_cross_sectional_area*ireach_length

○ wetted_area[Habitat_Patch_Type] = wetted_width*reach_length

- cumulative_substrate_size_distribution[Habitat_Patch_Type] $=$ GRAPH(critical_substrate_size) $(0.00,0.00),(0.0853,0.05),(0.171,0.16),(0.25 \overline{6}, 0.5),(0.341,0.84),(0.427,0.9 \overline{5}),(0.512,1.00)$

- proportion_of_flow_going_through_side_channel $=\mathrm{GRAPH}($ total_discharge $)$ $(1.36,0.00),(\overline{2} .32,0.00),(\overline{3} .77,0.00),(5.89,0.00843),(7.08,0.00 \overline{7} 96),(8.24,0.0183),(12.2,0.0451)$, $(16.8,0.0685),(19.8,0.0787),(20.2,0.0805),(38.8,0.124),(83.8,0.184),(85.5,0.209),(126,0.222),(268$, $0.26),(294,0.27),(332,0.275),(404,0.274),(570,0.298),(610,0.298),(619,0.298),(838,0.289)$ 
- total_discharge $=$ GRAPH(julian_day $)$

$(1.00,1.93),(2.00,1.93),(3.00,1.93),(4.00,1.93),(5.00,1.90),(6.00,1.90),(7.00,1.90),(8.00,1.98)$, (9.00, 1.98), (10.0, 1.95), (11.0, 1.93), (12.0, 1.90), (13.0, 1.90), (14.0, 1.90), (15.0, 1.93), (16.0, 1.95), $(17.0,2.21),(18.0,2.04),(19.0,2.04),(20.0,2.18),(21.0,2.18),(22.0,2.15),(23.0,2.24),(24.0,2.41)$, (25.0, 2.32), (26.0, 2.21), (27.0, 2.15), (28.0, 2.12), (29.0, 2.07), (30.0, 2.04), (31.0, 2.01), (32.0, 1.98), $(33.0,1.98),(34.0,2.01),(35.0,2.01),(36.0,1.98),(37.0,1.95),(38.0,1.98),(39.0,2.01),(40.0,2.01)$, $(41.0,2.01),(42.0,2.01),(43.0,1.98),(44.0,1.95),(45.0,1.95),(46.0,1.95),(47.0,1.98),(48.0,1.98)$, (49.0, 2.01), (50.0, 2.07), (51.0, 2.15), (52.0, 2.21), (53.0, 2.24), (54.0, 2.27), (55.0, 2.24), (56.0, 2.18), $(57.0,2.18),(58.0,2.21),(59.0,2.21),(60.0,2.49),(61.0,2.21),(62.0,2.21),(63.0,2.24),(64.0,2.24)$, $(65.0,2.24),(66.0,2.24),(67.0,2.27),(68.0,2.27),(69.0,2.32),(70.0,2.38),(71.0,2.44),(72.0,2.72)$, (73.0, 2.89), (74.0, 2.97), (75.0, 3.11), (76.0, 3.23), (77.0, 3.26), (78.0, 3.34), (79.0, 3.51), (80.0, 3.68), (81.0, 3.74), (82.0, 3.82), (83.0, 3.99), (84.0, 4.13), (85.0, 4.36), (86.0, 4.47), (87.0, 4.53), (88.0, 4.59), (89.0, 4.64), (90.0, 4.84), (91.0, 5.21), (92.0, 5.61), (93.0, 5.83), (94.0, 6.06), (95.0, 6.20), (96.0, 6.34), (97.0, 6.43), (98.0, 6.68), (99.0, 7.16), (100, 7.73), (101, 8.04), (102, 8.16), (103, 8.24), (104, 8.50), (105, 8.69), (106, 8.55), (107, 8.52), (108, 8.64), (109, 8.78), (110, 9.09), (111, 9.51), (112, 10.1), (113, 10.6), $(114,11.0),(115,12.0),(116,12.8),(117,13.1),(118,13.3),(119,13.5),(120,13.8),(121,14.3),(122$, 14.5), (123, 15.3), (124, 15.7), (125, 15.8), (126, 16.0), (127, 16.7), (128, 17.6), (129, 18.5), (130, 19.4), $(131,20.8),(132,20.9),(133,21.9),(134,23.4),(135,24.7),(136,26.6),(137,27.6),(138,29.4),(139$, $30.9),(140,31.4),(141,30.0),(142,28.9),(143,27.5),(144,26.9),(145,27.0),(146,28.3),(147,28.3)$, $(148,27.8),(149,28.0),(150,28.9),(151,29.4),(152,30.0),(153,31.7),(154,32.6),(155,32.8),(156$, $33.4),(157,33.4),(158,32.3),(159,30.9),(160,29.7),(161,27.8),(162,27.4),(163,27.0),(164,27.5)$, $(165,27.8),(166,27.6),(167,27.4),(168,27.0),(169,26.3),(170,25.8),(171,24.3),(172,23.9),(173$, 24.6), (174, 24.4), (175, 24.0), (176, 22.8), (177, 21.6), (178, 20.3), (179, 19.5), (180, 19.4), (181, 20.5), $(182,20.0),(183,18.5),(184,17.6),(185,17.6),(186,17.2),(187,16.7),(188,16.4),(189,16.2),(190$, 16.0), (191, 15.4), (192, 14.4), (193, 13.6), (194, 12.9), (195, 12.3), (196, 11.5), (197, 10.5), (198, 10.0), (199, 9.54), (200, 9.00), (201, 8.50), (202, 8.04), (203, 7.90), (204, 7.45), (205, 7.11), (206, 6.88), (207, 6.68), (208, 6.29), (209, 6.00), (210, 5.64), (211, 5.41), (212, 5.21), (213, 4.84), (214, 4.62), (215, 4.33), (216, 4.11), (217, 4.13), (218, 3.96), (219, 3.77), (220, 3.88), (221, 3.65), (222, 3.37), (223, 3.17), (224, $3.03),(225,2.83),(226,2.69),(227,2.58),(228,2.46),(229,2.38),(230,2.29),(231,2.24),(232,2.24)$, (233, 2.15), (234, 2.15), (235, 2.07), (236, 1.93), (237, 1.87), (238, 1.87), (239, 1.84), (240, 1.76), (241, $1.67),(242,1.64),(243,1.61),(244,1.61),(245,1.56),(246,1.50),(247,1.50),(248,1.47),(249,1.42)$, (250, 1.67), (251, 1.59), (252, 1.53), (253, 1.44), (254, 1.42), (255, 1.39), (256, 1.33), (257, 1.27), (258, $1.25),(259,1.27),(260,1.27),(261,1.25),(262,1.25),(263,1.22),(264,1.25),(265,1.22),(266,1.22)$, (267, 1.22), (268, 1.22), (269, 1.25), (270, 1.22), (271, 1.25), (272, 1.25), (273, 1.33), (274, 1.33), (275, $1.33),(276,1.44),(277,1.50),(278,1.61),(279,1.64),(280,1.61),(281,1.59),(282,1.59),(283,1.61)$, (284, 1.64), (285, 1.70), (286, 1.67), (287, 1.64), (288, 1.64), (289, 1.67), (290, 1.70), (291, 1.78), (292, 1.87), (293, 1.84), (294, 2.01), (295, 3.00), (296, 2.29), (297, 2.12), (298, 2.10), (299, 2.04), (300, 2.01), (301, 2.01), (302, 1.95), (303, 1.98), (304, 2.01), (305, 2.10), (306, 2.12), (307, 2.12), (308, 2.07), (309, 2.10), (310, 2.18), (311, 2.49), (312, 3.77), (313, 3.26), (314, 3.11), (315, 3.28), (316, 3.23), (317, 3.37), $(318,3.62),(319,3.45),(320,3.28),(321,3.20),(322,3.03),(323,2.94),(324,2.97),(325,2.83),(326$, 2.72), (327, 2.66), (328, 2.69), (329, 3.71), (330, 3.65), (331, 3.31), (332, 3.00), (333, 2.92), (334, 4.02), (335, 4.16), (336, 3.43), (337, 3.14), (338, 2.97), (339, 2.92), (340, 3.31), (341, 3.09), (342, 2.92), (343, 2.75), (344, 2.66), (345, 2.66), (346, 2.63), (347, 2.55), (348, 2.52), (349, 2.49), (350, 2.35), (351, 2.38), $(352,2.29),(353,2.21),(354,2.15),(355,2.12),(356,2.10),(357,2.07),(358,2.07),(359,2.07),(360$, 2.04), (361, 2.01), (362, 2.01), (363, 2.04), (364, 1.98), (365, 1.95)

- $\quad$ water_depth[main_channel] $=$ GRAPH(disharge $)$ $(0.00,0.00),(0.28,0.07),(0.71,0.11),(1.42,0.15),(4.96,0.25),(8.50,0.32),(12.0,0.36),(15.6,0.41)$, (19.1, 0.44), (22.6, 0.48), (26.2, 0.52), (29.7, 0.56), (33.4, 0.58), (43.8, 0.67), (58.3, 0.77), (86.8, 0.87), $(107,0.76),(134,0.71),(154,0.74),(176,0.74)$

- $\quad$ water_depth[side_channel] $=\mathrm{GRAPH}($ disharge $)$ $(0.00,0.00),(0.1,0.05),(0.2,0.07),(0.29,0.09),(0.39,0.09),(0.48,0.12),(0.58,0.14),(0.67,0.14),(0.77$, $0.16),(0.87,0.16),(0.96,0.16),(1.57,0.22),(2.52,0.28),(3.48,0.33),(4.43,0.37),(5.39,0.4),(6.35,0.44)$, (7.30, 0.47), (8.26, 0.49), (9.22, 0.52), (11.7, 0.58), (21.3, 0.33), (30.9, 0.49), (40.4, 0.65), (50.0, 0.77) 
- $\quad$ water_depth[upstream_channel] $=$ GRAPH(disharge $)$

$(0.00,0.00),(0.28,0.07),(0.71,0.11),(1.42,0.15),(4.96,0.25),(8.50,0.32),(12.0,0.36),(15.6,0.41)$, (19.1, 0.44), (22.6, 0.48), (26.2, 0.52), (29.7, 0.56), (33.4, 0.58), (43.8, 0.67), (58.3, 0.77), (86.8, 0.87), $(107,0.76),(134,0.71),(154,0.74),(176,0.74)$

- $\quad$ wetted_width[main_channel] $=$ GRAPH(disharge $)$

$(0.00,0.00),(0.28,16.1),(0.71,17.5),(1.42,18.6),(4.96,22.0),(8.50,23.9),(12.0,24.6),(15.6,25.4)$, (19.1, 27.2), (22.6, 27.7), (26.2, 28.0), (29.7, 28.5), (33.4, 29.2), (43.8, 30.3), (58.3, 32.0), (86.8, 37.8), $(107,52.3),(134,63.7),(154,70.9),(176,73.8)$

- $\quad$ wetted_width[side_channel] $=$ GRAPH(disharge $)$

$(0.00,0.00),(0.1,5.66),(0.2,5.83),(0.29,6.00),(0.39,6.00),(0.48,6.16),(0.58,6.33),(0.67,6.33),(0.77$, 6.50), (0.87, 6.50), (0.96, 6.50), (1.57, 7.00), (2.52, 7.50), (3.48, 8.00), (4.43, 8.33), (5.39, 8.66), (6.35, 9.00), (7.30, 9.33), (8.26, 9.50), (9.22, 9.83), (11.7, 10.5), (21.3, 30.0), (30.9, 30.0), (40.4, 30.0), (50.0, $30.0)$

- $\quad$ wetted_width[upstream_channel] $=$ GRAPH(disharge) $(0.00,0.00),(0.28,16.1),(0.71,17.5),(1.42,18.6),(4.96,22.0),(8.50,23.9),(12.0,24.6),(15.6,25.4)$, $(19.1,27.2),(22.6,27.7),(26.2,28.0),(29.7,28.5),(33.4,29.2),(43.8,30.3),(58.3,32.0),(86.8,37.8)$, $(107,52.3),(134,63.7),(154,70.9),(176,73.8)$

\section{Depth and Velocity Habitat Suitability Index}

Note: The coding of the Habitat Suitability Index (HSI) for depth and velocity is similar. Therefore, we only present the diagram for velocity.

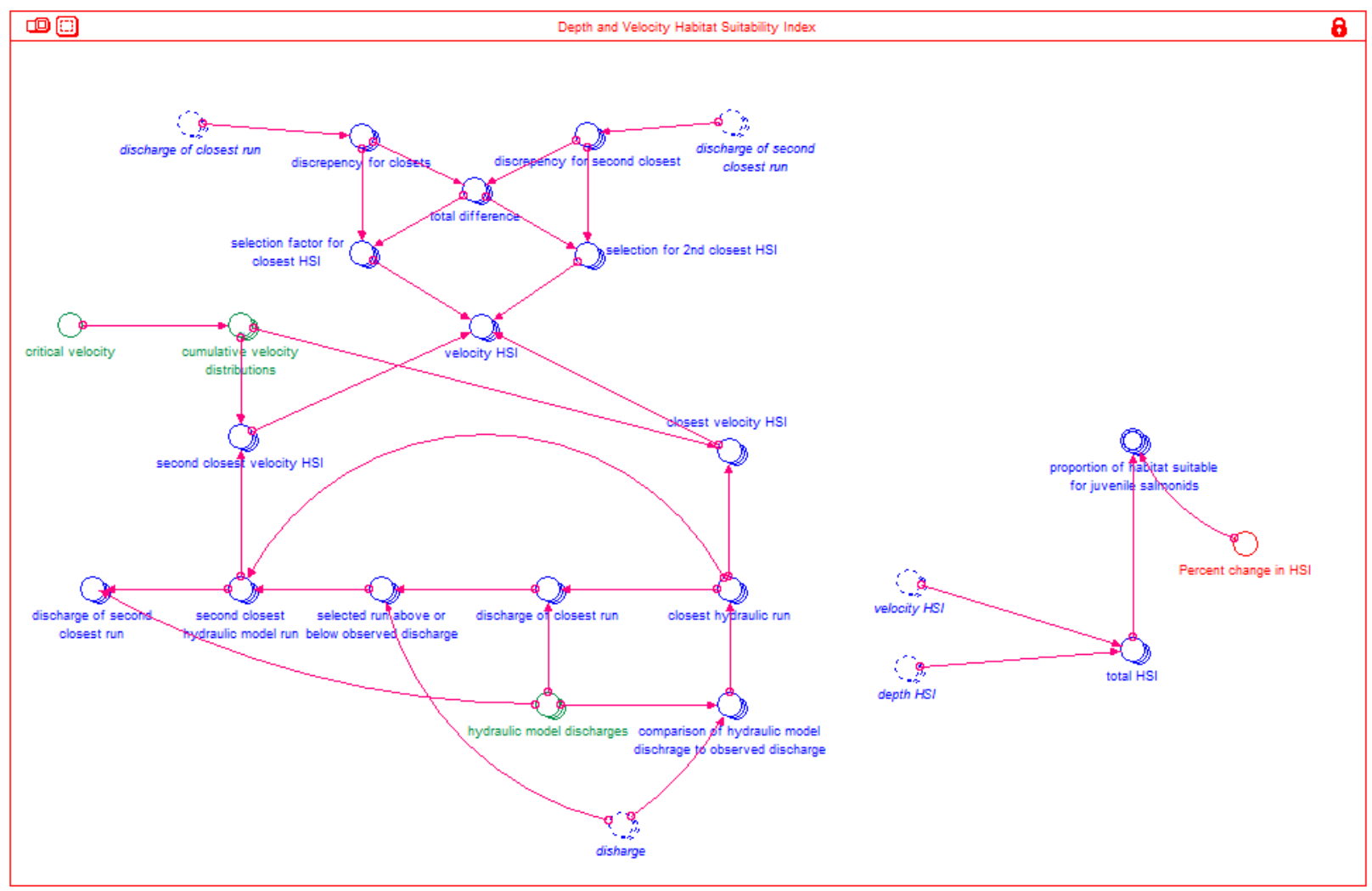

Figure B3. Habitat Suitability Index calculations for velocity in the Physical Controls Module. Diagram is as it appears in STELLA ${ }^{\circledR}$. 
- Depth and Velocity Habitat Suitability Index

- closest_hydraulic_run[Habitat_Patch_Type] = rank(comparison_of hydraulic_mode-_dischrage_to_observed_discharge[*, Habitat_Patch_Type],1)

○ closest_velocity_HSI[Habitat_Patch_Type] = cumulative_velocity_distributions[closest_hydraulic_run]

o comparison_of_hydraulic_model_dischrage_to_observed_discharge[Hydraulic_Model_Runs,

Habitat_Patch_Type] =abs(disharge[Habitat_Patch_Type]-

hydraulic_model_discharges[Hydraulic_Model_Runs])

○ critical velocity $=0.75$

○ discharge_of_closest_run[Habitat_Patch_Type]=hydraulic_model_discharges[closest_hydraulic_run]

o discharge_of_second_closest_run[Habitat_Patch_Type] $=$

hydraulic_model_discharges[second_closest_hydraulic_model_run]

o discrepency_for_closets[main_channel] $=$ abs(disharge[main_channel]-

discharge_of_closest_run[main_channel])

○ discrepency_for_closets[side_channel] $=$ abs(disharge[side_channel]-

discharge_of_closest_run[side_channel])

o discrepency_for_closets[upstream_channel] = abs(disharge[main_channel]-

discharge_of_closest_run[main_channel])

○ discrepency_for_second_closest[main_channel] $=$ abs(disharge[main_channel]-

discharge_of_second_closest_run[main_channel])

○ discrepency_for_second_closest[side_channel] = abs(disharge[side_channel]-

discharge_of_second_closest_run[side_channel])

- discrepency_for_second_closest[upstream_channel] $=$ abs(disharge[main_channel]-

discharge_of_second_closest_run[main_channel])

○ hydraulic_model_discharges[D_0_71] $=0.707947$

○ hydraulic_model_discharges[D_1_41] $=1.415894$

○ hydraulic_model_discharges[D_4_96] $=4.955629$

○ hydraulic_model_discharges[D_8_50] $=8.495364$

○ hydraulic_model_discharges[D_12_0] $=12.0351$

○ hydraulic_model_discharges[D_15_57] $=15.57483$

○ hydraulic_model_discharges[D_19_11] $=19.11457$

○ hydraulic_model_discharges[D_22_65] $=22.6543$

○ hydraulic_model_discharges[D_26_19] $=26.19404$

○ hydraulic_model_discharges[D_29_73] $=29.73377$

○ hydraulic_model_discharges[D_33_42] $=33.4151$

○ hydraulic_model_discharges[D_43_75] $=43.75112$

- Percent_change_in_HSI $=0$

○ proportion_of_habitat_suitable_for_juvenile_salmonids[main_channel] $=$

○ (((1-total_HSİ̄main_channel] $) *($ Percent_change_in_HSI $))+$ total_HSI[main_channel] $)$

○ proportion_of_habitat_suitable_for_juvenile_salmonids[side_channel] $=$ total_HSI[side_channel]

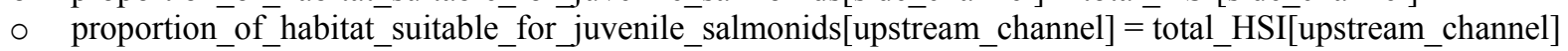

- second_closest hydraulic_model_run[Habitat_Patch_Type] $=$

closest_hydraulic_run+selected_run_above_or_below_observed_discharge

- second_closest_velocity_HSI[Habitat_Patch_Type] $=$

cumulative_velocity_distributions[second_closest_hydraulic_model_run]

○ selected_run_above_or_below_observed_discharge[Habitat_Patch_Type] $=\mathrm{IF}(($ disharge-

discharge_of_closest_run) $>0) \bar{T} \operatorname{HEN}(1) \operatorname{ELSE}(-1)$

○ selection_factor_for_closest_HSI[Habitat_Patch_Type] $=\mathrm{IF}($ total_difference $=0)$ THEN(0)ELSE(1(discrepency_for_closets/total_difference))

○ selection_for_2nd_closest_HSI $[$ Habitat_Patch_Type] $=$ IF(total_difference $=0)$ THEN(0)ELSE(1(discrepency_for_second_closest/total_difference))

○ total_difference[Habitat_Patch_Type] $=$ discrepency_for_closets+discrepency_for_second_closest

o total_HSI[Habitat_Patch_Type] $=($ velocity_HSI)-(1-depth_HSI) 
○ velocity_HSI[Habitat_Patch_Type] $=$ (selection_factor_for_closest_HSI*closest_velocity_HSI)+(selection_for_2nd_closest_HSI*second_closest _velocity_HSI)

- cumulative_velocity_distributions[D_0 71] $=\mathrm{GRAPH}($ critical_velocity) $(0.00,0.00),(0.111,0.202),(0.222,0.3 \overline{7} 1),(0.333,0.545),(0 . \overline{4} 44,0.752),(0.555,0.9),(0.666,0.964)$, (0.777, 0.991), (0.888, 0.997), (0.999, 0.999), (1.11, 1.00), (3.50, 1.00)

- cumulative_velocity_distributions[D_1_41]=GRAPH(critical_velocity) $(0.00,0.00),(0.157,0.198),(0.314,0.349),(0.471,0.525),(0.628,0.756),(0.785,0.909),(0.942,0.973)$, $(1.10,0.995),(1.26,0.998),(1.41,0.999),(1.57,1.00),(3.50,1.00)$

- cumulative_velocity_distributions[D_4_96] $=$ GRAPH(critical_velocity) (0.00, 0.00), (0.216, 0.183), (0.43, 0.297), (0.645, 0.422), (0.86, 0.591), (1.07, 0.83), (1.29, 0.943), (1.50, $0.99),(1.72,0.997),(1.93,0.999),(2.15,1.00),(3.50,1.00)$

- cumulative_velocity_distributions[D_8_50]=GRAPH(critical_velocity) (0.00, 0.00), (0.24, 0.168), (0.478, 0.271), (0.716, 0.37), (0.954, 0.513), (1.19, 0.729), (1.43, 0.904), (1.67, $0.98),(1.91,0.997),(2.14,0.998),(2.38,1.00),(3.50,1.00)$

- cumulative_velocity_distributions[D_12_0] $=$ GRAPH(critical_velocity) $(0.00,0.00),(0.276,0.155),(0.551,0.253),(0.826,0.344),(1.10,0.466),(1.38,0.653),(1.65,0.873),(1.93$, $0.968),(2.20,0.996),(2.48,0.998),(2.75,1.00),(3.50,1.00)$

- cumulative_velocity_distributions[D_15_57] = GRAPH(critical_velocity) $(0.00,0.00),(0.289,0.145),(0.577,0.23 \overline{8}),(0.865,0.322),(1.15,0.426),(1.44,0.592),(1.73,0.833),(2.02$, $0.955),(2.31,0.995),(2.59,0.998),(2.88,1.00),(3.50,1.00)$

- cumulative_velocity_distributions[D_19_11] $=$ GRAPH(critical_velocity) $(0.00,0.00),(0.303,0.16),(0.603,0.255),(0.903,0.337),(1.20,0.428),(1.50,0.574),(1.80,0.802),(2.10$, $0.944),(2.40,0.993),(2.70,0.999),(3.00,1.00),(3.50,1.00)$

- cumulative_velocity_distributions[D_22_65] = GRAPH(critical_velocity) $(0.00,0.00),(0.312,0.15),(0.622,0.241),(0.933,0.322),(1.24,0.406),(1.55,0.541),(1.86,0.763),(2.17$, $0.932),(2.48,0.992),(2.79,0.998),(3.10,1.00),(3.50,1.00)$

- cumulative velocity_distributions[D 26 19] = GRAPH(critical_velocity) $(0.00,0.00),(0.321,0.143),(0.64,0.232),(0.959,0.311),(1.28,0.39),(1.60,0.514),(1.92,0.722),(2.24$, $0.918),(2.55,0.99),(2.87,0.998),(3.19,1.00),(3.50,1.00)$

- cumulative_velocity_distributions[D_29_73] $=$ GRAPH(critical_velocity) $(0.00,0.00),(0.328,0.143),(0.656,0.228),(0.984,0.305),(1.31,0.382),(1.64,0.494),(1.97,0.69),(2.30$, $0.906),(2.62,0.988),(2.95,0.999),(3.28,1.00),(3.50,1.00)$

- cumulative_velocity_distributions[D_33_42] = GRAPH(critical_velocity) $(0.00,0.00),(0.336,0.15),(0.672,0.234),(1.01,0.308),(1.34,0.38),(1.68,0.484),(2.01,0.667),(2.35$, $0.894),(2.69,0.986),(3.02,0.999),(3.36,1.00),(3.50,1.00)$

- cumulative_velocity_distributions[D 43 75] = GRAPH(critical_velocity) $(0.00,0.00),(0.356,0.145),(0.71,0.228),(1.06,0.296),(1.42,0.366),(1.77,0.451),(2.13,0.614),(2.48$, $0.848),(2.83,0.976),(3.19,0.998),(3.50,1.00),(3.54,1.00)$ 


\section{Suitable Spawning Habitat Conditions}

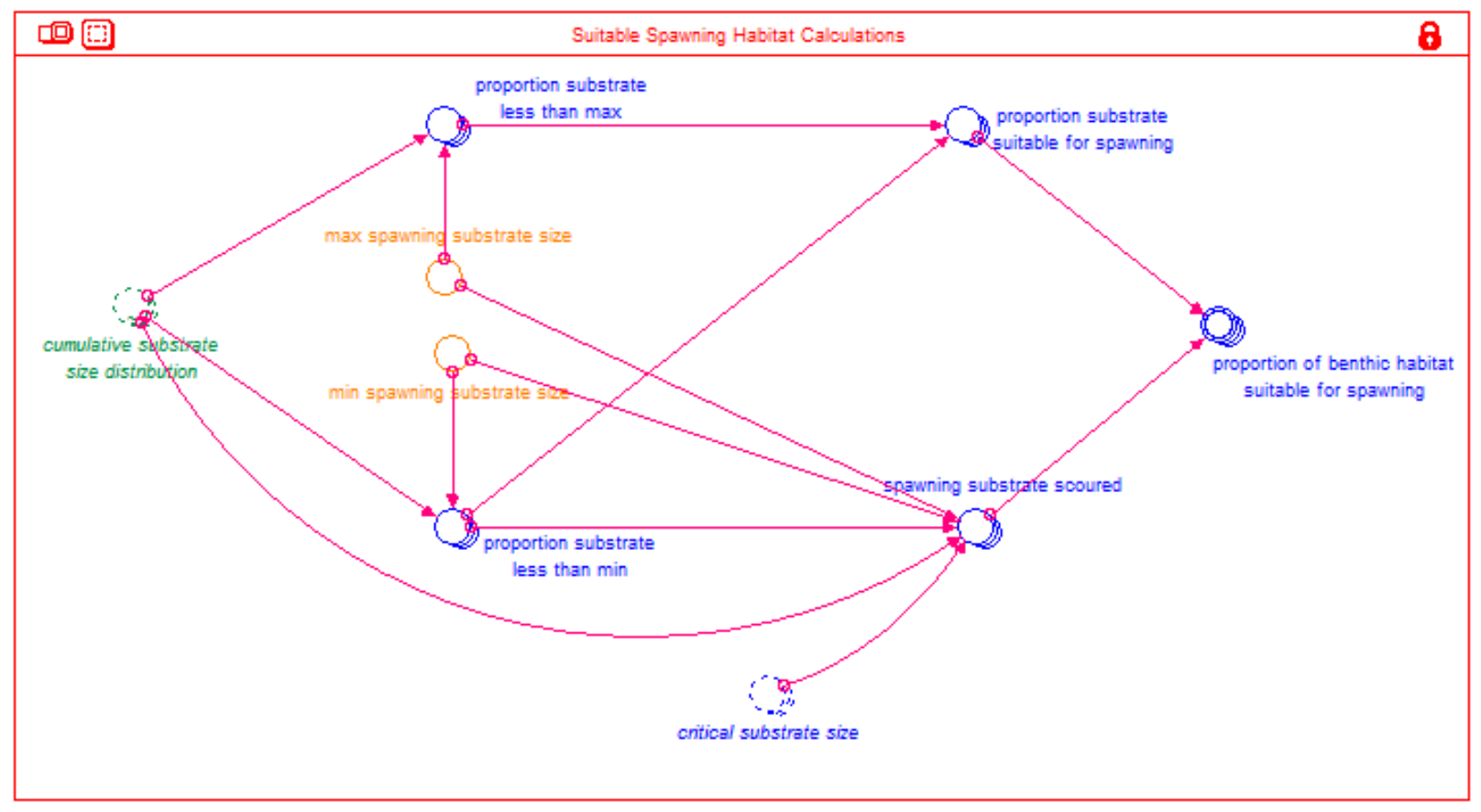

Figure B4. Calculations used to estimate suitable spawning habitat for Chinook salmon in the Physical Controls Module. Diagram is as it appears in STELLA ${ }^{\circledR}$.

○ max_spawning_substrate_size $=0.15$

○ min_spawning_substrate_size $=0.01$

○ proportion_of_benthic_habitat_suitable_for_spawning[Habitat_Patch_Type] = proportion_substrate_suitable_for_spawning-spawning_substrate_scoured

○ proportion_substrate_less_than_max[Habitat_Patch_Type] $=$

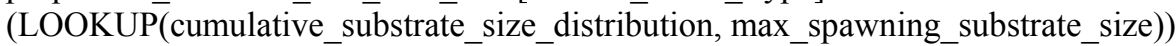

○ proportion_substrate_less_than_min[Habitat_Patch_Type] $=$

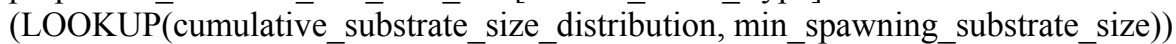

○ proportion_substrate_suitable_for_spawning[Habitat_Patch_Type] $=$ proportion_substrate_less_than_maxproportion_substrate_less_than_min

○ spawning_substrate_scoured[Habitat_Patch_Type] $=$ If(critical_substrate_size $<=$ min_spawning_substrate_size) then 0 else

○ If(critical_substrate_size $>=$ max_spawning_substrate_size) then 1 else

○ (If(critical_substrate_size $>$ min_spawning_substrate_size AND critical_substrate_size $<$ max_spawning_substrate_size) then (cumulative_substrate_size_distributionproportion_substrate_less_than_min) else 0) 
Returning Salmon Spawners Module

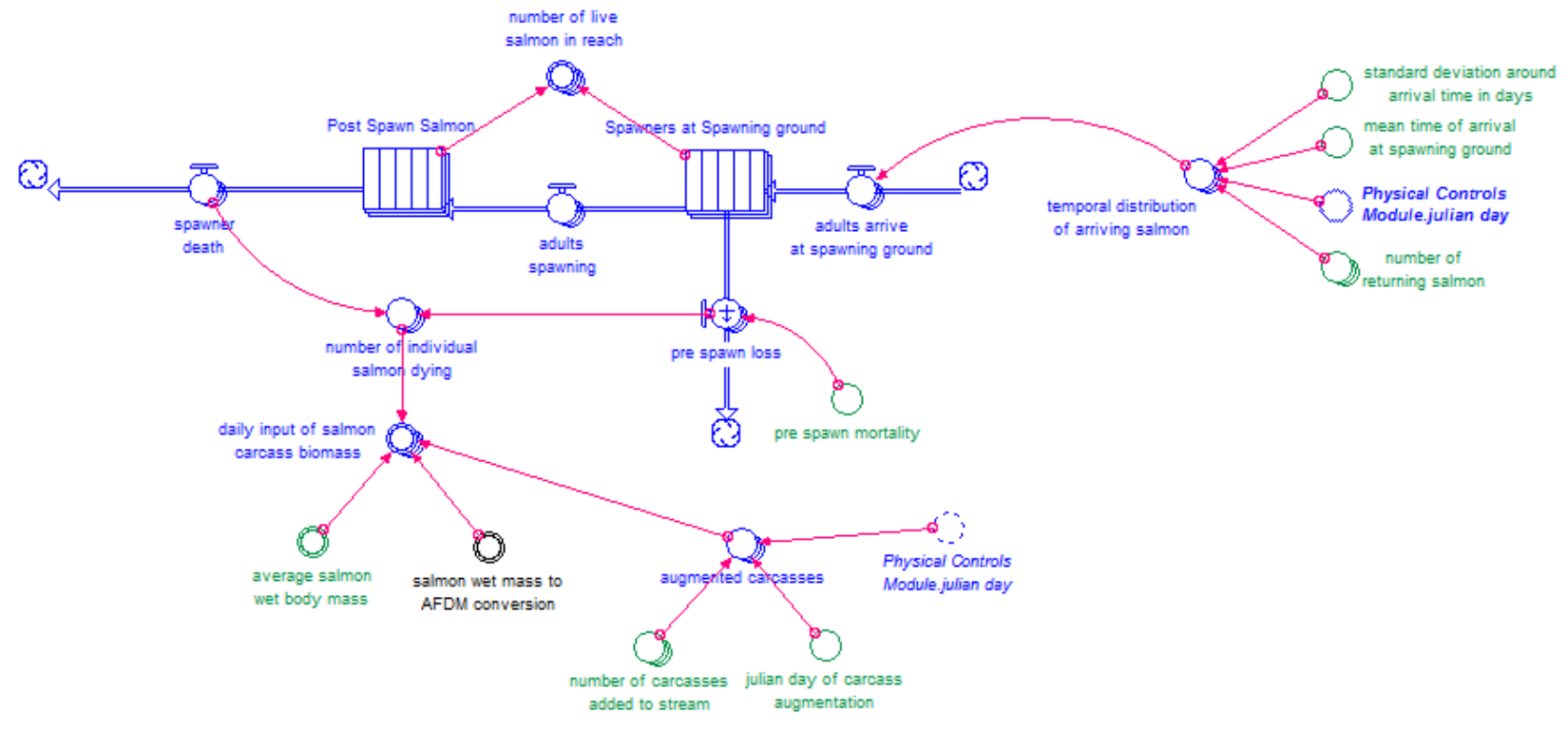

Figure B5. Timing of salmon returning to spawning grounds as represented in the Returning Salmon Spawners Module in the ATP model. Diagram is as it appears in STELLA ${ }^{\circledR}$.

ш Post_Spawn_Salmon[Habitat_Patch_Type](t) $=$ Post_Spawn_Salmon[Habitat_Patch_Type](t $-\mathrm{dt})+$ (adults_spawning[Habitat_Patch_Type] - spawner_death[Habitat_Patch_Type] $) * \mathrm{dt}$

○ INIT Post_Spawn_Salmon[Habitat_Patch_Type] $=0$

INFLOWS:

- TRANSIT TIME $=20$

$=>$ adults_spawning[Habitat_Patch_Type] $=$ CONVEYOR OUTFLOW

OUTFLOWS:

$=>$ spawner_death[Habitat_Patch_Type] $=$ CONVEYOR OUTFLOW

ш Spawners_at_Spawning_ground[Habitat_Patch_Type] $(\mathrm{t})=$

Spawners_at_Spawning_ground[Habitat_Patch_Type] $(\mathrm{t}-\mathrm{dt})+$

(adults_arrive_at_spawning_ground[Habitat_Patch_Type] - adults_spawning[Habitat_Patch_Type] -

pre_spawn_loss[Habitat_Patch_Type]) $* \mathrm{dt}$

INIT Spawners_at_Spawning_ground[Habitat_Patch_Type] $=0$

TRANSIT TIME $=62$

CAPACITY $=$ INF

INFLOWS:

INFLOW LIMIT $=$ INF

=> adults_arrive_at_spawning_ground[Habitat_Patch_Type] = temporal_distribution_of_arriving_salmon OUTFLOWS:

$=>$ adults_spawning[Habitat_Patch_Type] $=$ CONVEYOR OUTFLOW

$=>$ pre_spawn_loss[Habitat_Patch_Type] = LEAKAGE OUTFLOW

LEAKAGE FRACTION $=$ pre_spawn_mortality

LEAK ZONE $=0 \%$ to $100 \%$

○ augmented_carcasses[Habitat_Patch_Type] $=$

IF(Physical_Controls_Module.julian_day=julian_day_of_carcass_augmentation)THEN(number_of_carcass es_added_to_stream) $\overline{\mathrm{E} L S E}(0)$

$\circ$ average_salmon_wet_body_mass $=5000$

○ daily_input_of_salmon_carcass_biomass[Habitat_Patch_Type] $=$ (number_of_individual_salmon_dying+augmented_carcasses)*average_salmon_wet_body_mass*salmon_ wet_mass_to_AFDM_conversion

○ julian_day_of_carcass_augmentation $=264$ 
○ mean_time_of_arrival_at_spawning_ground $=213$

○ number_of_returning_salmon[main_channel] $=7$

$\circ$ number_of_returning_salmon[side_channel] $=0$

○ number_of_returning_salmon[upstream_channel] $=7$

○ number_of_carcasses_added_to_stream[main_channel] $=0$

○ number_of_carcasses_added_to_stream[side_channel] $=0$

○ number_of_carcasses_added_to_stream[upstream_channel] $=0$

○ number_of_individual_salmon_dying[Habitat_Patch_Type] $=$ spawner_death + pre_spawn_loss

o number_of_live_salmon_in_reach[Habitat_Patch_Type] $=$

Spawners_at_Spawning_ground+Post_Spawn_Salmon

$\circ$ pre_spawn_mortality $=0.1$

○ salmon_wet_mass_to_AFDM_conversion $=0.2$

$\circ$ standard_deviation_around_arrival_time_in_days $=6$

○ temporal_distribution_of_arriving_salmon[Habitat_Patch_Type] $=\exp (-$

$1 *$ (Physical_Controls_Module.julian_day-

mean_time_of_arrival_at_spawning_ground $)^{\wedge} 2 /\left(2 *\right.$ standard_deviation_around_arrival_time_in_days $\left.\left.{ }^{\wedge} 2\right)\right) /($

standard_deviation_around_arrival_time_in_days $\left.*(2 * \mathrm{PI})^{\wedge} .5\right)^{*}$ number_of_returning_salmon 
Spawner Bioturbation Calculations

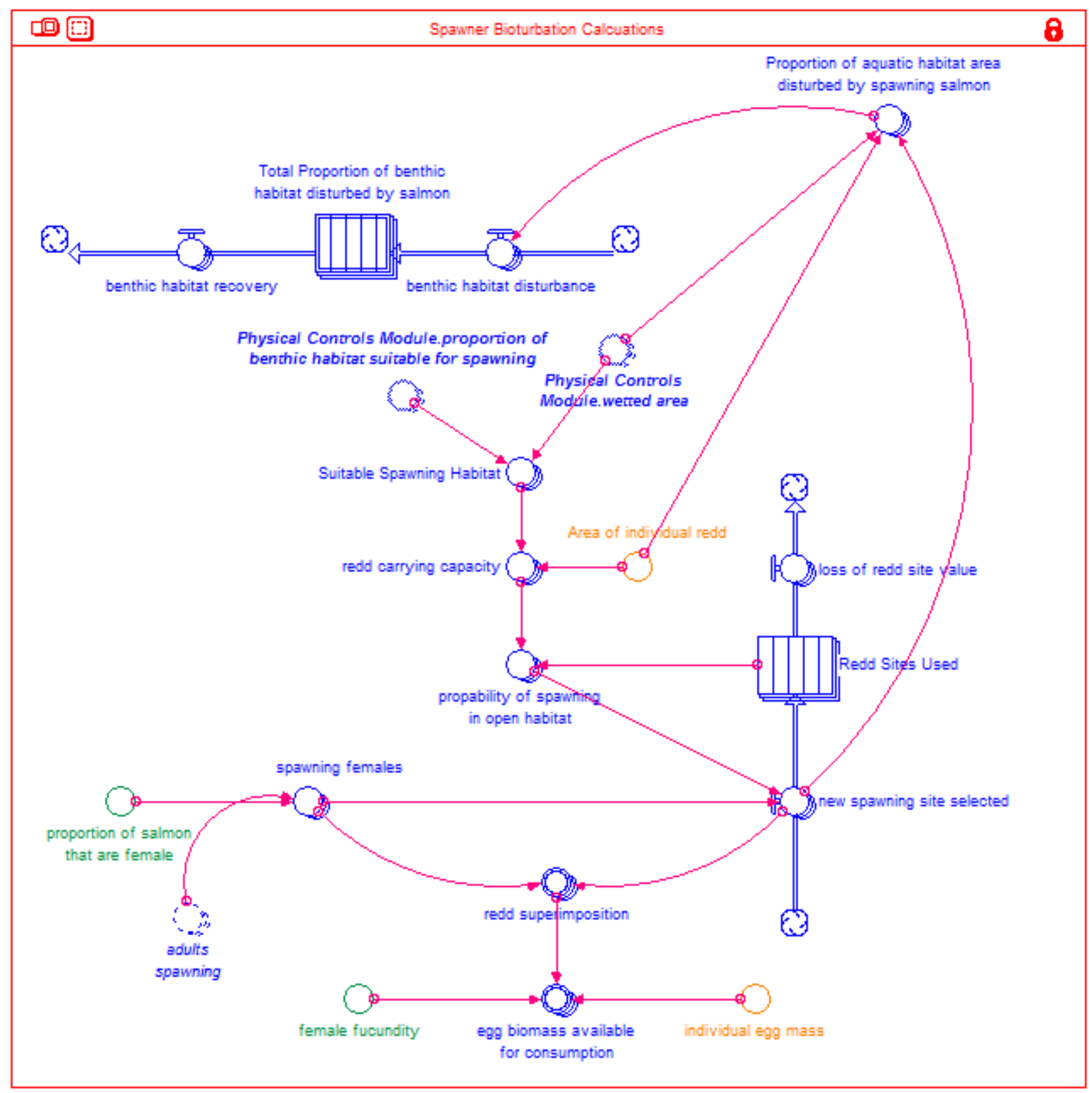

Figure B6. Bioturbation and superimposition of salmon during redd construction in the Returning Salmon Spawners Module. Diagram is as it appears in STELLA ${ }^{\circledR}$. 
ш Redd_Sites_Used[Habitat_Patch_Type](t) $=$ Redd_Sites_Used[Habitat_Patch_Type](t $-\mathrm{dt})+$ (new_spawning_site_selected[Häbitat_Patch_Type] - loss_of_redd_site_value[Habitat_Patch_Type])*dt INIT Redd Sites Used[Habitat Patch Type] $=0$

TRANSIT TIME $=180$

CAPACITY $=$ INF

INFLOWS:

INFLOW LIMIT $=$ INF

$=>$ new spawning site selected[Habitat Patch Type] $=$

propability_of_spawning_in_open_habitat*spawning_females

OUTFLOWS:

$=>$ loss of redd site value[Habitat Patch Type] $=$ CONVEYOR OUTFLOW

ш Total_Proportion_of_benthic_habitat_disturbed_by_salmon[Habitat_Patch_Type](t) $=$

Total_Proportion_of_benthic_habitat_disturbed_by_salmon[Habitat_Patch_Type](t - dt) +

(benthic_habitat_disturbance[Habitat_Patch_Type]-benthic_habitat_recovery[Habitat_Patch_Type]) $* \mathrm{dt}$

INIT Total_Proportion_of_benthic_habitat_disturbed_by_salmon[Hābitat_Patch_Type] $=0$

TRAANSIT TIME $=10$

CAPACITY $=$ INF

INFLOWS:

INFLOW LIMIT $=$ INF

$=>$ benthic_habitat_disturbance[Habitat_Patch_Type] $=$

Proportion of aquatic habitat area disturbed by spawning salmon

OUTFLOW'S:

$=>$ benthic_habitat_recovery[Habitat_Patch_Type] $=$ CONVEYOR OUTFLOW

○ Area of individual redd $=4.5$

○ egg_biomass_available_for_consumption[Habitat_Patch_Type] =

redd_superimposition*female_fucundity*individual_egg_mass

○ female fucundity $=3900$

$\circ \quad$ individual_egg_mass $=0.03$

○ propability_of_spawning_in_open_habitat[Habitat_Patch_Type] =

$\operatorname{IF}($ redd carrying capacity $=\overline{0}) \operatorname{THEN}(0) \operatorname{ELSE}((1-($ redd sites used/redd carrying capacity $)))$

o Proportion_of_aquatic_habitat_area_disturbed_by_spawning_salmon[Habitat_Patch_Type] $=$

IF(Physical_Controls_Module.wetted_area $=0) \overline{T H E N}(0)$ ELSE $((\mathrm{New}$ _spawning_site_selected*Area_of_indi vidual_redd)/Physical_Controls_Module.wetted_area)

$\circ$ proportion_of_salmon_that_are_female $=0.5$

○ redd_carrying_capacity[Habitat_Patch_Type] = Suitable_Spawning_Habitat/Area_of_individual_redd

o redd_superimposition[Habitat_Patch_Type] = spawning_females-New_spawning_site_selected

○ spawning_females[Habitat_Patch_Type]=adults_spawning*proportion_of_salmon_that_are_female

- Suitable_Spawning_Habitat[Habitat_Patch_Type] =

Physical_Controls_Module.wetted_area*Physical_Controls_Module.proportion_of_benthic_habitat_suitabl

e_for_spawning 
Food Web Module

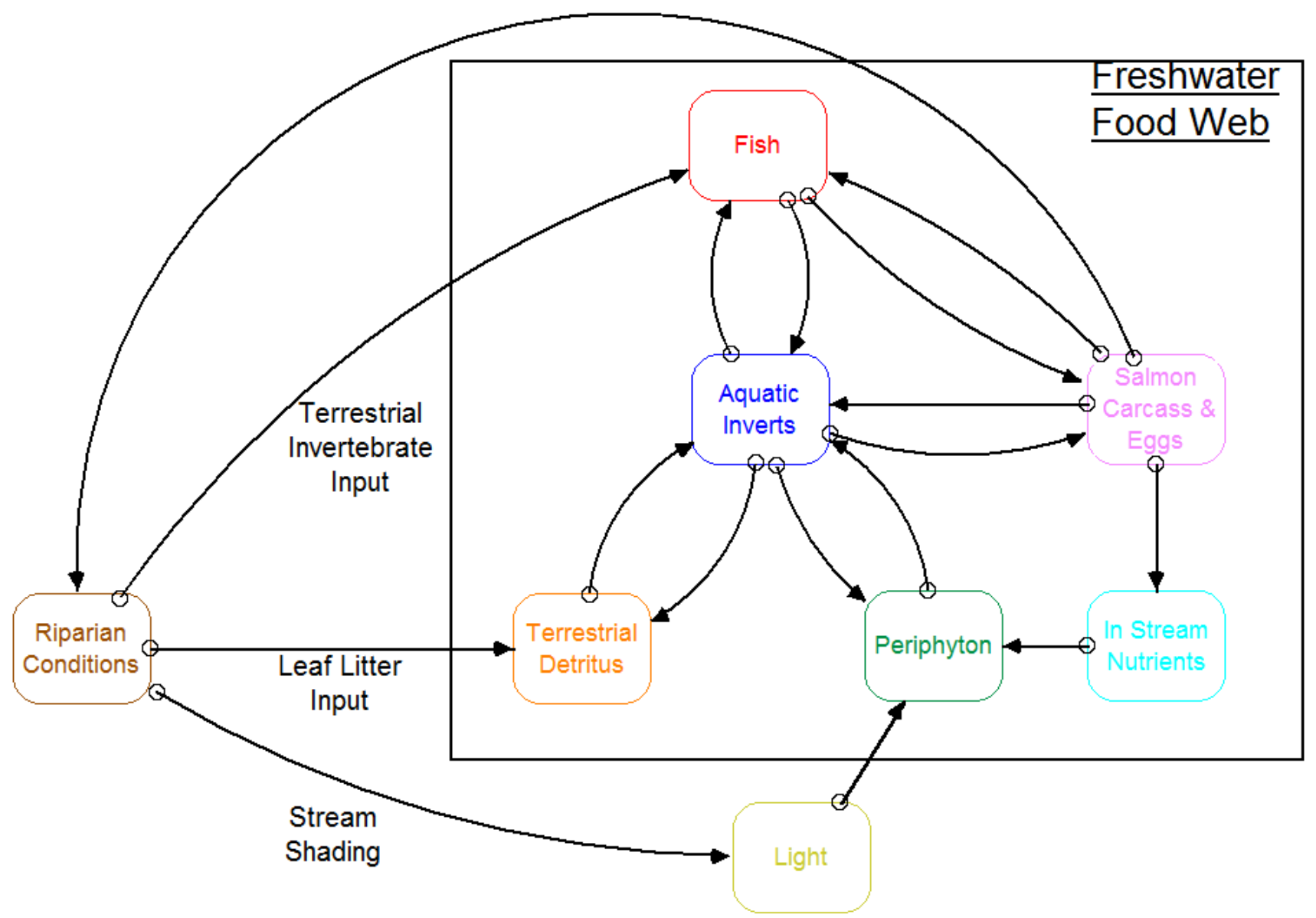

Figure B7. Linkages of modules within the Food Web Modules in the Aquatic Trophic Productivity (ATP) model. Diagram is as it appears in STELLA ${ }^{\circledR}$. 


\section{Riparian Conditions}

\section{Lateral Input of Terrestrial Detritus}

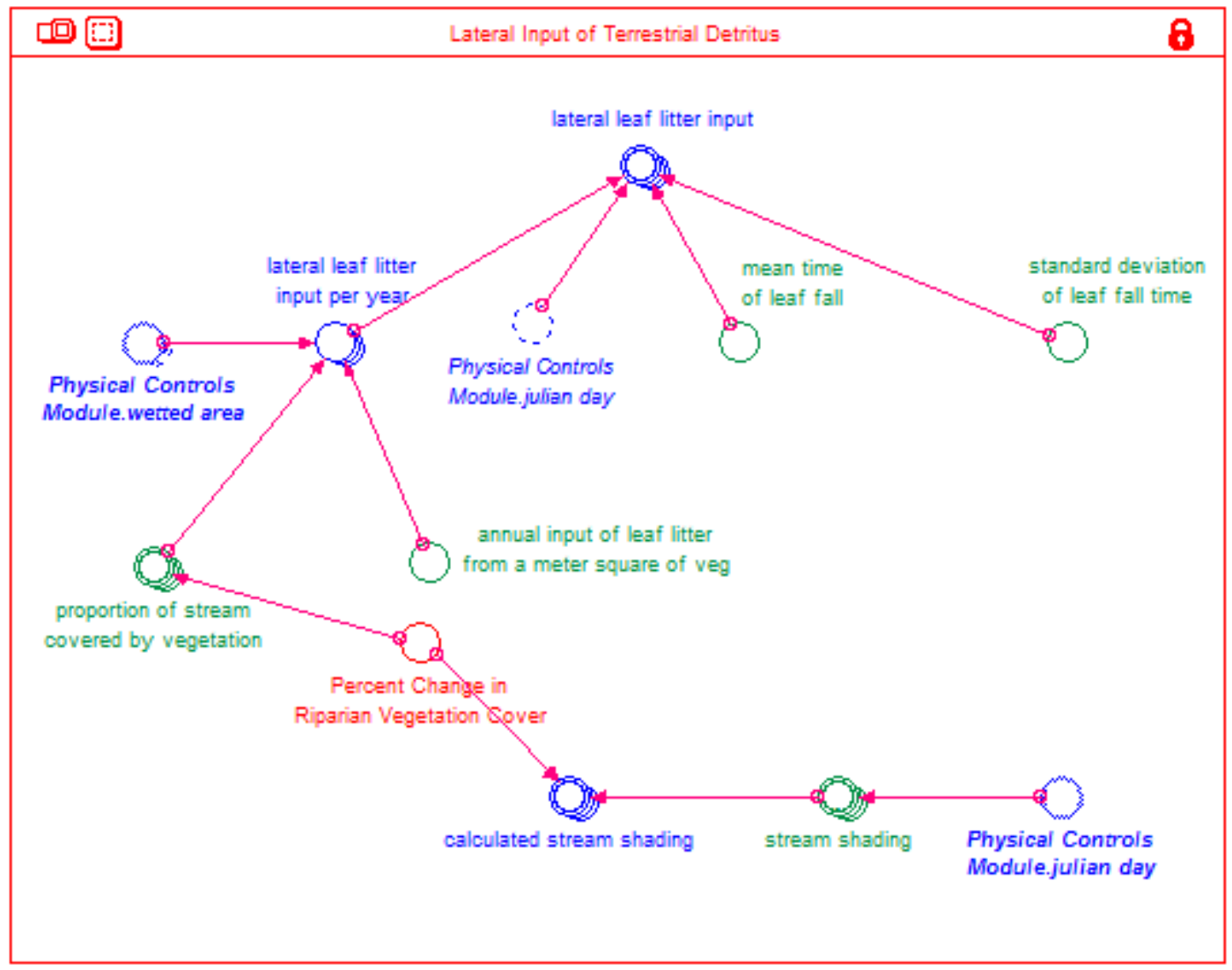

Figure B8. Timing and biomass of terrestrial leaf litter input into the modeled river reach in the Riparian Conditions Module. Diagram is as it appears in STELLA ${ }^{\circledR}$.

○ annual_input_of_leaf_litter_from_a_meter_square_of_veg $=181$

o calculated_stream_shading[main_channel] $=$ stream_shäding[main_channel]*(1+Percent_Change_in_Riparian_Vegetation_Cover $)$

o calculated_stream_shading[side_channel] = stream_shading[side_channel]

○ calculated_stream_shading[upstream_channel] $=$ stream_shading[upstream_channel]

○ lateral_leaf_litter_input[Habitat_Patch_Type] $=\exp (-1 *($ Physical_Controls_Module.julian_daymean_time_of_leaf_fall $)^{\wedge} 2 /\left(2 *{ }^{*}\right.$ standard_deviation_of_leaf_fall_time $\left.\left.{ }^{\wedge} 2\right)\right) /($ standard_deviation_of_leaf_fall_ time $\left.^{*}(2 * \mathrm{PI})^{\wedge} \cdot \overline{5}\right) *$ lateral_leaf_litter_input_per_year

○ lateral_leaf_litter_input_per_year[Habitat_Patch_Type] $=$ annual_input_of_leaf_litter_from_a_meter_square_of_veg*proportion_of_stream_covered_by_vegetation* Physical_Controls_Module.wetted_- area

o mean_time_of_leaf_fall $=305$

○ Percent_Change_in_Riparian_Vegetation_Cover $=0$

○ proportion_of_stream_covered_by_vegetation[main_channel] = $0.1 *(1+$ Percent_Change_in_Riparian_Vegetation_Cover $)$

○ proportion_of_stream_covered_by_vegetation[side_channel] $=0.25$

$\circ$ proportion_of_stream_covered_by_vegetation[upstream_channel] $=0.1$

- standard_deviation_of_leaf_fall_time $=20$

- stream_shading[main_channel] = GRAPH(Physical_Controls_Module.julian_day) 
(1.00, 0.249), (34.1, 0.212), (67.2, 0.183), (100, 0.119), (133, 0.15), (166, 0.13), (200, 0.14), (233, 0.193), $(266,0.357),(299,0.417),(332,0.251),(365,0.255)$

- $\quad$ stream_shading[side_channel] $=$ GRAPH(Physical_Controls_Module.julian_day) $(1.00, \overline{0} .249),(34.1, \overline{0} .212),(67.2,0.183),(100,0 . \overline{1} 19),(133,0.15),(166,0 . \overline{1} 3),(200,0.14),(233,0.193)$, $(266,0.357),(299,0.417),(332,0.251),(365,0.255)$

- $\quad$ stream_shading[upstream_channel] $=$ GRAPH(Physical_Controls_Module.julian_day) $(1.00, \overline{0} .249),(34.1,0.212),(67.2,0.183),(100,0.119),(133,0.15),(166,0.13),(200,0.14),(233,0.193)$, $(266,0.357),(299,0.417),(332,0.251),(365,0.255)$

\section{Lateral Inputs of Terrestrial Invertebrates from Vegetation}

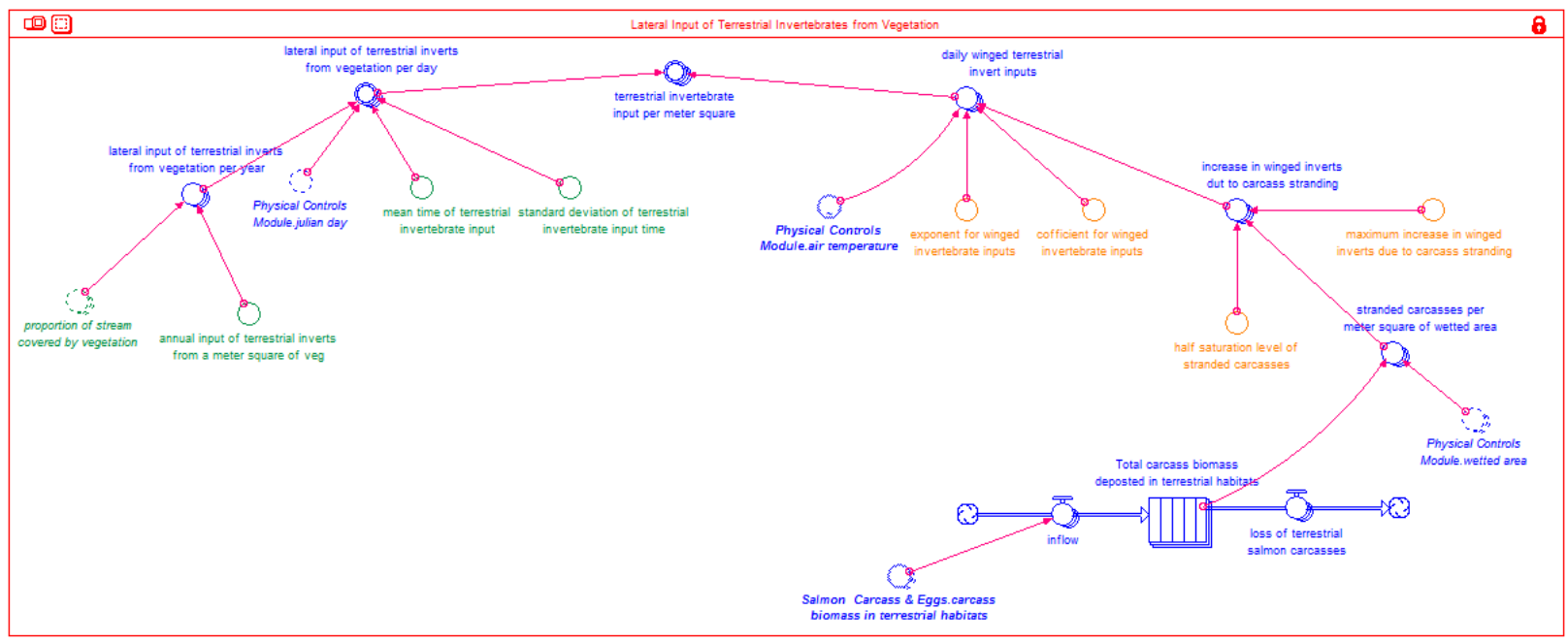

Figure B9. Timing and biomass of terrestrial invertebrate input into the modeled river reach in the Riparian Conditions Module. Diagram is as it appears in STELLA ${ }^{\circledR}$.

ш Total_carcass_biomass_deposted_in_terrestrial_habitats[Habitat_Patch_Type] $(\mathrm{t})=$

Total_carcass_biomass_deposted_in_terrestrial_habitats[Habitat_Patch_Type] $(\mathrm{t}-\mathrm{dt})+$ (inflow[Habitat_Patch_Type] - loss_of_terrestrial_salmon_carcasses[Habitat_Patch_Type]) $* \mathrm{dt}$ INIT Total_carcass_biomass_deposted_in_terrestrial_habitats[Habitat_Patch_Type] $=0$ TRANSIT TIME $=\overline{9} 0$

CAPACITY $=$ INF INFLOW LIMIT $=$ INF

INFLOWS:

$=>$ inflow[Habitat_Patch_Type] $=$

Salmon_Carcass_\&_Eggs.carcass_biomass_in_terrestrial_habitats OUTFLOWS:

$=>$ loss_of_terrestrial_salmon_carcasses[Habitat_Patch_Type] $=$ CONVEYOR OUTFLOW annual_input_of_terrestrial_inverts_from_a_meter_square_of_veg $=10$

cofficient_for_winged_invertebrate_inputs $=8 \mathrm{e}-06$

daily_winged_terrestrial_invert_inputs[Habitat_Patch_Type] =

If(Physical_Controls_Module.air_temperature $>0)$ Then $(($ cofficient_for_winged_invertebrate_input $\mathrm{s} *($ Physical_Controls_Module.air_temperature^exponent_for_winged_invertebrate_inputs) $){ }^{*}$ incre ase_in_winged_inverts_dut_to_carcass_stranding) $\operatorname{Else}(0)$

exponent_for_winged_invertebrate inputs $=2.43$

half_saturation_level_of_stranded_carcasses $=0.2$

increase_in_winged_inverts_dut_to_carcass_stranding[Habitat_Patch_Type] $=$

(maximum_increase_in_winged_inverts_due_to_carcass_stranding- 
$1)^{*}($ stranded_carcasses_per_meter_square_of_wetted_area/(stranded_carcasses_per_meter_square of_wetted_area+half_saturation_level_of_stranded_carcasses)) +1

- lateral_input_of terrestrial_inverts_from_vegetation_per_day[Habitat_Patch_Type] $=\exp (-$ $1 *$ (Physical_Controls_Module.julian_day-

mean_time_of terrestrial_invertebrate_input $)^{\wedge} 2 /(2 *$ standard_deviation_of_terrestrial_invertebrate _input_time $\left.{ }^{\wedge} 2\right) \overline{)} /\left(\right.$ standard_deviation_of_terrestrial_invertebrate_input_time $\left.*(2 * \mathrm{PI})^{\wedge} . \overline{5}\right) *$ lateral_in put_of_terrestrial_inverts_from_vegetation_per_year

- lateral_input_of_terrestrial_inverts_from_vegetation_per_year[Habitat_Patch_Type] = annual_input_of_terrestrial_inverts_from_a_meter_square_of_veg*proportion_of_stream_covered by_vegetation

- maximum_increase_in_winged_inverts_due_to_carcass_stranding $=3$

- mean_time_of_terrestrial_invertebrate_input $=213$

- standard_deviation_of_terrestrial_invertebrate_input_time $=20$

- stranded_carcasses_per_meter_square_of_wetted_area[Habitat_Patch_Type] $=$ IF(Physical_Controls_Module.wetted_area $=0)$ THEN(0)ELSE(Total_carcass_biomass_deposted_i n_terrestrial_habitats/Physical_Controls_Module.wetted_area)

○ terrestrial_invertebrate_input_per_meter_square[Habitat_Patch_Type] $=$ lateral_input_of_terrestrial_inverts_from_vegetation_per_day+daily_winged_terrestrial_invert_in puts 


\section{Terrestrial Detritus}

\section{Terrestrial Detritus Biomass}

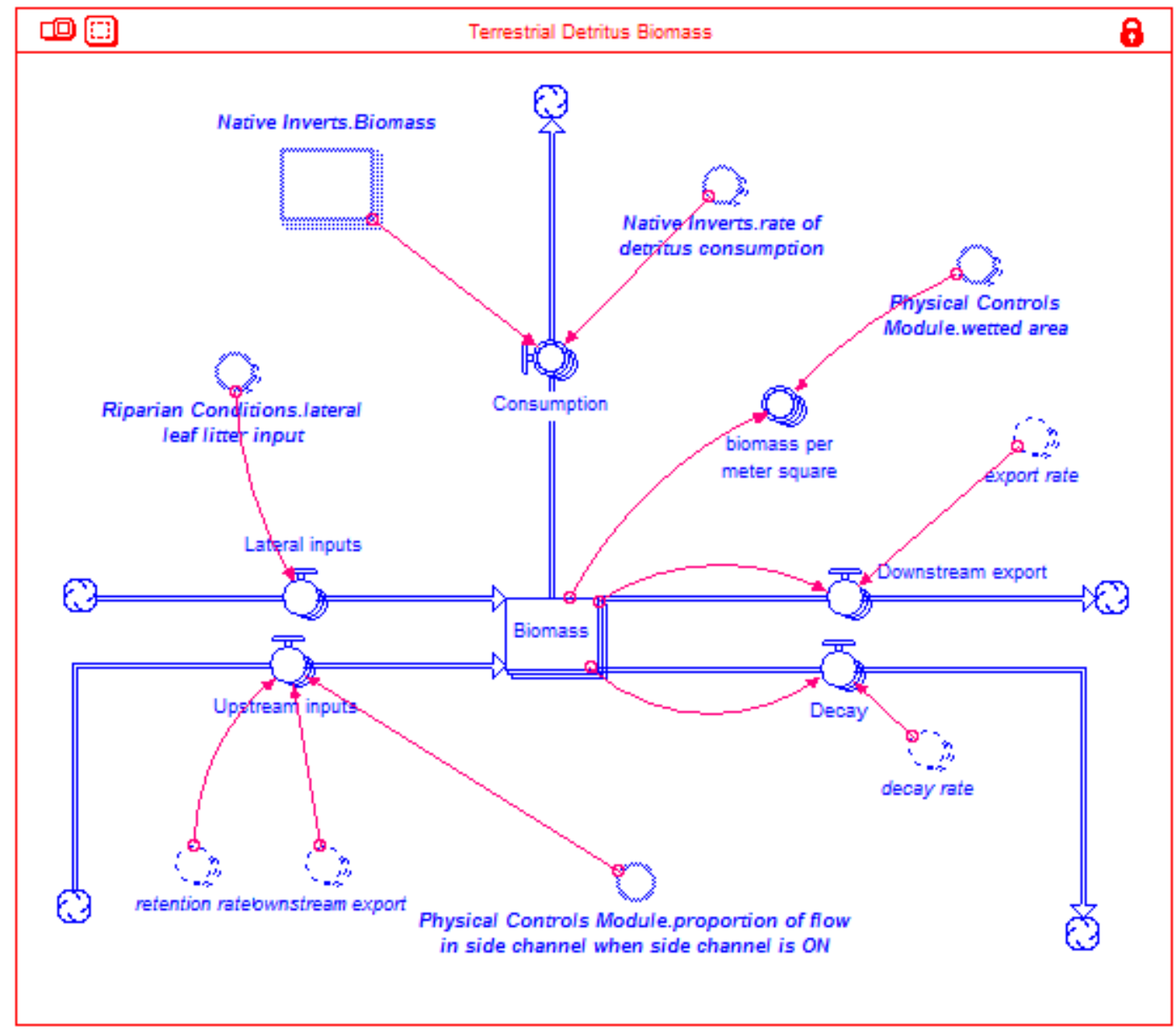

Figure B10. Biomass of terrestrial detritus in the modeled river reach in the Terrestrial Detritus Module. Diagram is as it appears in STELLA ${ }^{\circledR}$.

Biomass[Habitat_Patch_Type] $(\mathrm{t})=$ Biomass[Habitat_Patch_Type] $(\mathrm{t}-\mathrm{dt})+$ (Upstream_inputs[Habitat_Patch_Type] + Lateral_inputs[Habitat_Patch_Type] Decay[Habitat_Patch_Type] - Consumption[Habitat_Patch_Type] -

Downstream_export[Habitat_Patch_Type]) *dt

INIT Biomass[Habitat_Patch_Type] $=0$

INFLOWS:

$=>$ Upstream_inputs[main_channel] $=$

Downstream_export[upstream_channel]*retention_rate[main_channel]*(1-

Physical_Controls_Module.proportion_of_flow_in_side_channel_when_side_channel_is_ON)

$=>$ Upstream_inputs[side_channel] $=$

Downstream_export[upstream_channel]*retention_rate[side_channel]*Physical_Controls_Module.proporti on_of_flow_in_side_channel_when_side_channel_is_ON

$\Rightarrow$ Upstream_inputs[upstream_channel] $=$

Downstream_export[upstream_channel]*retention_rate[upstream_channel]

$=>$ Lateral_inputs[Habitat_Patch_Type] $=$ Riparian_Conditions.lateral_leaf_litter_input 
OUTFLOWS:

$\Rightarrow$ Decay[Habitat_Patch_Type] $=$ Biomass*decay_rate

$\Rightarrow$ Consumption[Habitat Patch $\_$Type] $=$

Native_Inverts.Biomass*Native_Inverts.rate_of_detritus_consumption

$=>$ Downstream_export[Habitat_Patch_Type] $=$ Biomass* export_rate

$\circ$ biomass_per_meter_square[Habitat_Patch_Type] $=$

IF(Physical_Controls_Module.wetted_area $=0$ )THEN(0)ELSE(Biomass/Physical_Controls_Module.wetted area)

\section{Temperature Dependent Decay Rate}

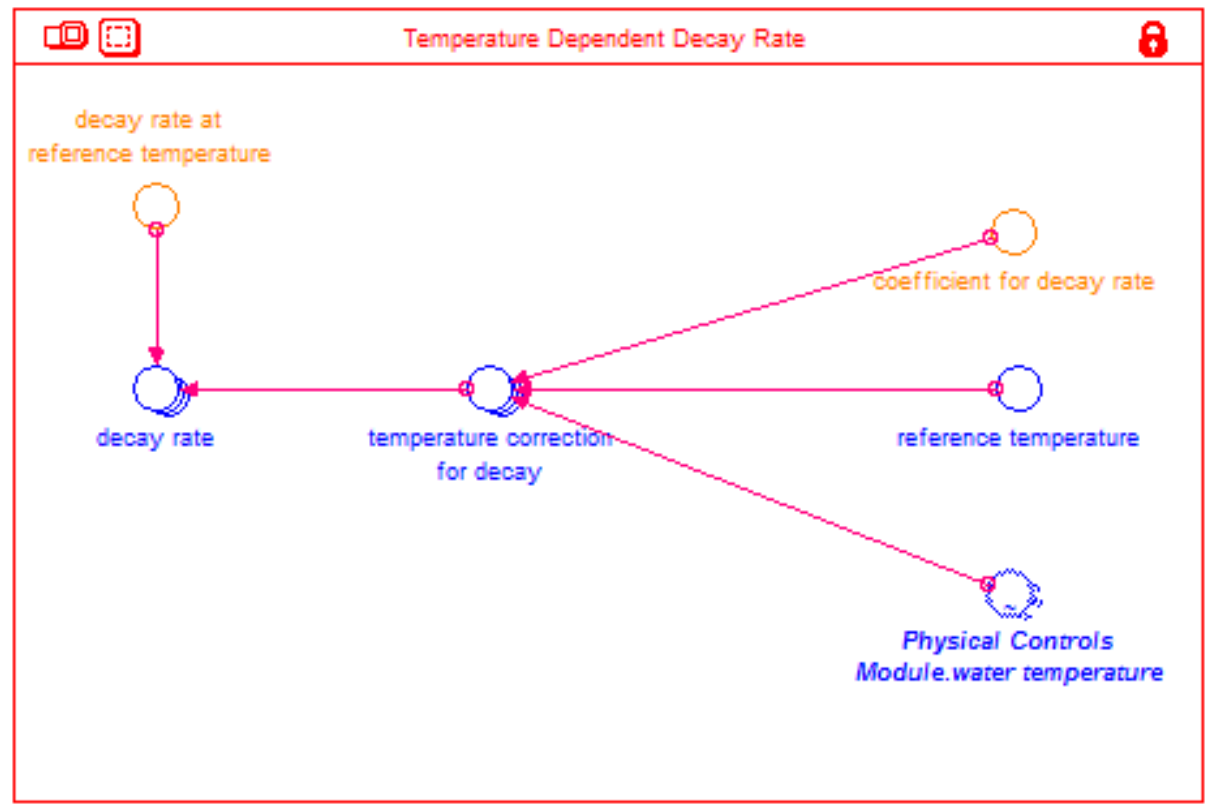

Figure B11. Decay rate of terrestrial detritus, salmon carcasses, and periphyton. Diagram is as it appears in STELLA ${ }^{\circledR}$.

- coefficient_for_decay_rate $=1.08$

- decay_rate[Habitat_Patch_Type] =

decay_rate_at_reference_temperature*temperature_correction_for_decay

0 decay_rate_at_reference_temperature $=0.015$

$\circ$ reference_temperature $=20$

- temperature_correction_for_decay[Habitat_Patch_Type] $=$

coefficient_for_decay_rate ${ }^{\wedge}($ Physical_Controls_Module.water_temperature-reference_temperature) 


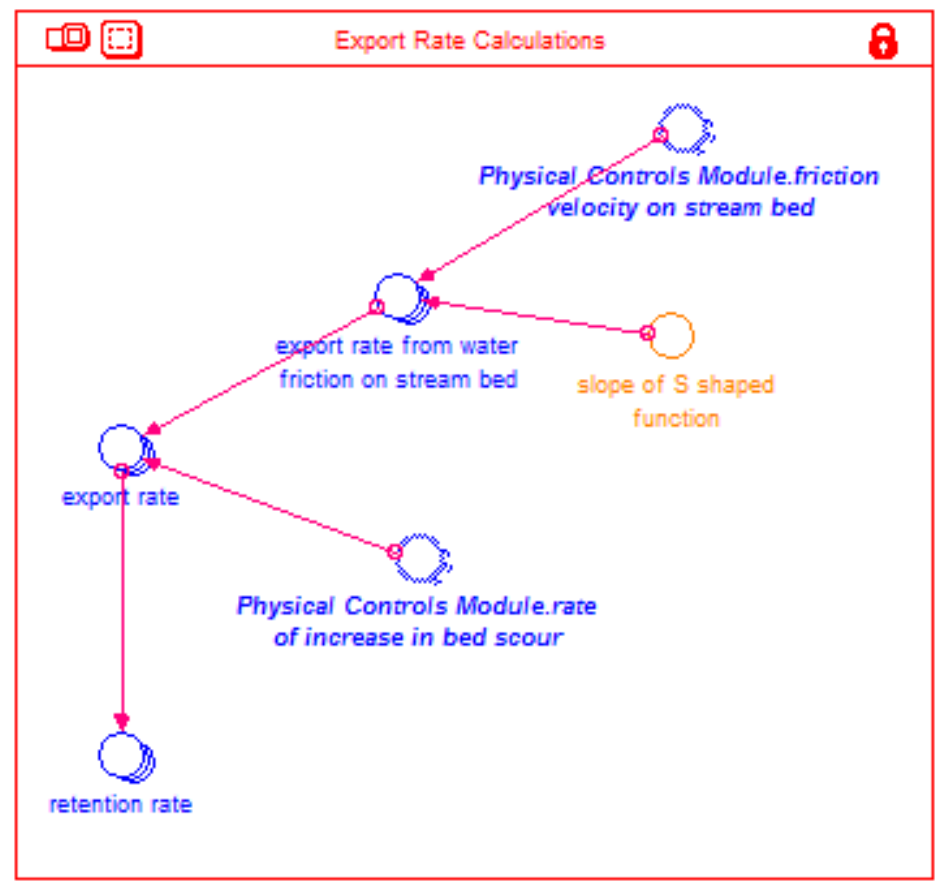

Figure B12. Export rate of terrestrial detritus and salmon carcasses, periphyton, and aquatic invertebrates. Diagram is as it appears in STELLA ${ }^{\circledR}$.

o export_rate[Habitat_Patch_Type] $=$

Physical_Controls_Module.rate_of_increase_in_bed_scour+(export_rate_from_water_friction_on_stream bed*(1-Physical_Controls_Module.rate_of_increase_in_bed_scour))

○ export_rate_from_water_friction_on_stream_bed[Habitat_Patch_Type] = $\left(\left(0.01^{\bar{*}} \exp (\bar{s}\right.\right.$ lope_of_S_- shaped_function*Physical_Controls_Module.friction_velocity_on_stream_bed $\left.)\right) /(($ $0.01 * \exp ($ slope_of_S_shaped_function*Physical_Controls_Module.friction_velocity_on_stream_bed)) +0.9 9)) -0.01

○ retention_rate[Habitat_Patch_Type] $=1$-export_rate

○ slope_of_S_shaped_function $=18$ 


\section{Light Module}

\section{Photosynthetically Active Radiation Calculations}

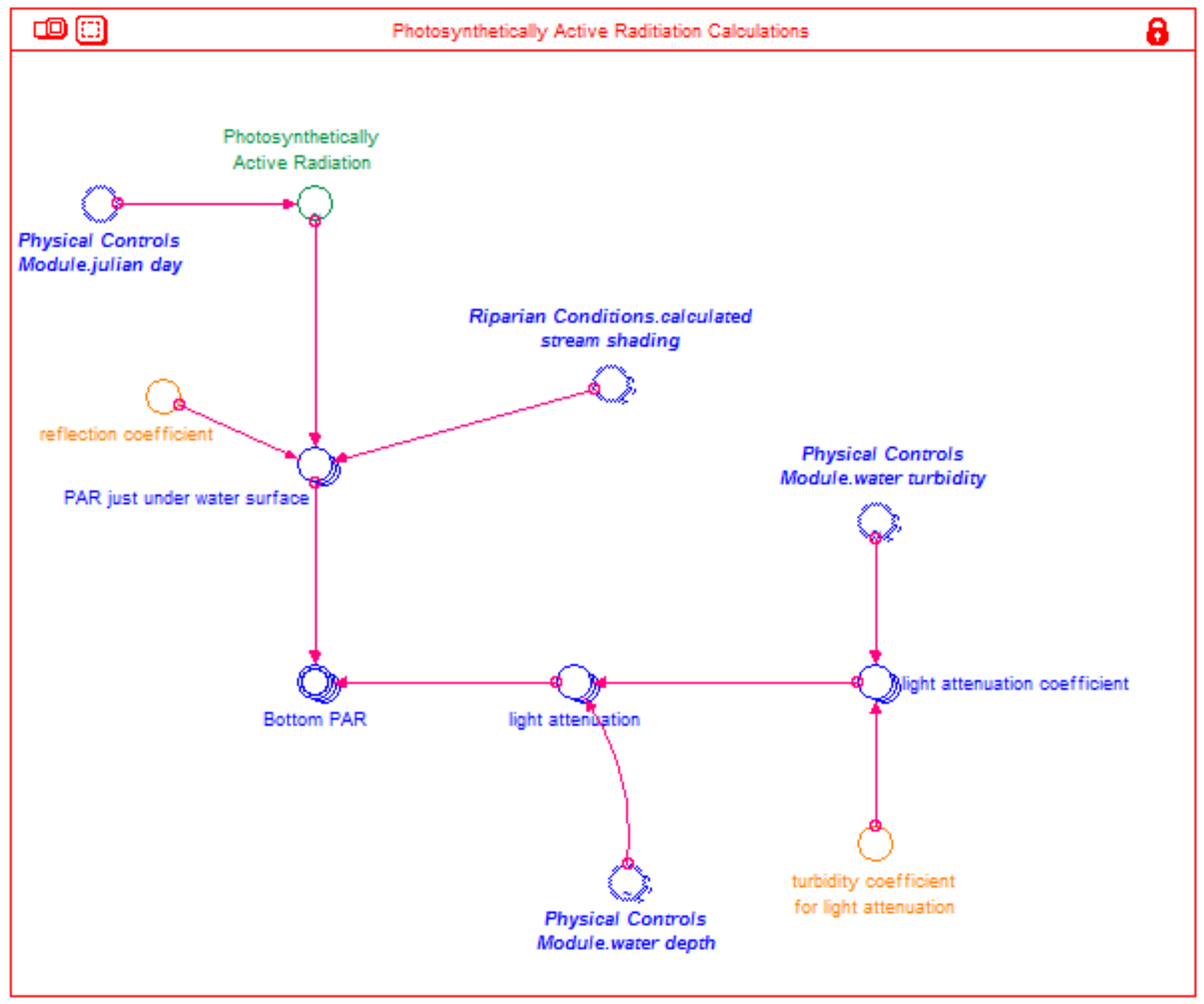

Figure B13. Photosynthetic active radiation (PAR) reaching the bottom of a river. Diagram is as it appears in STELLA ${ }^{\circledR}$.

- Bottom_PAR[Habitat_Patch_Type] = light_attenuation*PAR_just_under_water_surface

- light_attenuation[Habitat_Patch_Type] =

IF(Physical_Controls_Module.water_depth $=0)$ THEN(0)ELSE(EXP(-

light_attenuation_coefficient[Habitat_Patch_Type]*Physical_Controls_Module.water_depth[Habitat_Patch Type]))

- light_attenuation_coefficient[Habitat_Patch_Type] $=$ turbidity_coefficient_for_light_attenuation*Physical_Controls_Module.water_turbidity

- PAR_just_under_water_surface[Habitat_Patch_Type] $=$ Photosynthetically_Active_Radiation*(1Riparian_Conditions.calculated_stream_shading)*reflection_coefficient

$\circ$ reflection_coefficient $=0.88$

○ turbidity_coefficient_for_light_attenuation $=0.17$

- Photosynthetically_Active_Radiation $=$ GRAPH(Physical_Controls_Module.julian_day) $(1.00,9.51),(2.00,9.73),(3.00,9.95),(4.00,10.2),(5.00,10.4),(6.00,10.6),(7.00,10.8),(8.00,11.1)$, $(9.00,11.3),(10.0,11.5),(11.0,11.7),(12.0,11.9),(13.0,12.1),(14.0,12.4),(15.0,12.6),(16.0,12.8)$, 
(17.0, 13.0), (18.0, 13.2), (19.0, 13.5), (20.0, 13.7), (21.0, 13.9), (22.0, 14.1), (23.0, 14.3), (24.0, 14.6), $(25.0,14.8),(26.0,15.0),(27.0,15.2),(28.0,15.4),(29.0,15.7),(30.0,15.9),(31.0,16.1),(32.0,16.3)$, $(33.0,16.6),(34.0,16.8),(35.0,17.1),(36.0,17.3),(37.0,17.6),(38.0,17.8),(39.0,18.1),(40.0,18.3)$, $(41.0,18.6),(42.0,18.8),(43.0,19.1),(44.0,19.3),(45.0,19.6),(46.0,19.8),(47.0,20.1),(48.0,20.3)$, $(49.0,20.6),(50.0,20.8),(51.0,21.1),(52.0,21.3),(53.0,21.6),(54.0,21.8),(55.0,22.1),(56.0,22.3)$, $(57.0,22.6),(58.0,22.8),(59.0,23.1),(60.0,23.3),(61.0,23.6),(62.0,23.8),(63.0,24.2),(64.0,24.5)$, $(65.0,24.9),(66.0,25.2),(67.0,25.6),(68.0,25.9),(69.0,26.3),(70.0,26.6),(71.0,26.9),(72.0,27.3)$, $(73.0,27.6),(74.0,28.0),(75.0,28.3),(76.0,28.7),(77.0,29.0),(78.0,29.4),(79.0,29.7),(80.0,30.1)$, $(81.0,30.4),(82.0,30.7),(83.0,31.1),(84.0,31.4),(85.0,31.8),(86.0,32.1),(87.0,32.5),(88.0,32.8)$, $(89.0,33.2),(90.0,33.5),(91.0,33.9),(92.0,34.2),(93.0,34.5),(94.0,34.8),(95.0,35.0),(96.0,35.3)$, (97.0, 35.6), (98.0, 35.9), (99.0, 36.1), (100, 36.4), (101, 36.7), (102, 37.0), (103, 37.2), (104, 37.5), (105, 37.8), (106, 38.0), (107, 38.3), (108, 38.6), (109, 38.9), (110, 39.1), (111, 39.4), (112, 39.7), (113, 40.0), $(114,40.2),(115,40.5),(116,40.8),(117,41.1),(118,41.3),(119,41.6),(120,41.9),(121,42.2),(122$, 42.4), (123, 42.7), (124, 42.9), (125, 43.2), (126, 43.4), (127, 43.7), (128, 43.9), (129, 44.1), (130, 44.4), $(131,44.6),(132,44.9),(133,45.1),(134,45.4),(135,45.6),(136,45.8),(137,46.1),(138,46.3),(139$, 46.5), (140, 46.8), (141, 47.0), (142, 47.3), (143, 47.5), (144, 47.8), (145, 48.0), (146, 48.2), (147, 48.5), $(148,48.7),(149,49.0),(150,49.2),(151,49.5),(152,49.7),(153,49.9),(154,50.1),(155,50.2),(156$, $50.4),(157,50.5),(158,50.7),(159,50.9),(160,51.0),(161,51.2),(162,51.3),(163,51.5),(164,51.6)$, $(165,51.8),(166,51.9),(167,52.1),(168,52.2),(169,52.4),(170,52.5),(171,52.7),(172,52.9),(173$, 53.0), (174, 53.2), (175, 53.3), (176, 53.5), (177, 53.6), (178, 53.8), (179, 53.9), (180, 54.1), (181, 54.2), $(182,54.4),(183,54.5),(184,54.5),(185,54.1),(186,53.8),(187,53.5),(188,53.1),(189,52.8),(190$, 52.5), (191, 52.1), (192, 51.8), (193, 51.5), (194, 51.2), (195, 50.8), (196, 50.5), (197, 50.2), (198, 49.8), $(199,49.5),(200,49.2),(201,48.9),(202,48.5),(203,48.2),(204,47.9),(205,47.5),(206,47.2),(207$, 46.9), (208, 46.5), (209, 46.2), (210, 45.9), (211, 45.5), (212, 45.2), (213, 44.9), (214, 44.5), (215, 44.2), (216, 43.8), (217, 43.4), (218, 43.1), (219, 42.7), (220, 42.3), (221, 41.9), (222, 41.6), (223, 41.2), (224, 40.8), (225, 40.4), (226, 40.1), (227, 39.7), (228, 39.3), (229, 39.0), (230, 38.6), (231, 38.2), (232, 37.8), $(233,37.5),(234,37.1),(235,36.7),(236,36.3),(237,36.0),(238,35.6),(239,35.2),(240,34.8),(241$, $34.5),(242,34.1),(243,33.7),(244,33.3),(245,32.9),(246,32.5),(247,32.0),(248,31.6),(249,31.2)$, $(250,30.8),(251,30.3),(252,29.9),(253,29.4),(254,29.0),(255,28.6),(256,28.1),(257,27.7),(258$, 27.3), (259, 26.8), (260, 26.4), (261, 25.9), (262, 25.5), (263, 25.1), (264, 24.6), (265, 24.2), (266, 23.8), (267, 23.3), (268, 22.9), (269, 22.5), (270, 22.0), (271, 21.6), (272, 21.2), (273, 20.7), (274, 20.3), (275, 19.9), (276, 19.5), (277, 19.2), (278, 18.9), (279, 18.5), (280, 18.2), (281, 17.8), (282, 17.5), (283, 17.1), $(284,16.8),(285,16.5),(286,16.1),(287,15.8),(288,15.4),(289,15.1),(290,14.8),(291,14.4),(292$, 14.1), (293, 13.7), (294, 13.4), (295, 13.1), (296, 12.7), (297, 12.4), (298, 12.0), (299, 11.7), (300, 11.4), $(301,11.0),(302,10.7),(303,10.3),(304,9.99),(305,9.65),(306,9.53),(307,9.47),(308,9.40),(309$, 9.33), (310, 9.27), (311, 9.20), (312, 9.13), (313, 9.06), (314, 9.00), (315, 8.93), (316, 8.86), (317, 8.80), $(318,8.73),(319,8.66),(320,8.59),(321,8.53),(322,8.46),(323,8.39),(324,8.32),(325,8.26),(326$, 8.19), (327, 8.12), (328, 8.06), (329, 7.99), (330, 7.92), (331, 7.85), (332, 7.79), (333, 7.72), (334, 7.65), $(335,7.59),(336,7.57),(337,7.64),(338,7.70),(339,7.77),(340,7.83),(341,7.90),(342,7.96),(343$, $8.03),(344,8.09),(345,8.16),(346,8.22),(347,8.28),(348,8.35),(349,8.41),(350,8.48),(351,8.54)$, $(352,8.61),(353,8.67),(354,8.74),(355,8.80),(356,8.87),(357,8.93),(358,9.00),(359,9.06),(360$, 9.12), (361, 9.19), (362, 9.25), (363, 9.32), (364, 9.38), $(365,9.45)$ 


\section{Salmon Carcass and Egg}

\section{Salmon Carcass Biomass}

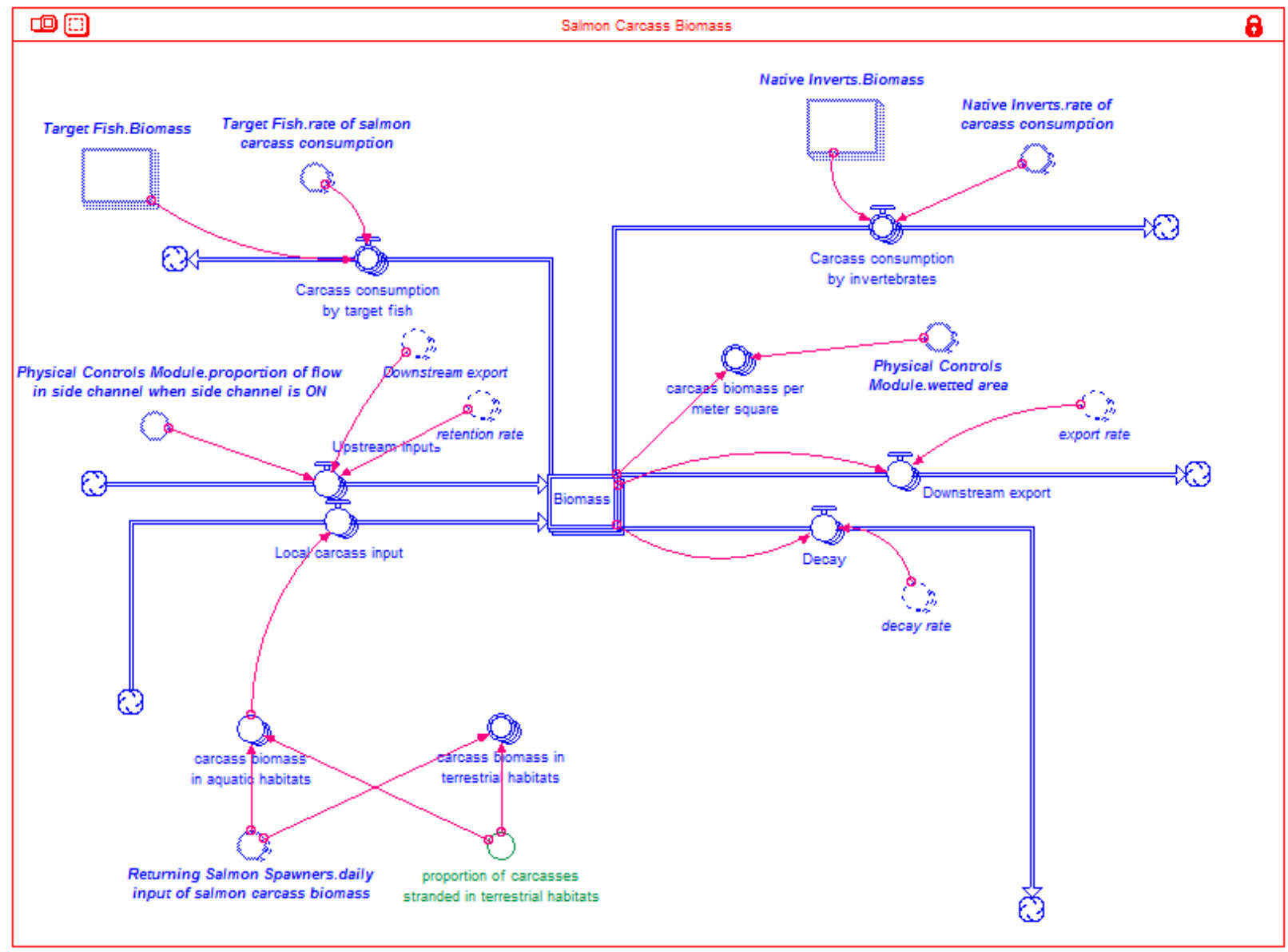

Figure B14. Biomass of salmon carcasses in the modeled river reach in the Salmon Carcass and Egg Module. Diagram is as it appears in STELLA ${ }^{\circledR}$.

Biomass[Habitat_Patch_Type] $(\mathrm{t})=$ Biomass[Habitat_Patch_Type] $(\mathrm{t}-\mathrm{dt})+$

(Upstream_inputs[Habitat_Patch_Type] + Local_carcass_input[Habitat_Patch_Type] -

Decay[Habitat_Patch_Type] - Carcass_consumption_by_target_fish[Habitat_Patch_Type] -

Downstream_export[Habitat_Patch_Type] - Carcass_consumption_by_invertebrates[Habitat_Patch_Type])

$* \mathrm{dt}$

INIT Biomass[Habitat_Patch_Type] $=0$

INFLOWS:

$=>$ Upstream_inputs[main_channel] $=$ Downstream_export[upstream_channel] * retention_rate[main_channel] $*(1-$

Physical_Controls_Module.proportion_of_flow_in_side_channel_when_side_channel_is_ON)

$=>$ Upstream_inputs[side_channel] $=$

Downstream_export[upstream_channel]*retention_rate[side_channel]*Physical_Controls_Module.proporti on_of_flow_in_side_channel_when_side_channel_is_ON

$=>$ Upstream_inputs[upstream_channel] $=$

Downstream_export[upstream_channel]*retention_rate[upstream_channel]

$=>$ Local_carcass_input[Habitat_Patch_Type] $=$ carcass_biomass_in_aquatic_habitats

OUTFLOWS: 
$=>$ Decay[Habitat_Patch_Type] $=$ Biomass*decay_rate

$=>$ Carcass_consumption_by_target_fish[Habitat_Patch_Type] $=$

Target_Fish.Biomass*Target_Fish.rate_of_salmon_carcass_consumption

$\Rightarrow$ Downstream_export[Habitat_Patch_Type] $=$ Biomass*export_rate

$=>$ Carcass_consumption_by_invertebrates[Habitat_Patch_Type] $=$

Native_Inverts.Biomass*Native_Inverts.rate_of_carcass_consumption

- carcass_biomass_in_aquatic_habitats[Habitat_Patch_Type] =

Returning_Salmon_Spawners.daily_input_of_salmon_carcass_biomass*(1-

proportion of carcasses stranded in terrestrial habitats)

- carcass_biomass_in_terrestrial_habitats[Habitat_Patch_Type] =

Returning_Salmon_Spawners.daily_input_of_salmon_carcass_biomass* ${ }^{*}$ proportion_of_carcasses_stranded in_terrestrial_habitats

- carcass_biomass_per_meter_square[Habitat_Patch_Type] $=$

IF(Physical_Controls_Module.wetted_area $=0$ )THEN(0)ELSE(Biomass/Physical_Controls_Module.wetted area)

○ proportion_of_carcasses_stranded_in_terrestrial_habitats $=0.2$

\section{Temperature Dependent Decay Rate}

Note: The diagram for these calculations is the same as that presented under Terrestrial Detritus.

○ coefficient_for_decay_rate $=1.25$

- decay_rate[Habitat_Patch_Type] =

decay_rate_at_reference_temperature*temperature_correction_for_decay

○ decay_rate_at_reference_temperature $=0.253$

$\circ$ reference_temperature_for_decay_rate $=20$

0 temperature_correction_for_decay[Habitat_Patch_Type] $=$ coefficient_for_decay_rate ${ }^{\wedge}$ (Physical_Controls_Module.water_temperature-

reference_temperature_for_decay_rate)

\section{Export Rate Calculations}

Note: The diagram for these calculations is the same as that presented under Terrestrial Detritus.

- export_rate[Habitat_Patch_Type] =

Physical_Controls_Module.rate_of_increase_in_bed_scour+(export_rate_from_water_friction_on_stream bed*(1-Physical_Controls_Module.rate_of_increase_in_bed_scour))

- export_rate_from_water_friction_on_stream_bed[Habitat_Patch_Type] $=$ $((0.01 * \exp (\mathrm{s} l o p e$ of_S_shaped_export_function*Physical_Controls_Module.friction_velocity_on_stream bed) $) /(0.01 * \exp ($ slope_of_S_shaped_export_function*Physical_Controls_Module.friction_velocity_on_str eam_bed) $)+0.99))-0.01$

- retention_rate[Habitat_Patch_Type] $=1$-export_rate

$\circ$ slope_of_S_shaped_export_function $=14$ 


\section{Salmon Egg Biomass}

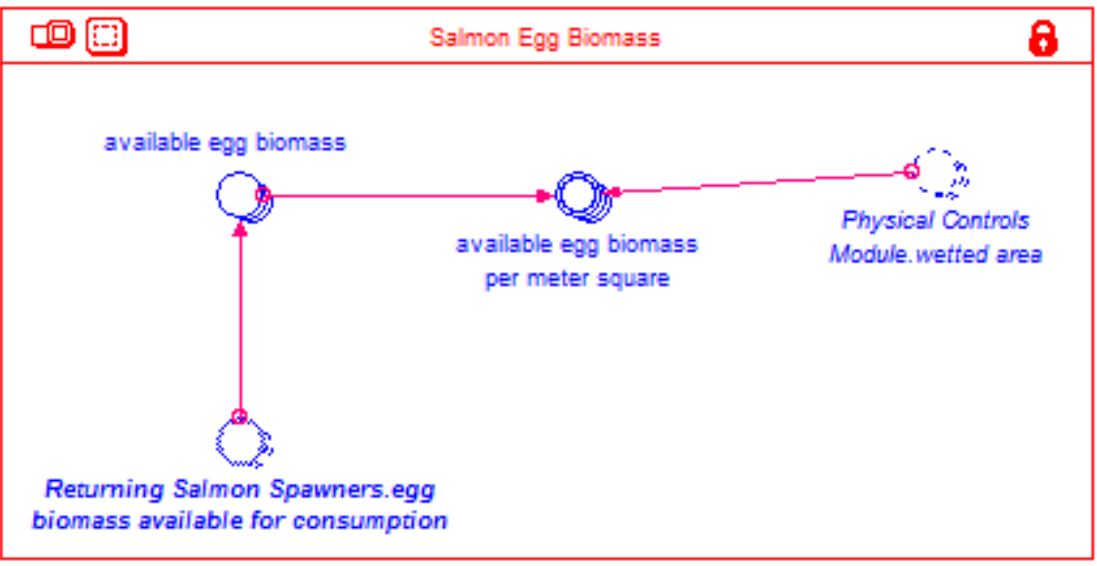

Figure B15. Biomass of salmon eggs available for consumption in the modeled river reach in the Salmon Carcass and Egg Module. Diagram is as it appears in STELLA ${ }^{\circledR}$.

○ available_egg_biomass[Habitat_Patch_Type] =

Returning_Salmon_Spawners.egg_biomass_available_for_consumption+HISTORY(Returning_Salmon_Sp awners.egg_biomass_available_for_consumption,TIME-1)

○ available_egg_biomass_per_meter_square[Habitat_Patch_Type] $=$

IF(Physical_Controls_Module.wetted_area=0)THEN(0)ELSE(available_egg_biomass/Physical_Controls Module.wetted_area)

\section{In Stream Nutrients}

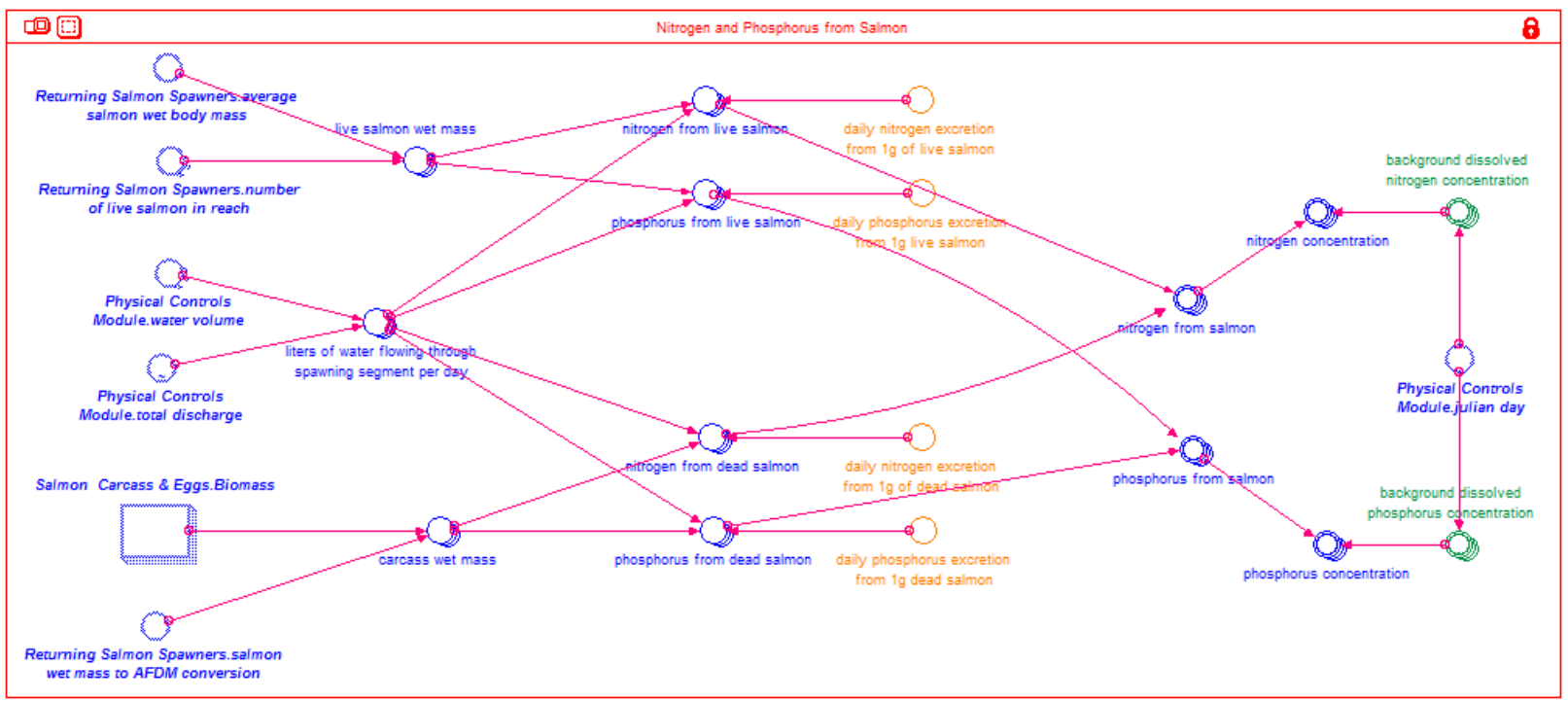

Figure B16. Accumulation of dissolved inorganic nitrogen (DIN) and soluble reactive phosphorus (SRP) due to background conditions and the accumulation of salmon carcasses. Diagram is as it appears in STELLA ${ }^{\circledR}$. 
- carcass_wet_mass[Habitat_Patch_Type] =

Salmon_Carcass_\&_Eggs.Biomass/Returning_Salmon_Spawners.salmon_wet_mass_to_AFDM_conversi on

○ daily_nitrogen_excretion_from_1g_of_dead_salmon $=0.016$

$\circ$ daily_nitrogen_excretion_from_1g_of_live_salmon $=0.161$

$\circ$ daily_phosphorus_excretion_from_1g_dead_salmon $=0.003$

$\circ$ daily_phosphorus_excretion_from_lg_live_salmon $=0.032$

○ liters_of_water_flowing_through_spawning_segment_per_day[Habitat_Patch_Type] = ((Physical_Controls_Module.total_discharge*60*60*24)+Physical_Controls_Module.water_volume)*1000

- live_salmon_wet_mass[Habitat_Patch_Type] =

((Returning_Salmon_Spawners.average_salmon_wet_body_mass*Returning_Salmon_Spawners.number_o f_live_salmon_in_reach))

- nitrogen_concentration[Habitat_Patch_Type] $=$ background_dissolved_nitrogen_concentration+nitrogen_from_salmon

○ nitrogen_from_dead_salmon[Habitat_Patch_Type] =

(carcass_wet_mass*daily_nitrogen_excretion_from_1g_of_dead_salmon)/liters_of_water_flowing_through _spawning_segment_per_day

- nitrogen_from_live_salmon[Habitat_Patch_Type] =

(live_salmon_wet_mass*daily_nitrogen_excretion_from_1g_of_live_salmon)/liters_of_water_flowing_thr ough_spawning_segment_per_day

○ nitrogen_from_salmon[Habitat_Patch_Type] $=$ nitrogen_from_live_salmon+nitrogen_from_dead_salmon

$\circ$ phosphorus_concentration[Habitat_Patch_Type] =

background_dissolved_phosphorus_concentration+phosphorus_from_salmon

- phosphorus_from_dead_salmon[Habitat_Patch_Type] $=$

(carcass_wet_mass*daily_phosphorus_excretion_from_1g_dead_salmon)/liters_of_water_flowing_through _spawning_segment_per_day

- phosphorus_from_live_salmon[Habitat_Patch_Type] =

(live_salmon_wet_mass*daily_phosphorus_excretion_from_1g_live_salmon)/liters_of_water_flowing_thr ough_spawning_segment_per_day

○ phosphorus_from_salmon[Habitat_Patch_Type] $=$ phosphorus_from_dead_salmon+phosphorus_from_live_salmon

- background_dissolved_nitrogen_concentration[main_channel] =

GRAPH(Physical_Controls_Module.julian_day) $(1.00,0.0913),(3 \overline{4} .1,0.071 \overline{2}),(67.2,0.07),(100,0.07),(133,0.063),(166,0.05),(200,0.047),(233$, 0.0992), (266, 0.0533), (299, 0.0363), (332, 0.0772), (365, 0.069)

- background_dissolved_nitrogen_concentration[side_channel] = GRAPH(Physical_Controls_Module.julian_day) $(1.00,0.0913),(3 \overline{4} .1,0.071 \overline{2}),(67.2,0.07),(100,0.07),(133,0.063),(166,0.05),(200,0.047),(233$, 0.0992), (266, 0.0533), (299, 0.0363), (332, 0.0772), (365, 0.069)

- background_dissolved_nitrogen_concentration[upstream_channel] $=$ GRAPH(Physical_Controls_Module.julian_day) $(1.00,0.0913),(3 \overline{4} .1,0.071 \overline{2}),(67.2,0.07),(100,0.07),(133,0.063),(166,0.05),(200,0.047),(233$, 0.0992), (266, 0.0533), (299, 0.0363), (332, 0.0772), (365, 0.069)

- background_dissolved_phosphorus_concentration[main_channel] = GRAPH(Physical_Controls_Module.julian_day) $(1.00,0.001),(34.1,0.001),(67.2,0.001),(100,0.001),(133,0.001),(166,0.001),(200,0.002),(233$, $0.001),(266,0.001),(299,0.001),(332,0.002),(365,0.002)$

- background_dissolved_phosphorus_concentration[side_channel] $=$ GRAPH(Physical_Controls_Module.julian_day) $(1.00,0.001),(34 . \overline{1}, 0.001),(67.2,0.001),(100,0.001),(133,0.001),(166,0.001),(200,0.002),(233$, $0.001),(266,0.001),(299,0.001),(332,0.002),(365,0.002)$

- background_dissolved_phosphorus_concentration[upstream_channel] = GRAPH(Physical_Controls_Module.julian_day) $(1.00,0.001),(34.1,0.001),(67.2,0.001),(100,0.001),(133,0.001),(166,0.001),(200,0.002),(233$, $0.001),(266,0.001),(299,0.001),(332,0.002),(365,0.002)$ 


\section{Periphyton}

\section{Periphyton Biomass}

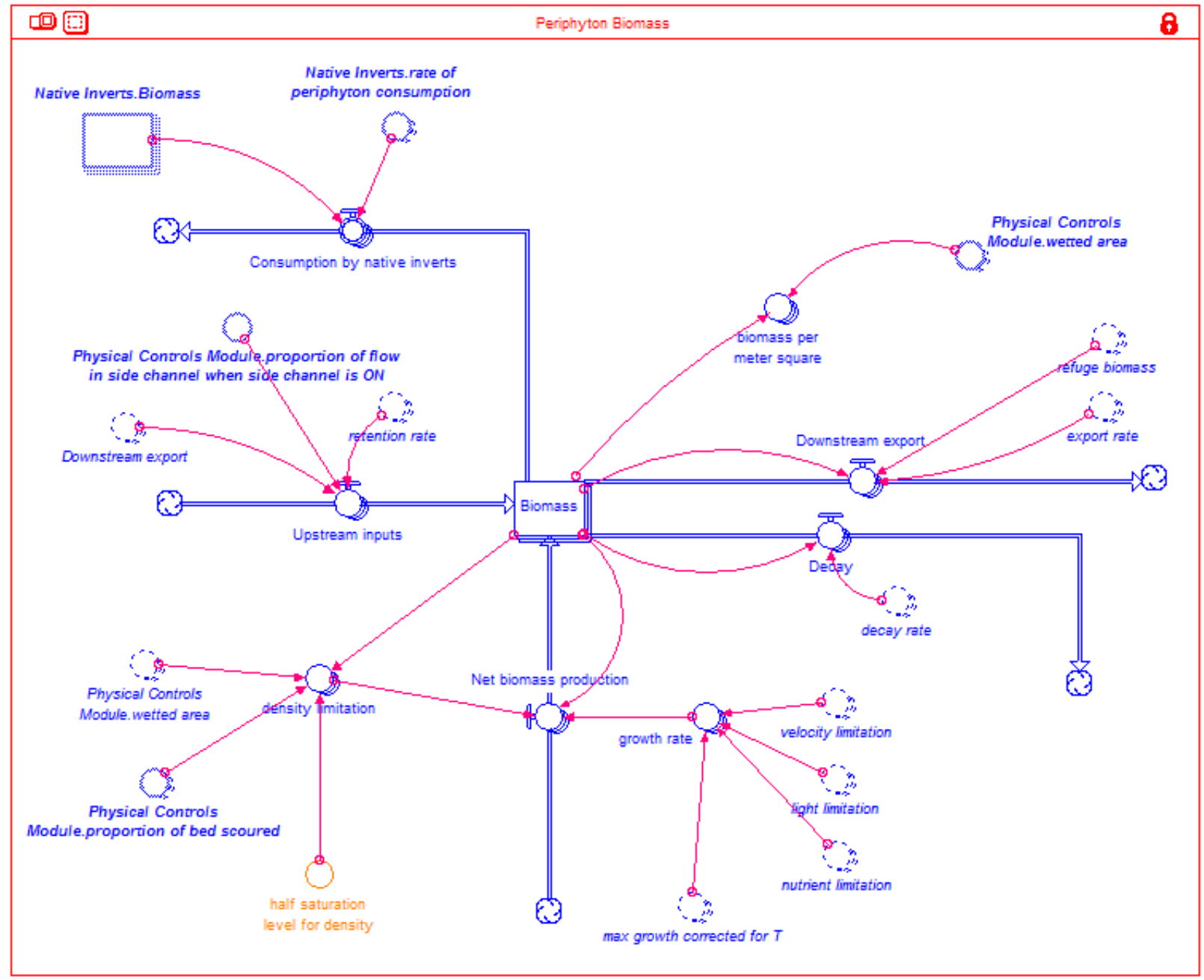

Figure B17. Biomass of periphyton in the modeled river reach in the Periphyton Module. Diagram is as it appears in STELLA ${ }^{\circledR}$.

Biomass[Habitat_Patch_Type] $(\mathrm{t})=$ Biomass[Habitat_Patch_Type] $(\mathrm{t}-\mathrm{dt})+$

(Net_biomass_production[Habitat_Patch_Type] + Upstream_inputs[Habitat_Patch_Type] -

Decay[Habitat_Patch_Type] - Consumption_by_native_inverts[Habitat_Patch_Type] -

Downstream_export[Habitat_Patch_Type])*dt

INIT Biomass[Habitat_Patch_Type] $=50000$

INFLOWS:

$=>$ Net_biomass_production[Habitat_Patch_Type] $=$ growth_rate*Biomass*density_limitation

$=>$ Upstream_inputs[main_channel] $=$

Downstream_export[upstream_channel]*retention_rate[main_channel]*(1-

Physical_Controls_Module.proportion_of_flow_in_side_channel_when_side_channel_is_ON)

$=>$ Upstream_inputs[side_channel] $=$

Downstream_export[upstream_channel]*retention_rate[side_channel]*Physical_Controls_Module.proporti on_of_flow_in_side_channel_when_side_channel_is_ON 
$=>$ Upstream_inputs[upstream_channel] $=$

Downstream_export[upstream_channel]*retention_rate[upstream_channel]

OUTFLOWS:

$\Rightarrow$ Decay[Habitat_Patch_Type] $=$ Biomass*decay_rate

$=>$ Consumption_by_native inverts[Habitat_Patch_Type] $=$

Native_Inverts.Biomass*Native_Inverts.rate_of_periphyton_consumption

$=>$ Downstream_export[Habitat_Patch_Type] $=(\text { Biomass-refuge biomass })^{*}$ export_rate

○ biomass_per_meter_square[Habitat_Patch_Type] $=\mathrm{IF}($ Physical_Controls_Module.wetted_area $=0)$

THEN(0) ELSE(Biomass/Physical Controls Module.wetted area)

○ density_limitation[Habitat_Patch_Type] $=\overline{I F}($ Physical_Controls_Module.wetted_area $=0)$ THEN $(0)$

ELSE(1-((Biomass/Physical Controls Module.wetted area)/

((Biomass/Physical_Controls_Module.wetted_area) $+((\overline{1}-$

Physical_Controls_Module.proportion_of_bed_scoured)*half_saturation_level_for_density))))

- growth_rate[Habitat_Patch_Type] $=$

max_growth_corrected_for_T*velocity_limitation*light_limitation*nutrient_limitation

$\circ$ half_saturation_level_for_density $=4$

\section{Temperature Dependent Growth \& Decay Rates}

Note: The diagram for the decay rate calculations is the same as that presented under Terrestrial Detritus.

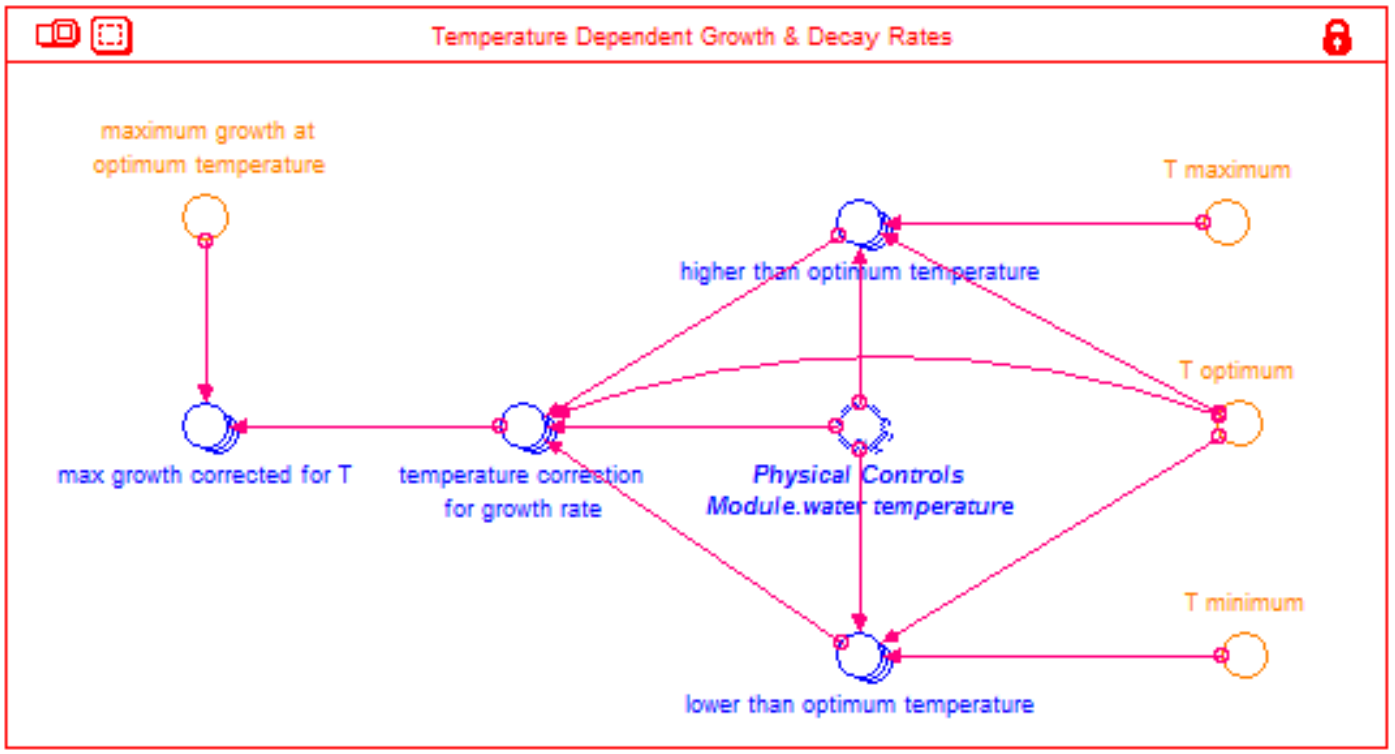

Figure B18. Temperature dependent growth rate of periphyton. Diagram is as it appears in STELLA ${ }^{\circledR}$.

○ coefficient_for_decay_rate $=1.08$

○ decay_rate[Habitat_Patch_Type] =

decay_rate_at_reference_temperature*temperature_correction_for_decay

$\circ$ decay_rate_at_reference_temperature $=0.035$

- higher_than_optimum_temperature[Habitat_Patch_Type] $=\exp (-$

((Physical_Controls_Module.water_temperature-T_optimum)/((T_maximum-

T_optimum $\left.) / \operatorname{sqrt}(\ln (100))))^{\wedge} 2\right)$

- lower_than_optimum_temperature[Habitat_Patch_Type] $=\exp (-$

((Physical_Controls_Module.water_temperature-T_optimum)/((T_optimum-

T_minimum $\left./ \operatorname{sqrt}(\ln (100))))^{\wedge} 2\right)$

- maximum_growth_at_optimum_temperature $=1.1$ 
○ max_growth_corrected_for_T[Habitat_Patch_Type] =

maximum_growth_at_optimum_temperature*temperature_correction_for_growth_rate

- reference temperature $=20$

- temperature_correction_for_decay[Habitat_Patch_Type] $=$

coefficient_for_decay_rate ${ }^{\wedge}$ (Physical_Controls_Module.water_temperature-reference temperature)

○ temperature_correction_for_growth_rate[Habitat_Patch_Type] $=$

If(Physical_Controls_Module.water_temperature $<$ T_optimum) Then(lower_than_optimum_temperature)

Else(higher_than_optimum_temperature)

- T_maximum $=30$

○ T_minimum $=-10$

○ T_optimum $=20$

\section{Export Rate Calculations}

Note: The diagram for these calculations is the same as that presented under Terrestrial Detritus.

- export_rate[Habitat_Patch_Type]=Physical_Controls_Module.rate_of_increase_in_bed_scour + (export rate from water friction on stream bed*(1-

Physical_Controls_Module.rate_of_increase_in_bed_scour))

- export_rate_from_water_friction_on_stream_bed[Habitat_Patch_Type] $=$

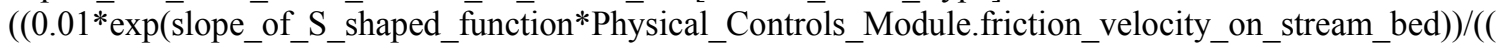
$0.01 * \exp ($ slope_of_S_shaped_function*Physical_Controls_Module.friction_velocity_on_stream_bed) $)+0.9$ 9)) -0.01

- retention_rate[Habitat_Patch_Type] $=1$-export_rate

- slope_of_S_shaped_function $=10$

\section{Refuge Biomass Calculations}

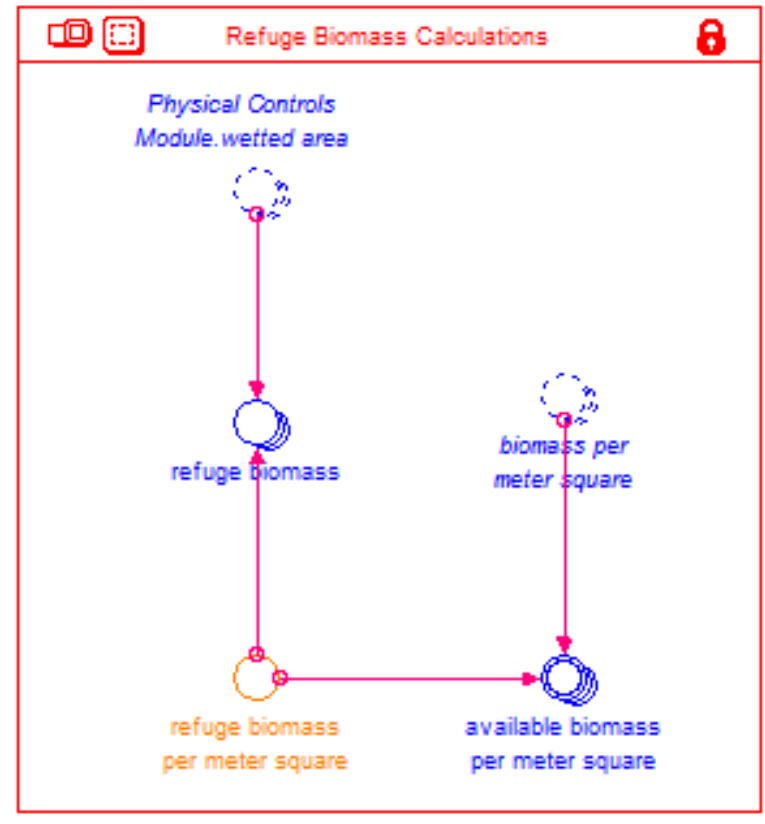

Figure B19. Biomass of periphyton, aquatic invertebrates, and fish. Diagram is as it appears in STELLA ${ }^{\circledR}$

○ available_biomass_per_meter_square[Habitat_Patch_Type] $=$ If(biomass_per_meter_square $>$ refuge_biomass_per_meter_square)Then(biomass_per_meter_squarerefuge_biomass_per_meter_square)Else(0) 
○ refuge_biomass[Habitat_Patch_Type] $=$

refuge_biomass_per_meter_square*Physical_Controls_Module.wetted_area

$\circ$ refuge_biomass_per_meter_square $=0.5$

\section{Effects of Nutrients, Light \& Velocity on Periphyton Growth}

(10)

Figure B20. Limitations to growth of periphyton due to nutrients, light, and velocity. Diagram is as it appears in STELLA ${ }^{\circledR}$.

Effects of Light on Periphyton Growth

$\circ$ half_saturation_level_for_PAR $=5$

- light_limitation[Habitat_Patch_Type] $=$

Light.Bottom_PAR/(Light.Bottom_PAR+half_saturation_level_for_PAR)

Effects of Nutrients on Periphyton Growth

$\circ$ half_saturation_level_for_nitrogen $=0.02$

$\circ$ half_saturation_level_for_phosphorus $=0.005$

- nitrogen_limitation[Habitat_Patch_Type] =

In_Stream_Nutrients.nitrogen_concentration/(half_saturation_level_for_nitrogen+In_Stream_Nutrients.nitr ogen_concentration)

○ nutrient_limitation[Habitat_Patch_Type] =

min(nitrogen_limitation[Hāitat_Patch_Type],phosphorus_limitation[Habitat_Patch_Type]) 
- phosphorus_limitation[Habitat_Patch_Type] =

In_Stream_Nutrients.phosphorus_concentration/(In_Stream_Nutrients.phosphorus_concentration + half_sat uration_level_for_phosphorus)

Effects of Velocity on Periphyton Growth

$\circ$ half_saturation_level_for_velocity $=0.18$

- velocity_limitation[Habitat_Patch_Type] = $\min (1,0.2+($ Physical_Controls_Module.water_velocity[Habitat_Patch_Type])/(half_saturation_level_for_v elocity+Physical_Controls_Module.water_velocity[Habitat_Patch_Type]))

\section{Aquatic Inverts}

\section{Aquatic Invertebrate Biomass}

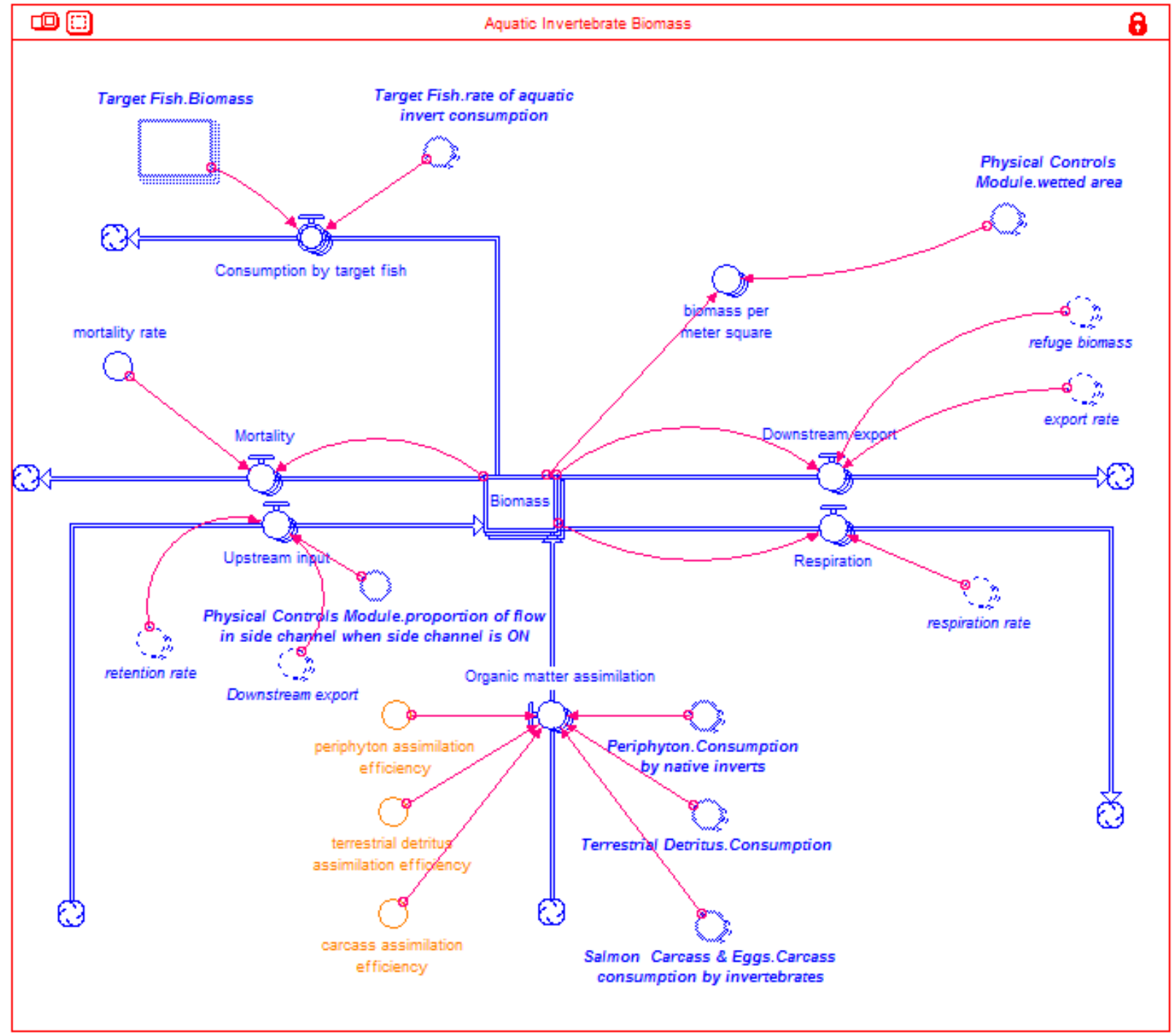

Figure B21. Biomass of aquatic invertebrates in the modeled river reach in the Aquatic Invert Module. Diagram is as it appears in STELLA ${ }^{\circledR}$. 
Biomass $[$ main_channel $](\mathrm{t})=$ Biomass $[$ main_channel $](\mathrm{t}-\mathrm{dt})+$

(Organic_matter_assimilation[Habitat_Patch_Type] + Upstream_input[Habitat_Patch_Type] Respiration[Habitat_Patch_Type] - Consumption_by_target_fish[Habitat_Patch_Type] -

Downstream_export[Habitat_Patch_Type] - Mortality[Habitat_Patch_Type] $) * \mathrm{dt}$

INIT Biomass[main_channel] $=8000$

Biomass[side_channel] $(\mathrm{t})=$ Biomass[side_channel] $(\mathrm{t}-\mathrm{dt})+$

(Organic_matter_assimilation[Habitat_Patch_Type] + Upstream_input[Habitat_Patch_Type] -

Respiration[Habitat_Patch_Type]-Consumption_by_target_fish[Habitat_Patch_Type] -

Downstream_export[Habitat_Patch_Type] - Mortality[Habitat_Patch_Type]) $* \overline{\mathrm{dt}}$

INIT Biomass[side_channel $]=8000$

$\square$ Biomass[upstream_channel] $(\mathrm{t})=$ Biomass[upstream_channel] $(\mathrm{t}-\mathrm{dt})+$

(Organic_matter_assimilation[Habitat_Patch_Type]+ Upstream_input[Habitat_Patch_Type] -

Respiration[Habitat_Patch_Type] - Consumption_by_target_fish[Habitat_Patch_Type] -

Downstream_export[Habitat_Patch_Type] - Mortality[Habitat_Patch_Type] $) * \overline{\mathrm{dt}}$

INIT Biomass[upstream_channel] $=8000$

INFLOWS:

$=>$ Organic_matter_assimilation[Habitat_Patch_Type] $=$

(Salmon_Carcass_\&_Eggs.Carcass_consumption_by_invertebrates

*carcass_assimilation_efficiency)+(Terrestrial_Detritus.Consumption*terrestrial_detritus_assimilation_effi

ciency)+(Periphyton.Consumption_by_native_inverts*periphyton_assimilation_efficiency)

$=>$ Upstream_input[main_channel] $=$

Downstream_export[upstream_channel]*retention_rate[main_channel]*(1-

Physical_Controls_Module.proportion_of_flow_in_side_channel_when_side_channel_is_ON)

$\Rightarrow$ Upstream_input $[$ side_channel] $=$

Downstream_export[upstream_channel]*retention_rate[side_channel]*Physical_Controls_Module.proporti on_of_flow_in_side_channel_when_side_channel_is_ON

$\Rightarrow>$ Upstream_input[upstream_channel] $=$

Downstream_export[upstream_channel]*retention_rate[upstream_channel]

OUTFLOWS:

$\Rightarrow$ Respiration[Habitat_Patch_Type] $=$ Biomass*respiration_rate

$=>$ Consumption_by_target_fish[Habitat_Patch_Type] $=$

Target_Fish.Biomass*Target_Fish.rate_of_aquatic_invert_consumption

$=>$ Downstream_export[Habitat_Patch_Type] $=($ Biomass-refuge_biomass $) *$ export_rate

$=>$ Mortality[Habitat_Patch_Type] $=\overline{\text { Biomass*mortality_rate }}$

○ biomass_per_meter_square[Habitat_Patch_Type] $=$

IF(Physical_Controls_Module.wetted_area $=0$ )THEN(0)ELSE(Biomass/Physical_Controls_Module.wetted area)

○ carcass_assimilation_efficiency $=0.7$

$\circ$ mortality_rate $=0.0 \overline{167}$

$\circ$ periphyton_assimilation_efficiency $=0.4$

$\circ$ terrestrial_detritus_assimilation_efficiency $=0.2$ 


\section{Temperature Dependent Consumption and Respiration Rates}

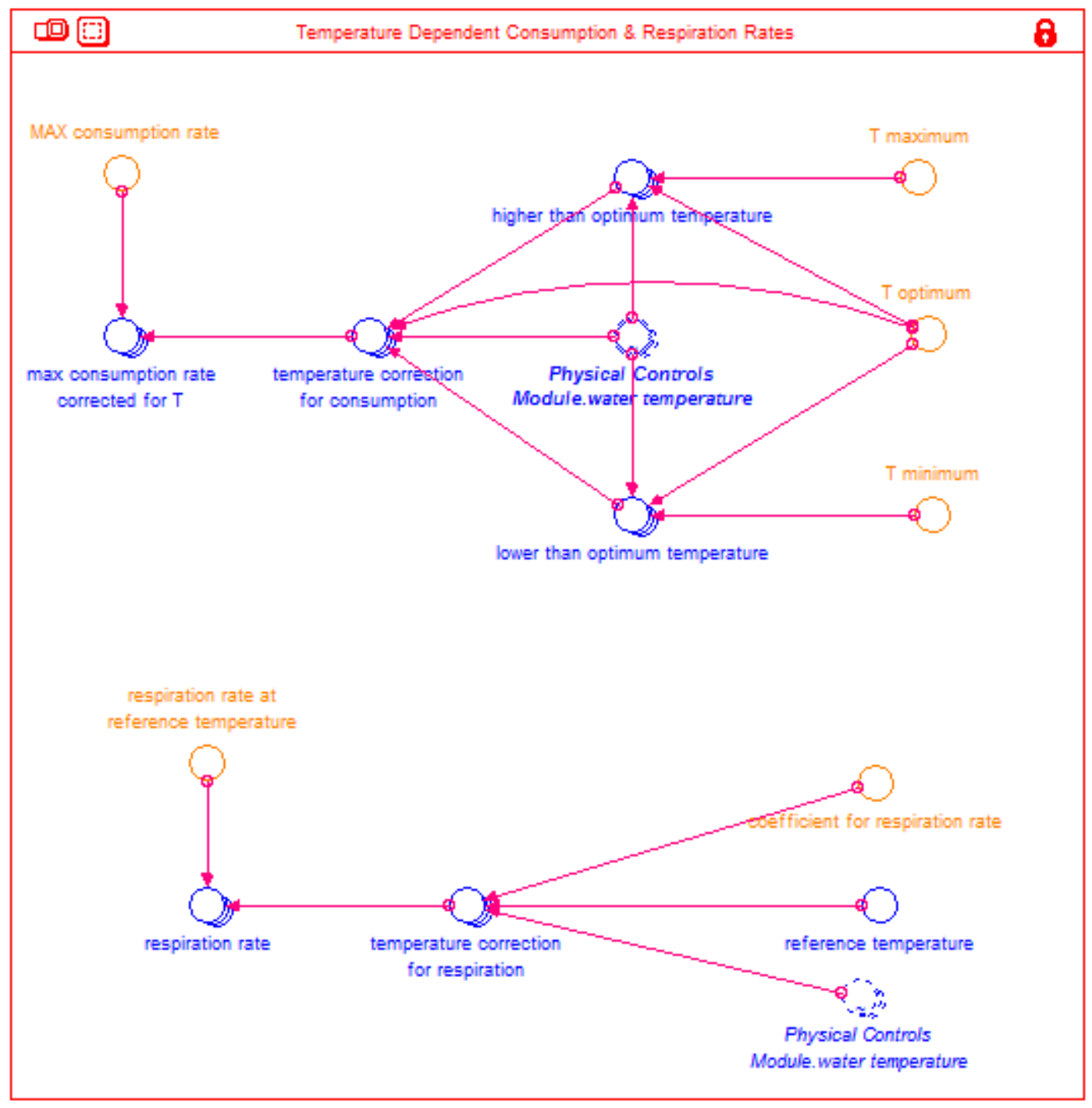

Figure B22. Temperature dependent consumption and respiration rates of aquatic invertebrates and fish. Diagram is as it appears in STELLA ${ }^{\circledR}$.

0 coefficient_for_respiration_rate $=1.05$

- higher_than_optimum_temperature[Habitat_Patch_Type] $=\exp (-$ ((Physical_Controls_Module.water_temperature-T_optimum)/((T_maximumT_optimum $\left.) / \operatorname{sqrt}(\ln (100))))^{\wedge} 2\right)$

- lower_than_optimum_temperature[Habitat_Patch_Type] $=\exp (-$ ((Physical_Controls_Module.water_temperature- $\bar{T}_{-}$optimum $) /\left(\left(T_{-}\right.\right.$_optimumT_minimum $\left.) / \operatorname{sqrt}(\ln (100))))^{\wedge} 2\right)$

○ MAX_consumption_rate $=0.5$

- max_consumption_rate_corrected_for_T $\mathrm{T}$ Habitat_Patch_Type $]=$ MAX_consumption_rate*temperature_correction_for_consumption

$\circ$ reference_temperature $=20$

- respiration_rate[Habitat_Patch_Type] $=$ respiration_rate_at_reference_temperature*temperature_correction_for_respiration

$\circ \quad$ respiration_rate_at_reference_temperature $=0.05$ 
○ temperature_correction_for_consumption[Habitat_Patch_Type] $=$

If(Physical_Controls_Module.water_temperature $<$ T_optimum)Then(lower_than_optimum_temperature)Els e(higher_than_optimum temperature)

○ temperature_correction_for_respiration[Habitat_Patch_Type] $=$

coefficient_for_respiration_rate^(Physical_Controls_Module.water_temperature-reference _temperature)

- T_maximum $=26$

○ T_minimum $=-10$

○ T_optimum $=15$

\section{Export Rate Calculations}

Note: The diagram for these calculations is the same as that presented under Terrestrial Detritus.

○ export_rate[Habitat_Patch_Type] =

Physical_Controls_Module.rate_of_increase_in_bed_scour+(export_rate_from_water_friction_on_stream bed*(1-Physical_Controls_Module.rate_of_increase_in_bed_scour $)$ )

- export rate_from_water_friction_on_stream_bed[Habitat_Patch_Type] $=$ $\left(\left(0.01^{*} \exp\right.\right.$ (slope_of_S_shaped_function*Physical_Controls_Module.friction_velocity_on_stream_bed[Ha bitat Patch Type $])) /((0.01 * \exp ($ slope of S shaped function*Physical Controls Module.friction velocity _on_stream_bed[Habitat_Patch_Type] $))+0.99))-0.01$

$\circ$ retention_rate[Habitat_Patch_Type] $=1$-export_rate

0 slope_of_S_shaped_function $=7$

\section{Refuge Biomass Calculations}

Note: The diagram for these calculations is the same as that presented under Periphyton.

- available_biomass_per_meter_square[Habitat_Patch_Type] = If(biomass_per_meter_square>refuge_biomass_per_meter_square)Then(biomass_per_meter_squarerefuge_biomass_per_meter_square)Else( 0 )

- refuge_biomass[Habitat_Patch_Type] = refuge_biomass_per_meter_square*Physical_Controls_Module.wetted_area

$\circ$ refuge_biomass_per_meter_square $=0.05$

\section{Prey Selection and Consumption Rate Calculations}

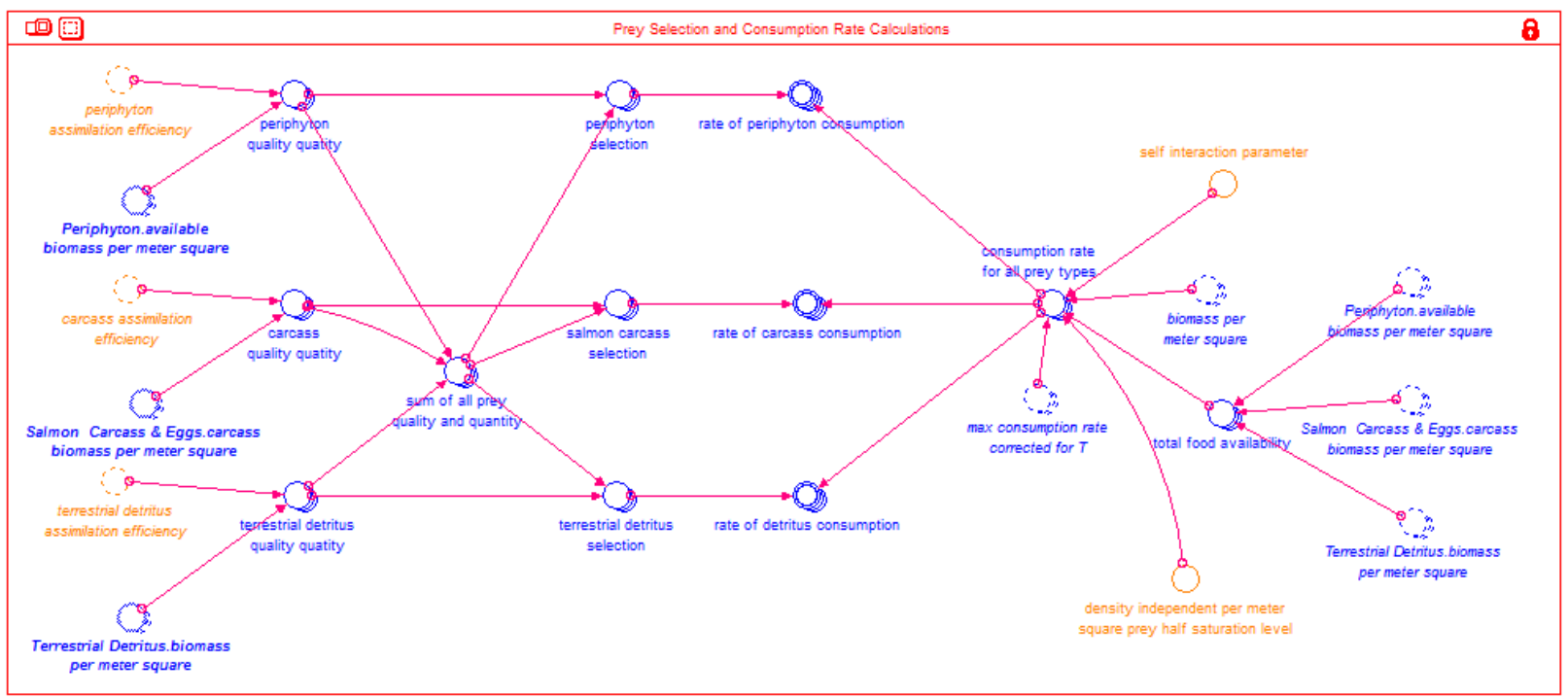

Figure B23. Prey selection and consumption rates of aquatic invertebrates. Diagram is as it appears in STELLA ${ }^{\circledR}$. 
- carcass_quality_quatity[Habitat_Patch_Type] =

Salmon_Carcass_\&_Eggs.carcass_biomass_per_meter_square*carcass_assimilation_efficiency

- consumption_rate_for_all_prey_types[Habitat_Patch_Type] =

max_consumption_rate_corrected_for_T*(total_food_availability/(total_food_availability+(density_indepe ndent_per_meter_square_prey_half_saturation_level+(biomass_per_meter_square*self_interaction_parame ter))))

0 density_independent_per_meter_square_prey_half_saturation_level $=5$

○ periphyton_quality_quatity[Habitat_Patch_Type] $=$

Periphyton.available_biomass_per_meter_square*periphyton_assimilation_efficiency

- periphyton_selection[Habitat_Patch_Type] $=$

If(sum_of_all_prey_quality_and_quantity $>0$ )Then(periphyton_quality_quatity/sum_of_all_prey_quality_a nd_quantity)else(0)

- rate_of_carcass_consumption[Habitat_Patch_Type] =

consumption_rate_for_all_prey_types* ${ }^{*}$ salmon_carcass_selection

○ rate_of_detritus_consumption[Habitat_Patch_Type] =

consumption_rate_for_all_prey_types* ${ }^{*}$ terrestrial_detritus_selection

○ rate_of_periphyton_consumption[Habitat_Patch_Type] =

consumption_rate_for_all_prey_types*periphyton_selection

- salmon_carcass_selection[Habitat_Patch_Type] =

If(sum_of_all_prey_quality_and_quantity $>0$ )Then(carcass_quality_quatity/sum_of_all_prey_quality_and_ quantity)else $(0)$

$0 \quad$ self_interaction_parameter $=8$

- sum_of_all_prey_quality_and_quantity[Habitat_Patch_Type] = periphyton_quality_quatity+carcass_quality_quatity+terrestrial_detritus_quality_quatity

$\circ$ terrestrial_detritus_selection[Habitat_Patch_Type] = If(sum_of_all_prey_quality_and_quantity $>$ 0) Then(terrestrial_detritus_quality_quatity/sum_of_all_prey_qu ality_and_quantity)else( 0 )

○ terrestrial_detritus_quality_quatity[Habitat_Patch_Type] = Terrestrial_Detritus.biomass_per_meter_square*terrestrial_detritus_assimilation_efficiency

○ total_food_availability[Habitat_Patch_Type] $=$

Salmon_Carcass_\&_Eggs.carcass_biomass_per_meter_square+Periphyton.available_biomass_per_meter_ square+Terrestrial_Detritus.biomass_per_meter_square 
Fish

Fish Biomass

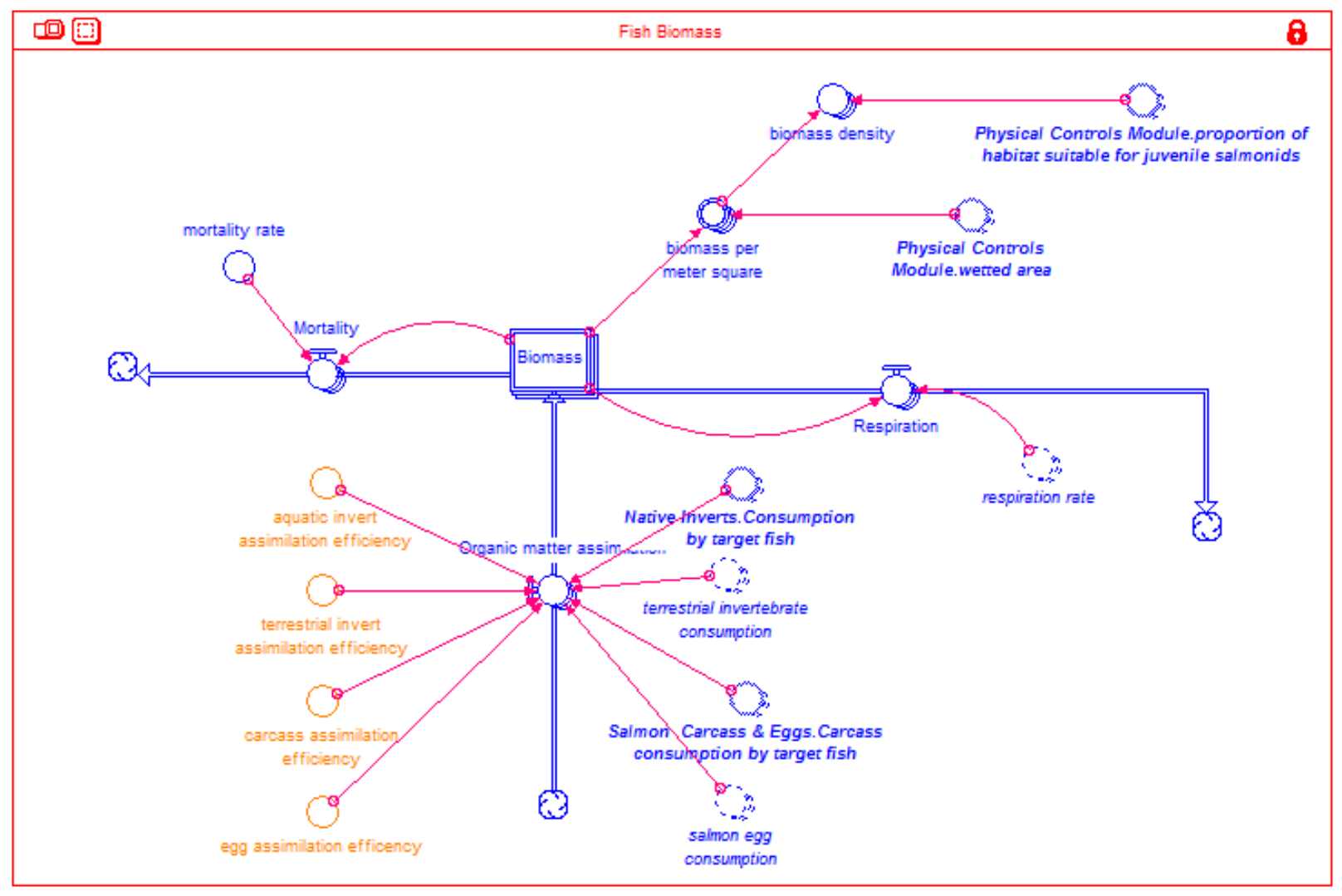

Figure B24. Biomass of fish in the modeled river reach in the Fish Module. Diagram is as it appears in STELLA ${ }^{\circledR}$.

Biomass[main_channel] $(\mathrm{t})=$ Biomass[main_channel] $(\mathrm{t}-\mathrm{dt})+$

(Organic_matter_assimilation[Habitat_Patch_Type] - Respiration[Habitat_Patch_Type] -

Mortality[Habitat_Patch_Type]) $* \mathrm{dt}$

INIT Biomass[main_channel] $=500$

$\square$ Biomass[side_channel] $(\mathrm{t})=$ Biomass[side_channel] $(\mathrm{t}-\mathrm{dt})+$

(Organic_matter_assimilation[Habitat_Patch_Type] - Respiration[Habitat_Patch_Type] -

Mortality[Habitat_Patch_Type] $) * \mathrm{dt}$

INIT Biomass[side_channel] $=500$

Biomass[upstream_channel] $(\mathrm{t})=$ Biomass[upstream_channel] $(\mathrm{t}-\mathrm{dt})+$

(Organic_matter_assimilation[Habitat_Patch_Type]- Respiration[Habitat_Patch_Type] -

Mortality[Habitat_Patch_Type] $*$ dt

INIT Biomass[upstream_channel] $=500$

INFLOWS:

$=>$ Organic_matter_assimilation[Habitat_Patch_Type] $=$

(Native_Inverts.Consumption_by_target_fish*aquatic_invert_assimilation_efficiency)+(terrestrial_inverteb rate_consumption*terrestrial_invert_assimilation_efficiency) ${ }^{-}($Salmon_C - arcass_\&_Eggs.Carcass_consu mption_by_target_fish*carcass_assimilation_efficiency)+(egg_assimilation_efficency*almon_egg_consu mption)

OUTFLOWS:

$=>$ Respiration[Habitat_Patch_Type] $=$ Biomass*respiration_rate 
$=>$ Mortality[Habitat_Patch_Type] $=$ Biomass*mortality_rate

$\circ \quad$ aquatic_invert_assimilation_efficiency $=0.75$

- biomass_density[Habitat_Patch_Type] $=$

IF(Physical_Controls_Module.proportion_of_habitat_suitable_for_juvenile_salmonids $=0$ )

THEN(0)ELSE(biomass_per_meter_square/Physical_Controls_Module.proportion_of_habitat_suitable_for juvenile_salmonids)

○ biomass_per_meter_square[Habitat_Patch_Type] $=\mathrm{IF}($ Physical_Controls_Module.wetted_area $=0$ )

THEN(0)ELSE(Biomass/Physical_Controls_Module.wetted_area)

- carcass_assimilation_efficiency $=\overline{0} .9$

$\circ \quad$ egg_assimilation_efficency $=0.95$

○ mortality_rate $=0.00274$

$\circ$ terrestrial_invert_assimilation_efficiency $=0.7$

\section{Temperature Dependent Consumption \& Respiration Rates}

Note: The diagram for these calculations is the same as that presented under Aquatic

Invertebrates.

0 coefficient_for_respiration_rate $=1.07$

- higher_than_optimum_temperature[Habitat_Patch_Type] $=\exp (-$

((Physical_Controls_Module.water_temperature-T_optimum)/((T_maximum-

T_optimum $\left.) / \operatorname{sqrt}(\ln (100))))^{\wedge} 2\right)$

- lower_than_optimum_temperature[Habitat_Patch_Type] $=\exp (-$

((Physical_Controls_Module.water_temperature- $\bar{T}$ _optimum)/((T_optimum-

T_minimum $\left.) / \operatorname{sqrt}(\ln (100))))^{\wedge} 2\right)$

- MAX_consumption_rate $=0.16$

- max_consumption_rate_corrected_for_T[Habitat_Patch_Type] $=$

MAX

$\circ$ reference_temperature $=25$

○ respiration_rate[Habitat_Patch_Type] $=$

respiration_rate_at_reference_temperature*temperature_correction_for_respiration

- respiration_rate_at_reference_temperature $=0.012$

0 temperature_correction_for_consumption[Habitat_Patch_Type] $=$ If(Physical_Controls_Module.water_temperature $<$ T_optimum)Then(lower_than_optimum_temperature)Els e(higher_than_optimum_temperature)

○ temperature_correction_for_respiration[Habitat_Patch_Type] $=$

coefficient_for_respiration_rate^(Physical_Controls_Module.water_temperature-reference_temperature)

- T_maximum $=25$

- T_minimum $=-5$

○ T_optimum $=16$

\section{Refuge Biomass Calculations}

Note: The diagram for these calculations is the same as that presented under Periphyton.

- available_biomass_per_meter_square[Habitat_Patch_Type] = biomass_per_meter_squarerefuge_biomass_per_meter_square

○ refuge_biomass[Habitat_Patch_Type] =

refuge_biomass_per_meter_square*Physical_Controls_Module.wetted_area

$\circ$ refuge_biomass_per_meter_square $=0.01$ 


\section{Prey Selection and Consumption Rate Calculations}

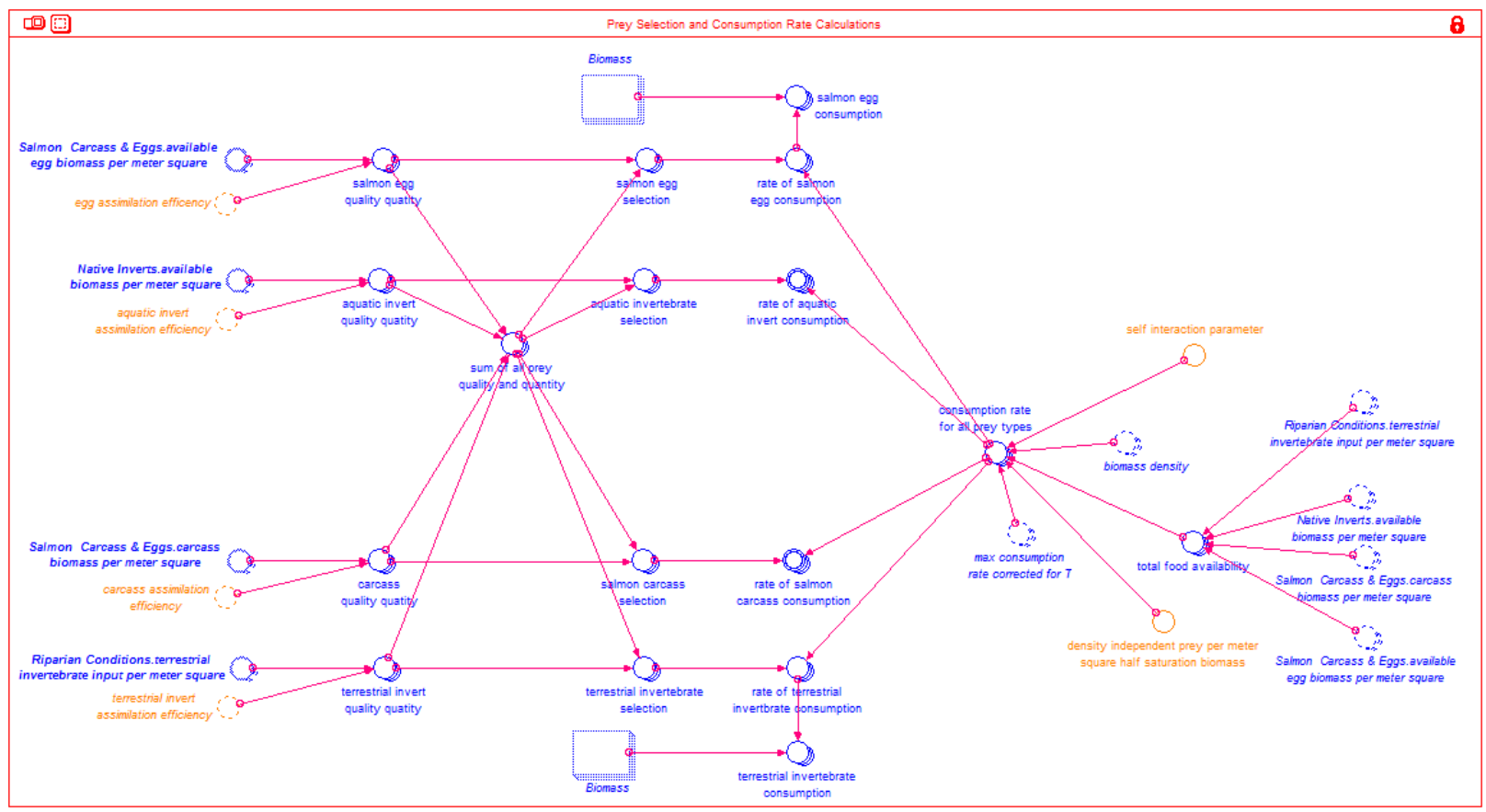

Figure B25. Prey selection and consumption rates of aquatic invertebrates. Diagram is as it appears in STELLA ${ }^{\circledR}$.

○ aquatic_invert_quality_quatity[Habitat_Patch_Type] $=$

Native_Inverts.available_biomass_per_meter_square*aquatic_invert_assimilation_efficiency

- aquatic_invertebrate_selection[Habitat_Patch_Type] =

aquatic_invert_quality_quatity/sum_of_all_prey_quality_and_quantity

- carcass_quality_quatity[Habitat_Patch_Type] =

Salmon_Carcass_\&_Eggs.carcass_biomass_per_meter_square*carcass_assimilation_efficiency

- consumption_rate_for_all_prey_types[Habitat_Patch_Type] $=$

max_consumption_rate_corrected_for_T*(total_food_availability/(total_food_availability+(density_indepe ndent_prey_per_meter_square_half_saturation__biomass $+($ biomass_density*self_interaction_parameter))))

0 density_independent_prey_per_meter_square_half_saturation_biomass $=1.5$

○ rate_of_aquatic_invert_consumption[Habitat_Patch_Type] = consumption_rate_for_all_prey_types*aquatic_invertebrate_selection

- rate_of_salmon_egg_consumption[Habitat_Patch_Type] = consumption_rate_for_all_prey_types*salmon_egg_selection

- rate_of_salmon_carcass_consumption[Habitat_Patch_Type] = consumption_rate_for_all_prey_types*salmon_carcass_selection

- rate_of_terrestrial_invertbrate_consumption[Habitat_Patch_Type] = consumption_rate_for_all_prey_types*terrestrial_invertebrate_selection

- salmon_carcass_selection[Habitat_Patch_Type] $=$ carcass_quality_quatity/sum_of_all_prey_quality_and_quantity

- salmon_egg_consumption[Habitat_Patch_Type] = Biomass*rate_of_salmon_egg_consumption

- salmon_egg_quality_quatity[Habitat_Patch_Type] = Salmon_Carcass_\&_Eggs.available_egg_biomass_per_meter_square*egg_assimilation_efficency

○ salmon_egg_selection[Habitat_Patch_Type] = salmon_egg_quality_quatity/sum_of_all_prey_quality_and_quantity

○ self_interaction_parameter $=3$ 
○ sum_of_all_prey_quality_and_quantity[Habitat_Patch_Type] =

aquatic_invert_quality_quatity+carcass_quality_quatity+terrestrial_invert_quality_quatity+salmon_egg_qu ality quatity

○ terrestrial_invertebrate_selection[Habitat_Patch_Type] =

terrestrial_invert_quality_quatity/sum_of_all_prey_quality_and_quantity

$\circ$ terrestrial_invertebrate_consumption[Habitat_Patch_Type] =

Biomass*rate_of_terrestrial_invertbrate_consumption

○ terrestrial_invert_quality_quatity[Habitat_Patch_Type] =

Riparian_Conditions.terrestrial_invertebrate_input_per_meter_square*terrestrial_invert_assimilation_effici ency

○ total_food_availability[Habitat_Patch_Type] $=$

Native_Inverts.available_biomass_per_meter_square+Salmon_Carcass_\&_Eggs.carcass_biomass_per_me ter_square+Riparian_Conditions.terrestrial_invertebrate_input_per_meter_square+Salmon_Carcass_\&_E ggs.available_egg_biomass_per_meter_square 

Publishing support provided by the U.S. Geological Survey Science Publishing Network, Tacoma Publishing Service Center

For more information concerning the research in this report, contact the Director, Forest and Rangeland Ecosystem Science Center U.S. Geological Survey

777 NW 9th St., Suite 400

Corvallis, Oregon 97330

http://fresc.usgs.gov/ 


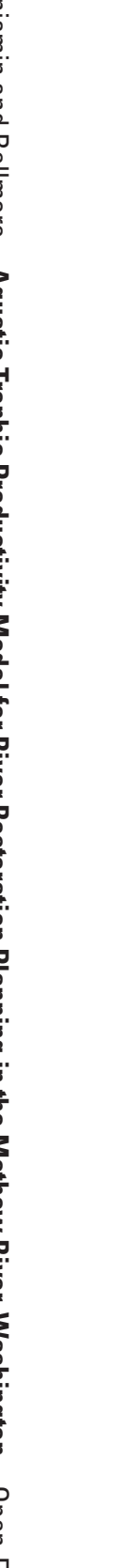

